DOC.20061002.0012

QA: QA

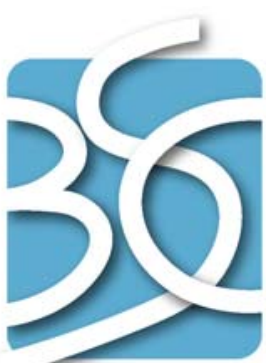

BECHTEL SAIC COMPANYLC

ANL-NBS-MD-000009 REV 03

September 2006

\title{
Soil-Related Input Parameters for the
} Biosphere Model

Prepared for:

U.S. Department of Energy

Office of Civilian Radioactive Waste Management

Office of Repository Development

1551 Hillshire Drive

Las Vegas, Nevada 89134-6321

Prepared by:

Bechtel SAIC Company, LLC

1180 Town Center Drive

Las Vegas, Nevada 89144

Under Contract Number

DE-AC28-01RW12101 


\section{DISCLAIMER}

This report was prepared as an account of work sponsored by an agency of the United States Government. Neither the United States Government nor any agency thereof, nor any of their employees, nor any of their contractors, subcontractors or their employees, makes any warranty, express or implied, or assumes any legal liability or responsibility for the accuracy, completeness, or any third party's use or the results of such use of any information, apparatus, product, or process disclosed, or represents that its use would not infringe privately owned rights. Reference herein to any specific commercial product, process, or service by trade name, trademark, manufacturer, or otherwise, does not necessarily constitute or imply its endorsement, recommendation, or favoring by the United States Government or any agency thereof or its contractors or subcontractors. The views and opinions of authors expressed herein do not necessarily state or reflect those of the United States Government or any agency thereof. 
QA: QA

Soil-Related Input Parameters for the Biosphere Model ANL-NBS-MD-000009 REV 03

September 2006 


\section{Scientific Analysis Title}

Soil-Related Input Parameters for the Biosphere Model

3. DI (including Rev. No.)

ANL-NBS-MD-000009 REV 03

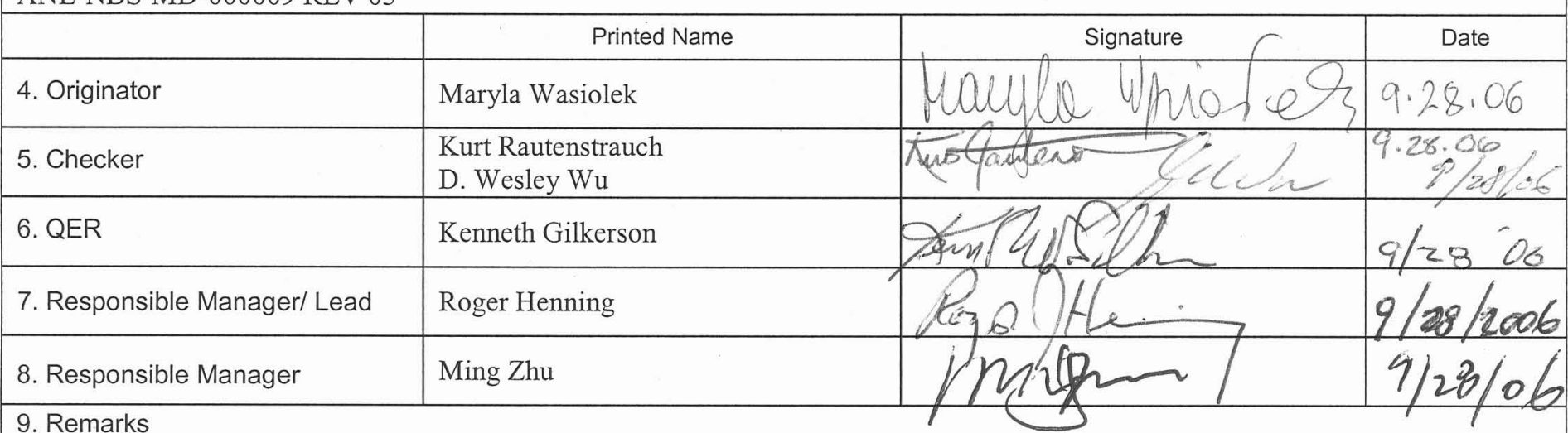

Remarks

This document has an electronic attachment.

Kurt Rautenstrauch was a lead technical checker. Wesley Wu checked calculations in Section 6.5.3 and supporting Mathcad files.

\section{Change History}

\begin{tabular}{|l|l|}
\hline \multicolumn{1}{|c|}{ 10. Revision No. } & \multicolumn{1}{c|}{ 11. Description of Change } \\
\hline Rev. 00 & Initial Issue \\
\hline Rev. 00 ICN 01 & $\begin{array}{l}\text { Inclusion of discussion of (1) potential effects of future climate change on calculated soil loss } \\
\text { estimates and leaching coefficients, (2) applicable FEPs and how these were addressed in the analysis, } \\
\text { and (3) to satisfy one of the issues addressed in CAT 10 (i.e., acknowledgement of the use of an } \\
\text { existing soil leaching model for calculating leaching coefficients). }\end{array}$ \\
\hline Rev. 01 & $\begin{array}{l}\text { Provide soil-related product output to be used with the Biosphere Model (ERMYN). Parameters and, } \\
\text { where appropriate, distributions are given for soil bulk density, partition coefficients, soil erosion rate, } \\
\text { enhancement factor for resuspension, soil water capacity at field capacity, and ash bulk density. }\end{array}$ \\
\hline Rev. 02 & $\begin{array}{l}\text { Revised in accordance with current AP-SIII.9Q. Improve traceability and transparency for analysis } \\
\text { documentation by addressing comments from the review by the Repository Integration Project. Made } \\
\text { editorial changes. The entire documentation of the scientific analysis was revised and thus change } \\
\text { bars were not used. }\end{array}$ \\
\hline Rev. 03 & $\begin{array}{l}\text { The document was revised to add a new parameter, irrigation duration, and re-develop distributions of } \\
\text { the enhancement factor. The discussion of erosion rate and volumetric water content were modified } \\
\text { and the parameter value adjusted; high and low bounds were added to the distributions of partition } \\
\text { coefficient. } \\
\text { The entire documentation of the scientific analysis was revised and thus change bars were not used. }\end{array}$ \\
\hline
\end{tabular}




\section{CONTENTS}

Page

ACRONYMS AND ABBREVIATIONS xiii

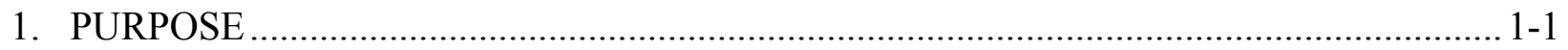

2. QUALITY ASSURANCE ............................................................................ 2-1

3. USE OF SOFTWARE ........................................................................................ $3-1$

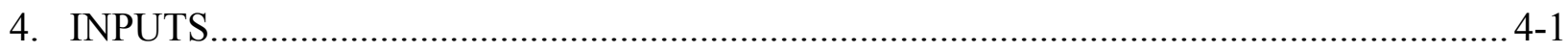

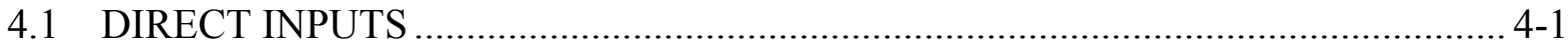

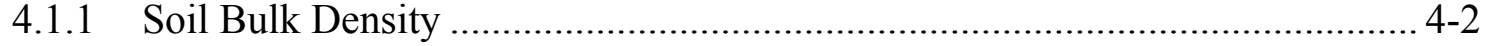

4.1.2 Partition Coefficients............................................................................... 4-2

4.1.2.1 Reliability of Data Source and Qualification of the Data Originator ........................................................................... 4-3

4.1.2.2 Extent to Which the Data Demonstrate the Properties of Interest............................................................................ 4-3

4.1.2.3 Prior Uses of the Data ................................................................ 4-4

4.1.2.4 Availability of Corroborating Data............................................... 4-4

4.1.3 Soil Erosion Rate .............................................................................. 4-5

4.1.4 Enhancement Factor for Resuspension ................................................ 4-5

4.1.4.1 Enhancement Factor for the Volcanic Ash Exposure Scenario ....... 4-6

4.1.4.2 Enhancement Factor for the Groundwater Exposure Scenario........ 4-8

4.1.5 Volumetric Water Content of Soil............................................................ 4-10

4.1.6 Irrigation Duration...................................................................... 4-10

4.1.6.1 2000 Census Population and Housing Data ................................ 4-11

4.1.6.2 Dietary and Lifestyle Survey .................................................... 4-11

4.1.6.3 History of Settlement and Water Use in Amargosa Valley ............4-11

4.1.6.4 Time Span of a Generation .................................................... 4-12

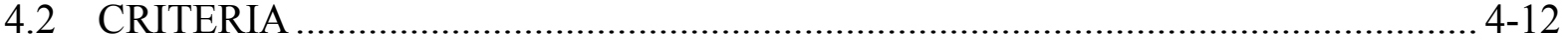

4.3 CODES, STANDARDS, AND REGULATIONS ............................................. $4-14$

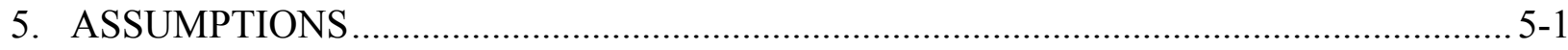

5.1 UNDEFINED STANDARD DEVIATIONS FOR THE PARTITION COEFFICIENT DISTRIBUTIONS ..................................................................... $5-1$

5.2 UNDEFINED IRRIGATION DURATION .................................................. 5-1

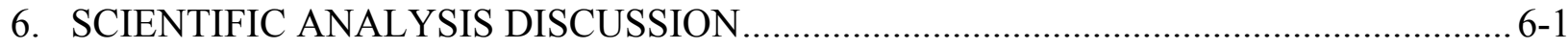

6.1 MODELING ENVIRONMENTAL TRANSPORT PATHWAYS INVOLVING

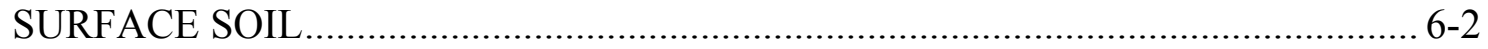

6.1.1 Radionuclide Buildup in Surface Soil ....................................................... 6-2

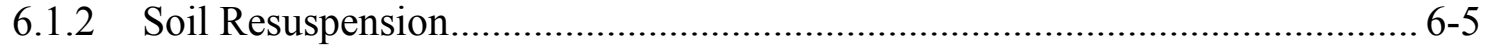

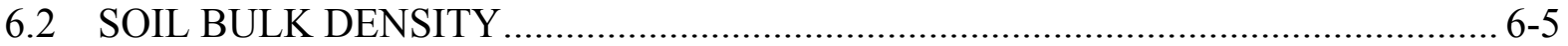

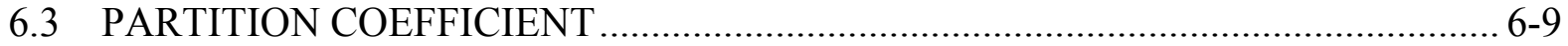

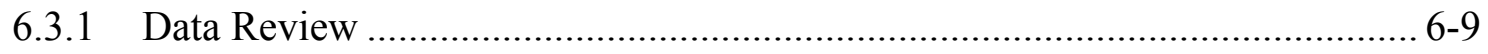




\section{CONTENTS (Continued)}

6.3.2 Development of Parameter Distribution..................................................... 6-13

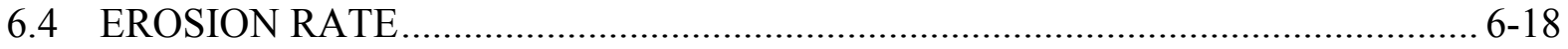

6.4.1 Leaching and Soil Erosion as Competing Removal Processes …….............. 6-18

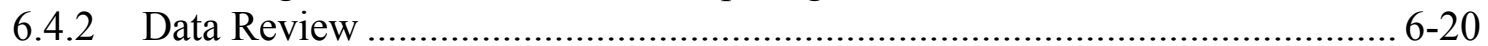

6.4.3 Estimate of Lower Loss Limit for Erosion.................................................. 6-22

6.4.4 Estimate of Upper Loss Limit for Erosion ................................................... 6-22

6.4.5 Recommended Distribution and Parameters for the Annual Rate of Soil

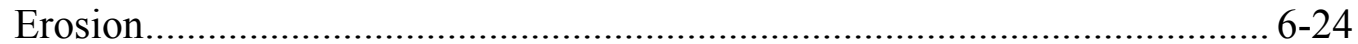

6.5 ENHANCEMENT FACTOR FOR RESUSPENSION ........................................ 6-24

6.5.1 Characteristics of the Radionuclide Resuspension Process............................. 6-24

6.5.1.1 Radionuclide Concentration in Soil and in Suspended Particulates........................................................................... 6-24

6.5.1.2 Particle Size Distribution of Suspended Particulates...................... 6-25

6.5.1.3 Particle Size Distribution of Suspended Activity ........................... 6-27

6.5.2 Enhancement Factor for the Volcanic Ash Exposure Scenario...................... 6-28

6.5.2.1 Plutonium Behavior in Soil.......................................................... 6-28

6.5.2.2 Measurements of Enhancement Factor-Data Review and Analysis of Data Applicability..................................................... 6-28

6.5.2.3 Development of Parameter Distribution ......................................... 6-36

6.5.3 Enhancement Factor for the Groundwater Exposure Scenario ....................... 6-40

6.5.3.1 Radionuclide Enhancement as a Result of Particle Size Selective Resuspension of Soil Particles ...................................... 6-41

6.5.3.2 Particle Size Distribution for Amargosa Valley Soils ..................... 6-42

6.5.3.3 Particle Size Distribution of Suspended Particulate Matter........... 6-46

6.5.3.4 Development of Surface-to-Mass Ratio for Soils and Suspended Particulate Matter ......................................................... 6-48

6.5.3.5 Enhancement Factor for Example Particle Size Distributions....... 6-50

6.5.3.6 Development of Parameter Distribution ......................................... 6-55

6.5.4 Summary of the Recommendations............................................................ 6-56

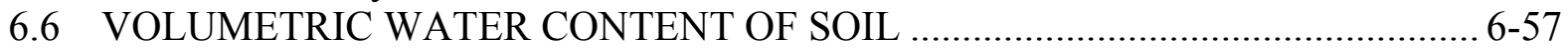

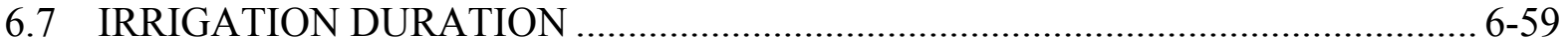

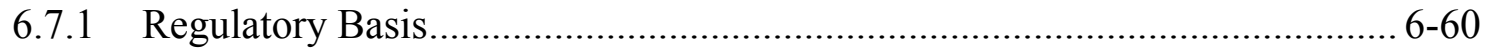

6.7.2 Evaluation of Physical Limitations on Agricultural Practices ....................... 6-61

6.7.2.1 Results of Literature Search....................................................... 6-61

6.7.2.2 Interviews with Local Experts ..................................................... 6-62

6.7.3 Evaluation of Local Agricultural Practices and Related Social

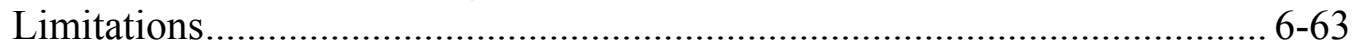

6.7.4 Inclusion of Irrigation Duration in the Surface Soil Submodel...................... 6-68

6.7.6 Evaluation of Occupancy of Land Contaminated by Irrigation ...................... 6-70

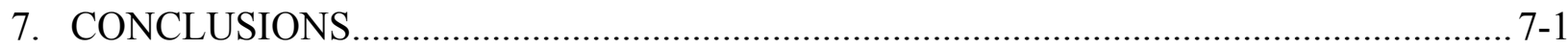

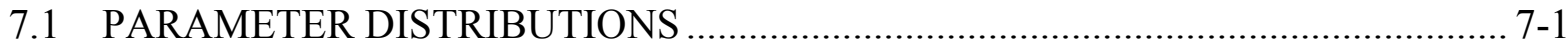

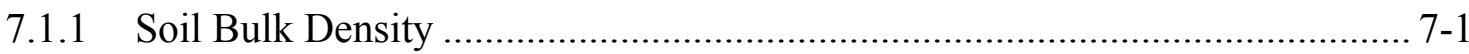

7.1.2 Partition Coefficient ……………………............................................. 7-1 


\section{CONTENTS (Continued)}

Page

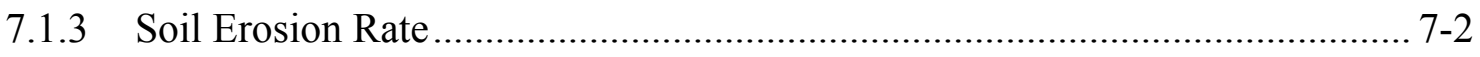

7.1.4 Enhancement Factor for Resuspension …………..................................... 7-2

7.1.5 Volumetric Water Content of Soil............................................................. 7-3

7.1.6 Irrigation Duration.........................................................................................

7.2 HOW THE ACCEPTANCE CRITERIA WERE ADDRESSED ................................ 7-3

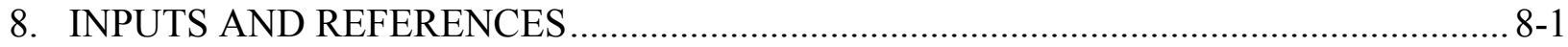

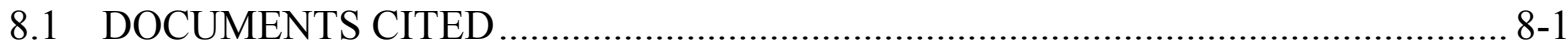

8.2 CODES, STANDARDS, REGULATIONS, AND PROCEDURES ……………….... 8-8

8.3 SOURCE DATA, LISTED BY DATA TRACKING NUMBER ……………............ 8-9

8.4 OUTPUT DATA, LISTED BY DATA TRACKING NUMBER ………………........ 8-9

APPENDIX A—LIST AND DESCRIPTION OF FILES USED IN THIS ANALYSIS........... A-1 


\section{INTENTIONALLY LEFT BLANK}




\section{FIGURES}

Page

1-1. Documentation for the Environmental Radiation Model for Yucca Mountain, Nevada....

6.5-1. Distribution of Measured Enhancement Factors . $6-35$

6.5-2. Graph of Enhancement Factors for Undisturbed and Disturbed Soil Conditions ..... 6-39

6.5-3. Cumulative Percent of Soil Separates in Amargosa Valley Soils ............................ 6-44

6.5-4. Cumulative Particle Size Distribution Function for Amargosa Valley Soils ........... 6-45

6.5-5. Illustration of Probability Density Function for Particle Size Distribution of Suspended Aerosols for Environments without Active Soil Disturbance................ 6-47

6.5-6. Mathcad Calculations of Surface-to-Mass Ratio for Amargosa Valley Soils .......... 6-51

6.5-7. Mathcad Calculations of Surface-to-Mass Ratio for Particle Size Distributions for Undisturbed Soil ......................................................................................... 6-52

6.5-8. Mathcad Calculations of Surface-to-Mass Ratio for Bimodal Particle Size Distributions for Actively Disturbed Soil

6.5-9. Mathcad Calculations of Enhancement Factor for Various Distributions of Suspended Particulates for Average Amargosa Valley Soils................................ 6-53

6.7-1. Population Tenure in Amargosa Valley in 1997 .................................................... 6-64

6.7-2. Satellite Image of the Amargosa Desert Area ...................................................... 6-67

A-1. List of Files Used in the Analysis ................................................................... A-1 


\section{INTENTIONALLY LEFT BLANK}




\section{TABLES}

Page

1-1. $\quad$ Parameters and Related Features, Events, and Processes .................................... 1-4

4.1-1. Sources of Parameter Information Used to Develop the Biosphere Model Input

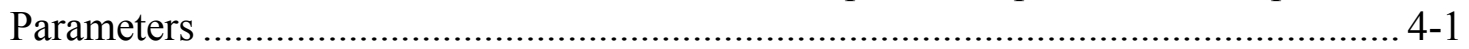

4.2-1. Requirements Applicable to This Analysis ......................................................... 4-12

6.2-1. Major Types of Agricultural Soils Occurring in Amargosa Valley .......................... 6-7

6.2-2. Physical Properties of Soils in Amargosa Valley .................................................. 6-8

6.3-1. Element Specific Partition Coefficients for Sandy Soil .......................................... 6-10

6.3-2. Element Specific Partition Coefficients for Loamy Soil ........................................ 6-10

6.3-3. Element Specific Partition Coefficients for Clayey Soil ...................................... 6-11

6.3-4. Element Specific Partition Coefficients for Organic Soil ....................................... 6-12

6.3-5. Logarithmic Parameters and the Associated Arithmetic Means of the Partition Coefficients for the Elements of Concern ............................................................... 6-16

6.3-6. Lognormal Distribution Parameters for Partition Coefficients ................................ 6-17

6.4-1. Time Required to Reach 50\% and 95\% Equilibrium Concentration in Surface Soil Assuming Leaching Is the Only Removal Mechanism.................................... 6-19

6.4-2. Estimated Average Annual Sheet and Rill Erosion on Non-Federal Land in Nevada by Year

6.4-3. Estimated Average Annual Wind Erosion on Non-Federal Land in Nevada by

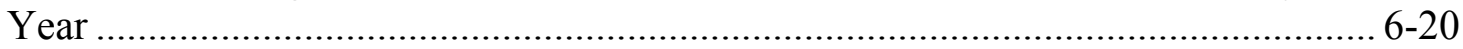

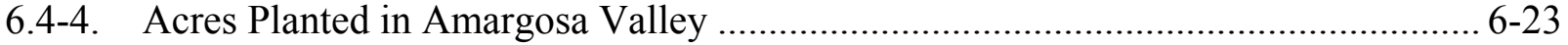

6.5-1. Summary of Enhancement Factor Measurements ................................................ 6-30

6.5-2. Measured Values of the Enhancement Factor under Undisturbed Soil

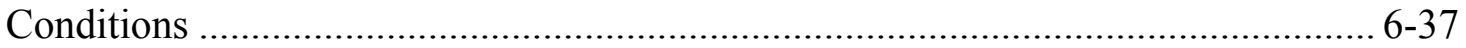

6.5-3. Measured Values of the Enhancement Factor under Disturbed Soil Conditions ...... 6-38

6.5-4. Percentage of Soil Separates in Farmed Soils Occurring in Amargosa Valley......... 6-43

6.5-5. Effect of GSD Change on the Value of Enhancement Factor ................................. 6-54

6.5-6. Effect of GSD Change on the Value of Enhancement Factor ............................... 6-55

6.5-7. Distribution Parameters for the Enhancement Factor ........................................... 6-56

6.6-1. Volumetric Water Content at Field Capacity and Wilting Point for Sandy Loam

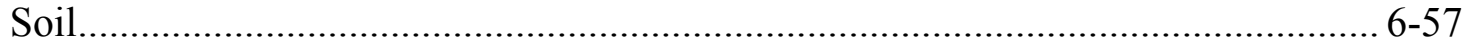

6.6-2. Calculations of the Term $\left[\theta\left(1+\rho K d_{i} / \theta\right)\right]$ in Support of the Volumetric Water Content Analysis ....................................................................................... 6-58

6.6-3. Soil Water Content at Field Capacity ..................................................................... 6-59

7.1-1. Lognormal Distribution Parameters for Partition Coefficients ............................... 7-2

7.1-2. Distribution Parameters for the Enhancement Factor ........................................... 7-3 


\section{INTENTIONALLY LEFT BLANK}




\section{ACRONYMS AND ABBREVIATIONS}

AMAD activity median aerodynamic diameter

BDCF biosphere dose conversion factor

CLEA Contaminated Land Exposure Assessment Model

FAO Food and Agriculture Organization of the United Nations

FEPs features, events, and processes

GM geometric mean

GSD geometric standard deviation

MAD median aerodynamic diameter

MGSD mass geometric standard deviation

MMAD mass median aerodynamic diameter

NCRP National Council on Radiation Protection and Measurements

NRCS Natural Resources Conservation Service

RMEI reasonably maximally exposed individual

SD standard deviation

TSP total suspended particulates

TSPA total system performance assessment

UNCE University of Nevada Cooperative Extension

USDA U.S. Department of Agriculture 


\section{INTENTIONALLY LEFT BLANK}




\section{PURPOSE}

This report presents one of the analyses that support the Environmental Radiation Model for Yucca Mountain Nevada (ERMYN), referred to in this report as the biosphere model. Biosphere Model Report (BSC 2004 [DIRS 169460]) describes the details of the conceptual and mathematical biosphere models and the required input parameters. The biosphere model is one of a series of process models supporting the postclosure total system performance assessment (TSPA) for the Yucca Mountain repository.

A schematic representation of the documentation flow for the biosphere model and its input to TSPA is presented in Figure 1-1. This figure shows the relationships among the products (i.e., analysis and model reports) developed for biosphere modeling, and the biosphere abstraction products for TSPA (based on BSC 2006 [DIRS 176938]). This figure is included to provide an understanding of how this analysis report contributes to biosphere modeling.

This report, Soil-Related Input Parameters for the Biosphere Model, is one of the five analysis reports that develop input parameters for use in the biosphere model. This report is the source documentation for the six biosphere parameters identified in Table 1-1. Most of these parameters (partition coefficients, soil erosion rate, volumetric water content of soil, and irrigation duration) are only used in the surface soil submodel of the biosphere model for the groundwater exposure scenario and are associated with the accumulation and depletion of radionuclides in the soil. These parameters support the calculation of radionuclide concentrations in surface soil from on-going irrigation. The biosphere model for the volcanic ash exposure scenario does not consider radionuclide accumulation and depletion in surface soil. This is because the radionuclide concentration in surface soil is calculated in the tephra redistribution model (BSC 2005 [DIRS 174067], Section 6.6) and is the source term for the calculations of dose from volcanic release of radionuclides (just like the radionuclide concentration in groundwater is the source term for calculation of doses from radionuclide release in groundwater). The soil bulk density and enhancement factors are used in biosphere models for both exposure scenarios. Radionuclide concentration in surface soil affects radionuclide concentration in other environmental media, such as air, plants, and animals. The six parameters developed in this analysis are subsequently used as biosphere model inputs to calculate the biosphere dose conversion factors (BDCFs) for the biosphere groundwater exposure scenario and for the volcanic ash exposure scenario.

This analysis was conducted in accordance with LP-SIII.9Q-BSC, Scientific Analyses, and an approved technical work plan (BSC 2006 [DIRS 176938]). This analysis revises the previous version with the same title (BSC 2004 [DIRS 169459]). The scope of this revision includes the development of an additional input parameter, irrigation duration, in support of the modified surface soil submodel. The purpose of the additional parameter was to address conservatism caused by the postulated long-term continuous agricultural land use. In this report, feasibility of long-term irrigation from the perspectives of agricultural land management and socio-economic conditions is evaluated. In addition, one of the previously developed sets of parameters, the environment-specific enhancement factors, is re-developed with inclusion of additional literature data sources. 


\section{LA FEP List (Biosphere)}

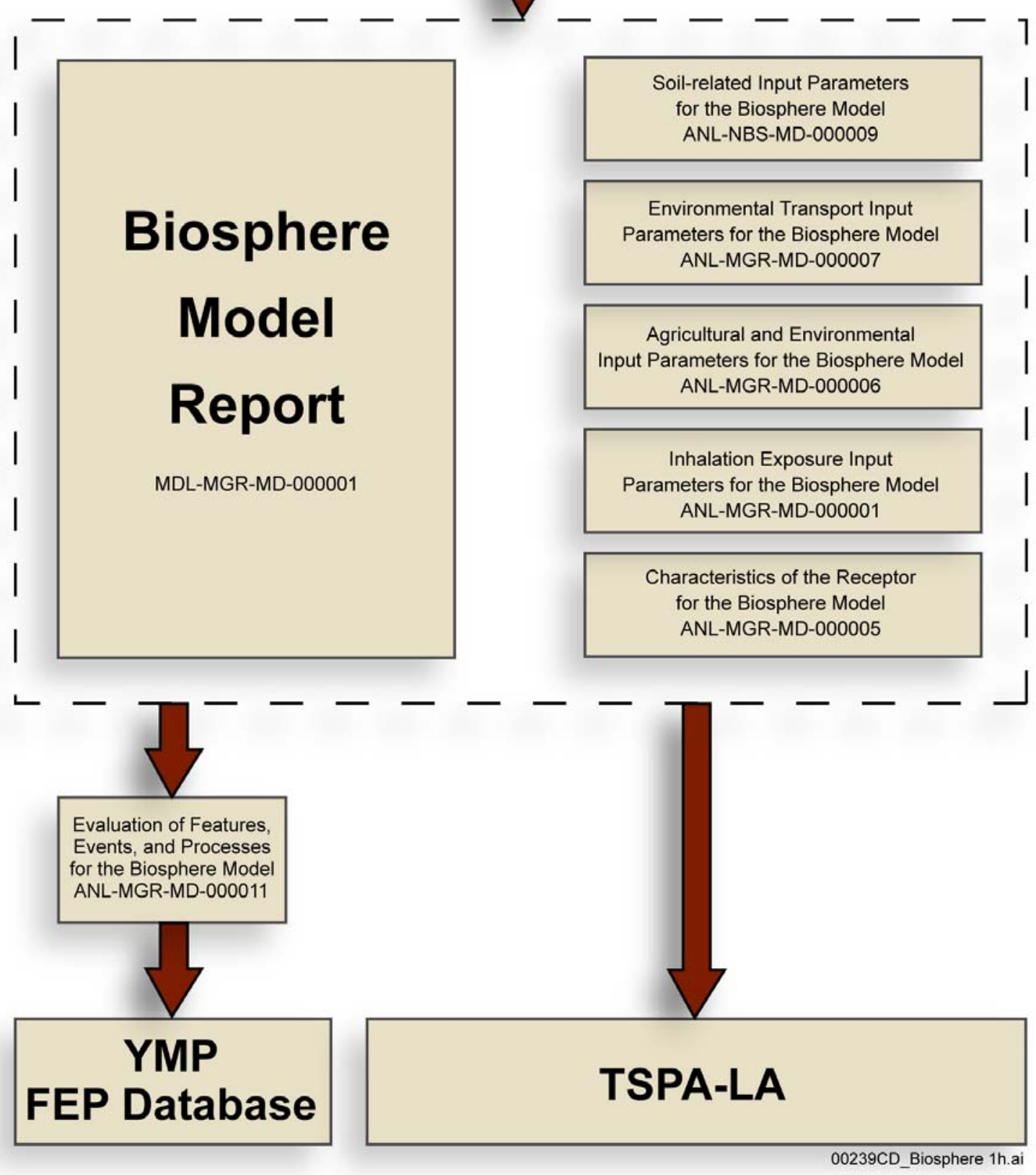

NOTE: $\quad$ FEP = feature, event, and process; $L A=$ license application.

Figure 1-1. Documentation for the Environmental Radiation Model for Yucca Mountain, Nevada 
This analysis report supports the treatment of 10 of the features, events, and processes (FEPs) applicable to the Yucca Mountain reference biosphere (DTN: MO0508SEPFEPLA.002 [DIRS 175064]). The parameters developed in this report support treatment of these 10 FEPs addressed in the biosphere model that are listed in Table 1-1. Inclusion and treatment of FEPs in the biosphere model are described in Biosphere Model Report (BSC 2004 [DIRS 169460], Section 6.2).

The biosphere model is constructed for a specific environment identified in 10 CFR 63.305 [DIRS 173164], and thus the reference biosphere (the modeling domain) has characteristics of that environment. The biosphere model includes pathways that are consistent with arid or semi-arid climates (10 CFR 63.305(d) [DIRS 173164]). Consequently, the model representation of these pathways, including the model input parameters developed in this analysis, is consistent with arid or semi-arid climates. The climate states considered in the biosphere model include the present-day conditions, which are typical of the interglacial climate (BSC 2004 [DIRS 170002], Section 6.2) and are characterized by hot, dry summers; warm winters; and low precipitation. The other climate states within the applicability range of the model (i.e., within the range from arid to semi-arid conditions) are the monsoon and glacial transition climates. The glacial transition climate is predicted to have cooler, wetter winters and to have warm-to-cool, dry summers relative to current conditions; the monsoon climate has about twice the precipitation of the present-day climate (BSC 2004 [DIRS 170002], Section 6.6.2).

The biosphere model (BSC 2004 [DIRS 169460], Section 6.3.5) was constructed for 28 radionuclides screened in for the TSPA. Consequently, this analysis developed partition coefficient distributions for the 17 elements represented by the 28 radionuclides.

The technical work plan (BSC 2006 [DIRS 176938]) calls for consolidation of some technical reports within the biosphere model documentation suite. The documentation illustrated in Figure 1-1 is consistent with that plan. Technical reports shown in this figure, but not scheduled for revision under the current work plan, include an earlier version of Figure 1-1 that shows reports that will become incorporated into the revision of Biosphere Model Report (BSC 2004 [DIRS 169460]). 
Table 1-1. Parameters and Related Features, Events, and Processes

\begin{tabular}{|c|c|c|c|c|}
\hline Parameter & Related FEPs $^{a}$ & FEP Number & $\begin{array}{l}\text { Associated } \\
\text { Submodel(s) }\end{array}$ & Summary of Disposition in TSPA ${ }^{b}$ \\
\hline \multirow{6}{*}{$\begin{array}{l}\text { Soil bulk } \\
\text { density }\end{array}$} & Soil type & 2.3.02.01.0A & \multirow{6}{*}{$\begin{array}{l}\text { Soil } \\
\text { Air } \\
\text { Carbon-14 }\end{array}$} & \multirow{6}{*}{$\begin{array}{l}\text { The treatment of this parameter is described in } \\
\text { Sections } 4.1 .1 \text { and } 6.2 \text { and summarized in Section } 7.1 .1\end{array}$} \\
\hline & Radionuclide accumulation in soils & 2.3.02.02.0A & & \\
\hline & Atmospheric transport of contaminants & 3.2.10.00.0A & & \\
\hline & Soil and sediment transport in the biosphere & 2.3.02.03.0A & & \\
\hline & Biosphere characteristics & 2.3.13.01.0A & & \\
\hline & Plant uptake & 3.3.02.01.0A & & \\
\hline $\begin{array}{l}\text { Partition } \\
\text { coefficient }\end{array}$ & Radionuclide accumulation in soils & 2.3.02.02.0A & Soil & $\begin{array}{l}\text { The treatment of this parameter is described in } \\
\text { Sections } 4.1 .2 \text { and } 6.3 \text { and summarized in Section 7.1.2 }\end{array}$ \\
\hline \multirow{4}{*}{$\begin{array}{l}\text { Soil erosion } \\
\text { rate }\end{array}$} & Soil type & 2.3.02.01.0A & \multirow{4}{*}{ Soil } & \multirow{4}{*}{$\begin{array}{l}\text { The treatment of this parameter is described in } \\
\text { Sections } 4.1 .3 \text { and } 6.4 \text { and summarized in Section } 7.1 .3\end{array}$} \\
\hline & Radionuclide accumulation in soils & 2.3.02.02.0A & & \\
\hline & Soil and sediment transport in the biosphere & 2.3.02.03.0A & & \\
\hline & Biosphere characteristics & 2.3.13.01.0A & & \\
\hline \multirow{2}{*}{$\begin{array}{l}\text { Enhancement } \\
\text { factor for } \\
\text { resuspension }\end{array}$} & Atmospheric transport of contaminants & 3.2.10.00.0A & \multirow{2}{*}{ Air } & \multirow{2}{*}{$\begin{array}{l}\text { The treatment of this parameter is described in } \\
\text { Sections } 4.1 .4 \text { and } 6.5 \text { and summarized in Section 7.1.4 }\end{array}$} \\
\hline & Biosphere characteristics & 2.3.13.01.0A & & \\
\hline \multirow{3}{*}{$\begin{array}{l}\text { Volumetric } \\
\text { water content }\end{array}$} & Soil type & 2.3.02.01.0A & \multirow{3}{*}{ Soil } & \multirow{3}{*}{$\begin{array}{l}\text { The treatment of this parameter is described in } \\
\text { Sections } 4.1 .5 \text { and } 6.6 \text { and summarized in Section } 7.1 .5\end{array}$} \\
\hline & Radionuclide accumulation in soils & 2.3.02.02.0A & & \\
\hline & Biosphere characteristics & 2.3.13.01.0A & & \\
\hline \multirow{6}{*}{$\begin{array}{l}\text { Irrigation } \\
\text { duration }\end{array}$} & Water management activities & 1.4.07.01.0A & \multirow{6}{*}{ Soil } & \multirow{6}{*}{$\begin{array}{l}\text { The treatment of this parameter is described in } \\
\text { Sections } 4.1 .6 \text { and } 6.7 \text { and summarized in Section } 7.1 .6\end{array}$} \\
\hline & Radionuclide accumulation in soils & 2.3.02.02.0A & & \\
\hline & Biosphere characteristics & 2.3.13.01.0A & & \\
\hline & Human lifestyle & 2.4.04.01.0A & & \\
\hline & Dwellings & 2.4.07.00.0A & & \\
\hline & Agricultural land use and irrigation & 2.4.09.01.0B & & \\
\hline
\end{tabular}

${ }^{a}$ DTN: MO0508SEPFEPLA.002 [DIRS 175064].

${ }^{b}$ The effects of the related FEPs are included in the TSPA through the BDCFs. See BSC 2004 [DIRS 169460], Section 6.2, for a complete description of the inclusion and treatment of FEPs in the biosphere model. 


\section{QUALITY ASSURANCE}

Development of this report involves analysis of data to support performance assessment as identified in the technical work plan (BSC 2006 [DIRS 176938]) and thus is a quality-affecting activity in accordance with LP-2.29Q-BSC, Planning for Science Activities. Approved quality assurance procedures identified in the technical work plan (BSC 2006 [DIRS 176938], Section 4) have been used to conduct and document the activities described in this report. Electronic data used in this analysis were controlled in accordance with the methods specified in the technical work plan (BSC 2006 [DIRS 176938], Section 8).

The natural barriers and items identified in Q-List (BSC 2005 [DIRS 175539]) are not pertinent to this analysis and a safety category per LS-PRO-0203, Q-List and Classification of Structures, Systems, Components and Barriers, is not applicable. 


\section{INTENTIONALLY LEFT BLANK}




\section{USE OF SOFTWARE}

No software controlled and baselined as described in IT-PRO-0011, Software Management, was used in the development of this analysis. The only software used during this analysis was the commercial off-the-shelf software Microsoft Excel (version 2000 SR-1) and Mathcad (version 11.2a). The Excel software was used to perform calculations using standard functions, such as logarithm and exponential, average, and standard deviation (SD). The Excel files containing these calculations are included in Appendix A. Graphics functions of Excel were used to create figures. The methods used within Excel to manipulate or combine data, and associated formulas, inputs, and outputs, are described in the text or tables of this report (Section 6 and Appendix A).

Mathcad was used to calculate derivatives and integrals of given functions and to find function solutions. Mathcad calculations are reproduced in Section 6 of this report and the Mathcad file is included in Appendix A. 


\section{INTENTIONALLY LEFT BLANK}




\section{INPUTS}

\subsection{DIRECT INPUTS}

The list of biosphere model parameters addressed in this analysis, and the sources of direct input used to develop the parameter values, are shown in Table 4.1-1. Descriptions of direct inputs in this section follow the same order in which the parameters appear in Table 4.1-1.

Table 4.1-1. Sources of Parameter Information Used to Develop the Biosphere Model Input Parameters

\begin{tabular}{|c|c|c|}
\hline $\begin{array}{l}\text { Biosphere } \\
\text { Model } \\
\text { Parameter }\end{array}$ & Source of Parameter or Data Used to Develop Parameter & $\begin{array}{l}\text { Description } \\
\text { and } \\
\text { Justification }\end{array}$ \\
\hline Soil bulk density & $\begin{array}{l}\text { Soil bulk density by location - } \\
\text { USDA } 2004 \text { [DIRS 173916], Part II, Table } 12\end{array}$ & Section 4.1.1 \\
\hline $\begin{array}{l}\text { Partition } \\
\text { coefficient }\end{array}$ & $\begin{array}{l}\text { Elemental partition coefficients for four soil types - } \\
\text { Sheppard and Thibault } 1990 \text { [DIRS 109991], Tables 3, A-1, A-2, A-3, } \\
\text { and A-4 } \\
\text { Soil texture for local soil series - } \\
\quad \text { USDA } 2004 \text { [DIRS 173916], Part II, Table } 12\end{array}$ & Section 4.1 .2 \\
\hline Soil erosion rate & $\begin{array}{l}\text { Soil erosion data by type and by state - } \\
\text { USDA } 2000 \text { [DIRS 160548], Tables } 10 \text { and } 11 \\
\text { Soil loss tolerance indices by soil series - } \\
\text { USDA } 2004 \text { [DIRS 173916], Part II, Table } 12\end{array}$ & Section 4.1 .3 \\
\hline $\begin{array}{l}\text { Enhancement } \\
\text { factor for } \\
\text { resuspension }\end{array}$ & 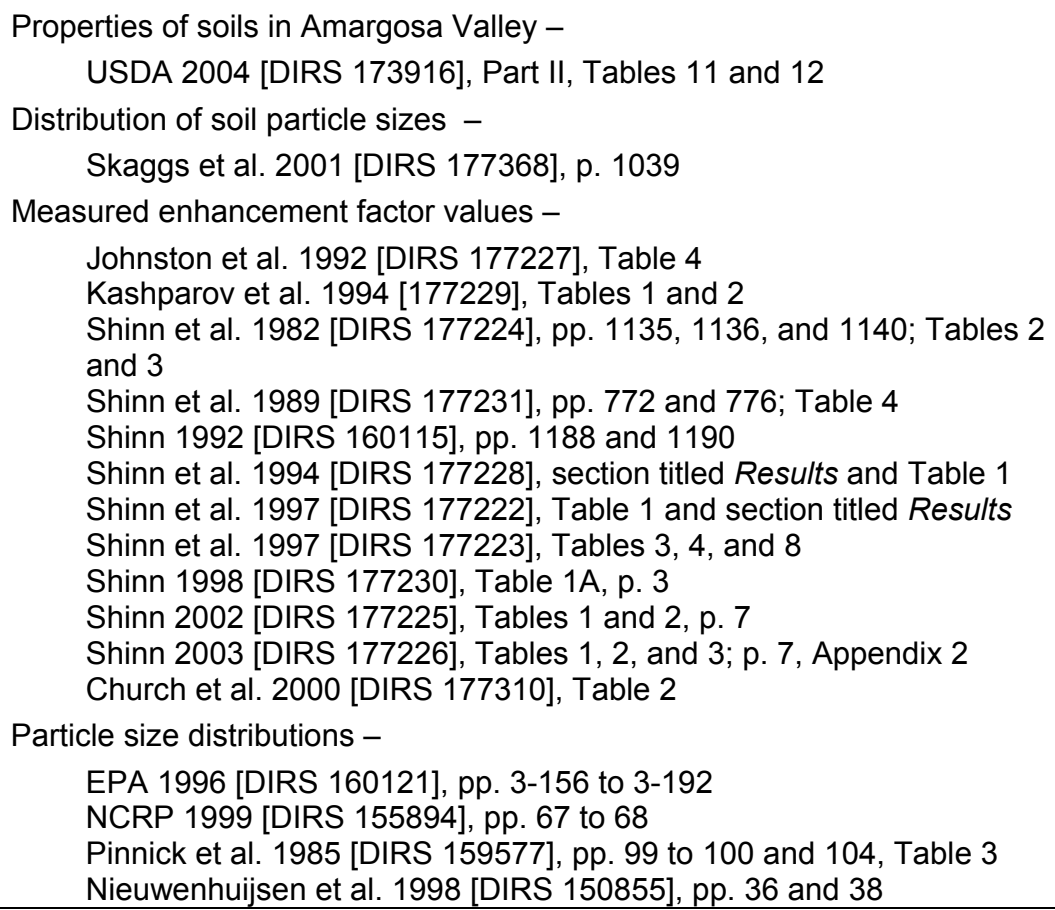 & Section 4.1 .4 \\
\hline $\begin{array}{l}\text { Volumetric water } \\
\text { content }\end{array}$ & $\begin{array}{l}\text { Soil water content at field capacity - } \\
\text { USDA } 2004 \text { [DIRS 173916], Part II, Table } 12 \\
\text { Allen et al. } 1998 \text { [DIRS 157311], Table } 19\end{array}$ & Section 4.1 .5 \\
\hline
\end{tabular}


Table 4.1-1. Sources of Parameter Information Used to Develop the Biosphere Model Input Parameters (Continued)

\begin{tabular}{|c|c|c|}
\hline $\begin{array}{c}\text { Biosphere } \\
\text { Model } \\
\text { Parameter }\end{array}$ & Source of Parameter or Data Used to Develop Parameter & $\begin{array}{c}\text { Description } \\
\text { and } \\
\text { Justification }\end{array}$ \\
\hline Irrigation duration & $\begin{array}{l}\text { Social characteristics of Amargosa Valley population - } \\
\text { DTN: MO0010SPANYE00.001 [DIRS 154976] } \\
\text { Bureau of the Census } 2002 \text { [DIRS 159728], Tables P47 and P49 } \\
\text { Bureau of the Census } 2002 \text { [DIRS 177451], Tables P115, H6, H7, } \\
\text { H15, H36, H38, and H39 } \\
\text { Lee et al. } 2005 \text { [DIRS } 177197 \text { ], pp. iii, 27, 36, 54; Section 3.5; Figure } 8 \\
\text { Mean age of mother - } \\
\text { Mathews and Hamilton } 2002 \text { [DIRS 177463], p. } 2\end{array}$ & Section 4.1.6 \\
\hline
\end{tabular}

\subsubsection{Soil Bulk Density}

The data associated with the soils in Amargosa Valley were taken from a report by the U.S. Department of Agriculture (USDA) Natural Resources Conservation Service (NRCS) entitled Soil Survey of Nye County, Nevada, Southwest Part (USDA 2004 [DIRS 173916], Part II, Table 12). The data from this reference are considered established fact.

NRCS is the federal authority on soil surveys in the United States and has held this authority since 1896. As such it can be considered to be the source of established fact data. The mission of the NRCS is to provide leadership to help people conserve and improve the nation's natural resources and environment. Part of this mission is to collect and disseminate agricultural land use data, including physical and chemical data for soils. These data are gathered under stringent standards and serve as a basis for land use management decisions that lead to "best-use" practices. The soil characterization process by the NRCS is ongoing to reflect advances in soil science, new and more specific soil taxonomy, and the increasing importance of soil use and conservation. The information provided by the NRCS is judged to be technically adequate for the purposes for which it is used in this analysis.

The data for soil characteristics referenced in Table 4.1-1 are suitable for the intended use, i.e., to develop distributions of the soil characteristics for the biosphere model, and are representative of the region surrounding Yucca Mountain. The data are presented, discussed, and used in Section 6.2.

\subsubsection{Partition Coefficients}

By definition, the partition coefficient is the ratio of the mass of the solute in the solid phase per unit mass of the solid phase to the concentration of the solute in the solution at equilibrium (Freeze and Cherry 1979 [DIRS 101173], Section 9.2). Synonyms for partition coefficient with this definition include $\mathrm{K}_{\mathrm{d}}$, sorption coefficient, and distribution coefficient. The dimensions of the partition coefficient are volume per mass, with units typically given in $\mathrm{L} \mathrm{kg}^{-1}$. The partition coefficient values are required by the biosphere model to determine the rate of leaching of radionuclides from the surface soil (see discussion in BSC 2004 [DIRS 169460], Section 6.4.1.3). 
A review of the literature was conducted in an attempt to find suitable partition coefficient values for the soil series found in the Amargosa Valley. This data search did not yield values specific to any of the six major soil series identified in the region or for similar soils in the vicinity of Yucca Mountain or southern Nevada. However, the distributions of partition coefficients recommended by Sheppard and Thibault (1990 [DIRS 109991], Tables 3, A-1, A-2, A-3, and A-4), following their extensive literature review, are appropriate for the intended use because the recommendations include the generic soil types identified in Section 6.2 that are present in agricultural fields in the Yucca Mountain region. Data from this source were qualified for use in this analysis, as described below. The planning and documentation of the qualification process is described below. The qualification criteria included the consideration of the extent to which the data demonstrate the properties of interest (described above) and other factors that substantiated the decision to qualify the data for intended use. The data are further described and displayed in Section 6.3 (Tables 6.3-1 through 6.3-4).

The following factors were considered in the following sections to evaluate the partition coefficient data developed by Sheppard and Thibault (1990 [DIRS 109991]) regarding their suitability and to qualify the data for their intended use.

- Reliability of data source and qualification of personnel or organizations generating the data

- Extent to which the data demonstrate the properties of interest

- Prior uses of the data

- Availability of corroborating data.

\subsubsection{Reliability of Data Source and Qualification of the Data Originator}

The review report, Default Soil Solid/Liquid Partition Coefficients, Kds, for Four Major Soil Types: A Compendium (Sheppard and Thibault 1990 [DIRS 109991]), is an article presenting the results of a review and synthesis of previously published elemental partition coefficient data for radionuclides of importance in nuclear waste management. The article was published in Health Physics, a scientific journal with international distribution. Prior to acceptance for publication, the article was subjected to rigorous scientific/technical peer review. Information extracted from the SciSearch Database of the Institute for Scientific Information revealed that the Sheppard and Thibault (1990 [DIRS 109991]) article had been cited 26 times by other published scientific works by the end of 1999 (Andrews 1999 [DIRS 169528]).

\subsubsection{Extent to Which the Data Demonstrate the Properties of Interest}

The partition coefficient data developed by Sheppard and Thibault (1990 [DIRS 109991]), based on a comprehensive review of previously published data, are considered adequate for representing variability and uncertainty in determining leaching rates. The data included in the source described in Section 4.1.2.1 were used to define the values and distributions of partition coefficients representative of Amargosa Valley soils. The relevant data from the reference were 
used as a basis for the values and distributions of the partition coefficients used in the biosphere model. Such a method ensures that the property of interest is adequately represented.

\subsubsection{Prior Uses of the Data}

Sheppard and Thibault (1990 [DIRS 109991]) developed the partition coefficient data for use in the Canadian nuclear waste program. The use of these data in that program is documented in The Disposal of Canada's Nuclear Fuel Waste: The Biosphere Model, BIOTRAC, for Postclosure Assessment (Davis et al. 1993 [DIRS 103767], Section 6.5.3).

Other researchers, including those at the Center for Nuclear Waste Regulatory Analysis in San Antonio, Texas, have used these values for their calculations of leaching coefficients in biosphere modeling for the Yucca Mountain repository (LaPlante and Poor 1997 [DIRS 101079], p. 2-22).

\subsubsection{Availability of Corroborating Data}

The authors of the cited reference, Sheppard and Thibault (1990 [DIRS 109991]), reviewed and synthesized a comprehensive set of published reports describing partition coefficients. While this reference was the sole source of input, the parameters characterizing the distributions were developed based on the applicable data reviewed and included in this report, as described in detail in Section 6.3. This method ensured that the relevant data were included or at least considered.

Based on the ranges of partition coefficient values presented by Sheppard and Thibault (1990 [DIRS 109991], Tables A-1 through A-4), this parameter exhibits large uncertainty for any nuclide. While some portion of the variability between the results of independent measurements for a given element can be attributed to variation in soil characteristics between the locations of the experimental sites, there is also known to be a significant variability between measurements conducted at specific sites. Local variability of partition coefficients has been reported in the Biosphere Modeling and Assessment (BIOMASS) project document (BIOMASS 2003 [DIRS 168563], Section BIII-2.5), which states that "It has been shown that measurements of soil $\mathrm{K}_{\mathrm{d}} \mathrm{S}$ on a single $100 \times 150 \mathrm{~m}^{2}$ field plot produced values ranging up to one order of magnitude for some radionuclides such as zinc, cobalt, cadmium, cerium and ruthenium, and a factor of 3 for critical ones such as caesium (sic) and iodine." Thus, even if the precise location of the receptor were known, it would be expected that any measured partition coefficient would be subject to significant variability over the lands that the receptor might use for agricultural purposes. This variability should be taken into account when modeling the biosphere. The non-location-specific data used here incorporate this variability as they are being synthesized from multiple measurements at multiple locations.

Based on the analysis of the factors considered in Sections 4.1.2.1 to 4.1.2.4, the data presented by Sheppard and Thibault (1990 [DIRS 109991]) are considered qualified for intended use. They are presented, further discussed, and used in Section 6.3.

The selection of the appropriate sets of partitions coefficients from the reference described above was informed by the data from Soil Survey of Nye County, Nevada, Southwest Part (USDA 2004 [DIRS 173916], Part II, Table 11), which was used in Section 6.3 to identify the types of soils 
occurring in the Amargosa Valley. This reference is a source of established fact data as discussed in Section 4.1.1. Also, equations from GoldSim User's Guide (GoldSim Technology Group 2003 [DIRS 166227], Appendix B) for calculation of geometric mean (GM) and geometric standard deviation (GSD) for the lognormal distribution were used to develop distributions of partition coefficients. These equations describe standard relationships between statistics of the lognormal distribution and can be considered established fact.

\subsubsection{Soil Erosion Rate}

Soil erosion rate is the parameter that quantifies mass removal of surface soil from a unit surface area per unit time. The distribution of soil erosion rate values for the biosphere model was based on the USDA NRCS data quantifying annual average water and wind erosion in the State of Nevada as well as the data on properties of soils in the southwest part of Nye County. These two references are described below.

The USDA data on erosion are provided in Summary Report, 1997 National Resources Inventory (Revised December 2000) (USDA 2000 [DIRS 160548]). This reference provides the annual average rates for wind and water (sheet and rill) erosion for different types of cropland and for pastureland for Nevada. The erosion values of interest to this work are those averaged over longer periods. Thus, it is considered that the published state-averaged data are sufficiently accurate for the purpose for which they are used in this analysis. The data from this reference are presented in Section 6.4.2. Table 6.4-2 provides the estimated annual average sheet and rill erosion on non-federal land in Nevada (USDA 2000 [DIRS 160548], Table 10). The values for wind erosion for the same states are given in Table 6.4-3 (USDA 2000 [DIRS 160548], Table 11).

The USDA data on tolerable soil loss rate provided in Soil Survey of Nye County, Nevada, Southwest Part (USDA 2004 [DIRS 173916], Part II) for soils occurring in Amargosa Valley were the basis for establishing the upper limit of erosion rates for sustainable agricultural production. These data are presented in Table 6.2-2. The soil survey data were supplemented by the data taken from Summary Report 1997 National Resources Inventory (Revised December 2000) (USDA 2000 [DIRS 160548], Tables 10 and 11), which were used to confirm upper limits of annual erosion rate.

The USDA NRCS can, for the reasons outlined in Section 4.1.1, be considered a source of established fact data. The data sufficiently represent the properties of interest and are therefore appropriate for intended use; they are further discussed and used in Section 6.4.

\subsubsection{Enhancement Factor for Resuspension}

The enhancement factor is the ratio of airborne particle activity concentration (activity per unit mass of resuspended soil) to surface soil activity concentration (activity per unit mass of surface soil). This parameter is used in the biosphere model as described in Section 6.5. 


\subsubsection{Enhancement Factor for the Volcanic Ash Exposure Scenario}

The values of the enhancement factor for the volcanic ash exposure scenario were developed based on the experimental data collected at several locations, including the Nevada Test Site. The source references are:

- Johnston et al. 1992 [DIRS 177227], Table 4 (Maralinga, Australia)

- Kashparov et al. 1994 [177229], Tables 1 and 2 (Chernobyl, Ukraine)

- Shinn et al. 1982 [DIRS 177224], pp. 1135, 1136, and 1140; Tables 2 and 3 (South Carolina) (also reported in Shinn 1998 [DIRS 177230], Table 1A)

- Shinn et al. 1989 [DIRS 177231], pp. 772 and 776; Table 4 (Nevada Test Site)

- Shinn et al. 1994 [DIRS 177228], Results and Table 1 (Johnston Island)

- Shinn et al. 1997 [DIRS 177222], Table 1 and section titled Results (Tonopah, near the Nevada Test Site)

- Shinn et al. 1997 [DIRS 177223], Tables 3, 4, and 8 (Marshall Islands)

- Shinn 1998 [DIRS 177230], Table 1A and p. 3 (California)

- Shinn 1998 [DIRS 177230], Table 1A (Nevada Test Site)

- Shinn 2002 [DIRS 177225], Tables 1 and 2; p. 7 (Palomares, Spain)

- Shinn 2003 [DIRS 177226], Tables 1, 2, and 3; pp. 5 and 7 (Maralinga, Australia)

- Church et al. 2000 [DIRS 177310], Table 2 (Nevada Test Site)

- Shinn 1992 [DIRS 160115], pp. 1189 and 1190 (various sites).

The data from the references used in this analysis include the measurements of enhancement factor as well as the measurements of associated parameters, such as characteristics of the particle size distribution of suspended soil. Data from the above sources were qualified for use in this analysis, as described below. Since the intended use is to collectively include the relevant data from the above references, the qualification concerns the whole set, rather than the individual references or data points. The planning and documentation of the qualification process is described below. The qualification process included the evaluation of several factors listed below and documentation of the basis of the decision to qualify the data.

The following factors were considered in the following sections to evaluate the suitability of enhancement factor data from external references and to qualify the data for their intended use.

- Reliability of data source and qualification of personnel or organizations generating the data 
- Extent to which the data demonstrate the properties of interest

- Prior uses of the data

- Availability of corroborating data.

\subsection{Reliability of Data Source and Qualification of the Data Originator}

Most enhancement factor data were collected by Joseph H. Shinn and are documented in Lawrence Livermore National Laboratory reports (Shinn et al. 1994 [DIRS 177228]; Shinn et al. 1997 [DIRS 177222]; Shinn 1998 [DIRS 177230]; Shinn 2002 [DIRS 177225]; Shinn 2003 [DIRS 177226]), in the journal Health Physics (Shinn et al 1989 [DIRS 177231]; Shinn et al. 1997 [DIRS 177223]), and in the proceedings of the International Conference on Precipitation Scavenging (Shinn 1992 [DIRS 160115]; Shinn et al. 1982 [DIRS 177224]). Shinn is a leading expert on measurements of resuspension and enhancement factor and he developed experimental methods used to measure these processes. Of the remaining two references not authored by Shinn, one was published in Journal of Aerosol Science (Kashparov et al. [DIRS 177229]) and the other in Health Physics (Johnston et al. 1992 [DIRS 177227]). Health Physics is a peer-reviewed technical journal, which is an official publication of the Health Physics Society. The Journal of Aerosol Science is a long-established international publication related to all aspects of basic and applied aerosol research. The journals publish high-quality scientific papers by adhering to high standards for published articles, which are subject to review by experts in the field. Most of the other reports were internally published by Lawrence Livermore National Laboratory under contracts to the U.S. Department of Energy.

\subsection{Extent to Which the Data Demonstrate the Properties of Interest}

The intended use of the data was to develop distributions of the enhancement factor for the volcanic ash exposure scenario as the biosphere model input and characterize the distributions of suspended particulates. The pertinent data included in the reports described above were field measurements of the enhancement factor as well as mass median aerodynamic diameter (MMAD) and GSD of suspended soil particles. These values were used to define the range and the distribution of the enhancement factor for the biosphere model. The bulk of the data were either site-specific, i.e., collected in Southern Nevada in the same general area as the location of the reasonably maximally exposed individual, or obtained from other arid or semi-arid locations, such as Southern California; Maralinga, Australia; and Palomares, Spain. The remaining references complete the set by bringing in additional data points for other environments and enhancing the understanding of the range of the parameter values. Therefore, the data provide a good basis for the development of the enhancement factor for the biosphere model.

\subsection{Prior Uses of the Data}

The data from many source references listed in Section 4.1.4 were reproduced in the National Council on Radiation Protection and Measurements (NCRP) report titled Recommended Screening Limits for Contaminated Surface Soil and Review of Factors Relevant to Site-Specific Studies (NCRP 1999 [DIRS 155894]). This NCRP report provides screening approaches that can be applied to sites where the surface soil is contaminated with radionuclides, to assist with 
impact evaluation and with making decisions regarding any necessary remediation. The reports of the NCRP can be considered as sources of established fact data.

\subsection{Availability of Corroborating Data}

The references used constitute a comprehensive set of reports describing the effect of radionuclide concentration change in resuspended soil relative to that of surface soil for the conditions analogous to those that can be expected following a volcanic eruption through the repository and subsequent dispersion of contaminated volcanic ash in the environment. As noted in Section 4.1.4.2, none of the references used to develop distributions the parameter values was a sole source of input, but rather the distributions were developed based on the applicable data from the references, as described in detail in Section 6.5.2. This method ensured that relevant data were included or at least considered.

\subsubsection{Enhancement Factor for the Groundwater Exposure Scenario}

The enhancement factor for the groundwater exposure scenario was developed based on the following several sources.

The data on texture of farmed soils occurring in Amargosa Valley were obtained from Soil Survey of Nye County, Nevada, Southwest Part (USDA 2004 [DIRS 173916], Part II, Tables 11 and 12). These data are further described and displayed in Section 6.5.3.2 and Table 6.5-4. The data from this source can be considered established fact, as discussed in Section 4.1.1. The data are representative of the conditions in the region surrounding Yucca Mountain and were used to develop and confirm the analytical representation of the texture of Amargosa Valley soils.

The equation used for this purpose was obtained from an article by Skaggs et al. (2001 [DIRS 177368], p. 1039). The article was published in Soil Science Society of America Journal, a peer-reviewed publication of the Soil Science Society of America, which is the professional organization dedicated to the advancement of the discipline and practice of soil science. The equation is appropriate for use in this analysis because it has been verified against particle size distributions for sandy loams soils, such as those occurring in the Yucca Mountain region. Also, the functional representation was used to define a range of possible values, rather than to provide a precise output. There was no strict requirement concerning the accuracy or precision of the functional representation of the particle size distribution in soils because of the relatively large range of the percentages of soil separates in the soil series of interest and the resulting uncertainty.

The data on particle size distribution of resuspended particulates include some of the reports described and justified in Section 4.1.4.1 (Shinn et al. 1989 [DIRS 177231], p. 776; Shinn et al. 1997 [DIRS 177222], Table 1 and Results; Shinn 2003 [DIRS 177226], Table 1; Shinn 2002 [DIRS 177225], Tables 1 and 2; Shinn et al. 1982 [DIRS 177224], p. 1136; Shinn et al. 1997 [DIRS 177223], Table 3; Shinn et al. 1994 [DIRS 177228], Results and Table 1). In addition, two references that report original measurements of resuspended particle concentrations (Pinnick et al. 1985 [DIRS 159577]; Nieuwenhuijsen et al. 1998 [DIRS 150855]), as well as two publications by scientific and government institutions (NCRP 1999 [DIRS 155894], pp. 67 to 68; EPA 1996 [DIRS 160121], pp. 3-156 to 3-192) were used. None of these sources was the sole 
source of input on particle size distribution of suspended particulates. Rather, the intended use was to collectively include relevant data in the analysis and define possible ranges of the parameters of interest. The qualification thus concerned the whole set, rather than the individual references or data points. The planning and documentation of the qualification process is described below. The qualification process included the evaluation of several factors as well as documentation of the basis of the decision to qualify the data. The qualification process and most of the sources of the original measurements were the same publications as those that were used to develop enhancement factor for the volcanic ash exposure scenario. The reasons why this data set is suitable for intended use were described in Section 4.1.4.1.

The additional publications containing original measurements not described in Section 4.1.4.1 were articles by Pinnick et al. (1985 [DIRS 159577], pp. 99 to 100, 104, and Table 3) and Nieuwenhuijsen et al. (1998 [DIRS 150855], pp. 36 and 38). The evaluation of these sources for data qualification purposes confirmed that (1) the information was published in a peer-reviewed scientific journal, (2) the methods used to measure particulate concentrations were sufficiently described to determine whether the methods and equipment used were applicable to this analysis and comparable to other studies, and (3) measurements were made in a setting applicable to this analysis. These data are described in Sections 6.5.1.2 and 6.5.3.3.

The following information was considered to evaluate whether the data were collected using acceptable methodology and to evaluate whether sufficient confidence in the acquisition and development of results is warranted to consider the data suitable for use in this analysis.

\subsection{Reliability of Data Sources}

Because the original measurements considered here came from peer-reviewed publications, and was thus judged to be appropriate for publication by experts in the associated fields of study, it was concluded that the data sources were reliable for use in this analysis. In addition, the methods used were described in sufficient detail to determine whether the results are applicable to this analysis.

\subsection{Extent to Which the Data Demonstrate the Properties of Interest}

Measurements of resuspended particle concentrations are most applicable to this analysis if they are measurements of personal exposure to total suspended particulates (TSP) taken in the environments considered in the biosphere model under conditions consistent with the conditions in the Yucca Mountain region. As described in Section 6, measurements considered here were taken in settings that are consistent with the receptor environments considered. Additional discussion of the applicability of the data to the conditions in the Yucca Mountain region is included in Section 6.5.3.3.

\subsection{Availability of Corroborating Data}

Applicable data on resuspended particle concentrations were considered in this analysis. The ranges of parameters describing particle size distributions from the original references were confirmed in Section 6.5.1.2 by comparisons with the data published by the scientific and government entities. These included the reports by the National Council on Radiation Protection and Measurements (NCRP 1999 [DIRS 155894], pp. 67 to 68) and the U.S. Environmental 
Protection Agency (EPA 1996 [DIRS 160121], pp. 3-156 to 3-192), which are considered sources of established fact data. These two reports were also used as sources of input data for this analysis.

Because the data considered here come from peer-reviewed journals, have sufficiently described methods, and were from studies conducted in applicable environments, it is concluded that the data are suitable for the specific application in this analysis. Confidence in the reliability of the data is raised by corroborative comparisons. Thus, the data are considered qualified for the intended use in this analysis. The data are presented, described, and used in Section 6.5.

\subsubsection{Volumetric Water Content of Soil}

Volumetric water content at field capacity is used in the biosphere model to represent the volumetric water content of surface soil. Site-specific data related to water content of soils were taken from Soil Survey of Nye County, Nevada, Southwest Part (USDA 2004 [DIRS 173916], Part II, Table 12). Data from this source are considered to be established fact as described in Section 4.1.1. The data are given in terms of available water capacity for soil series occurring in Amargosa Valley and are displayed in Table 6.2-2.

The distribution of the water content at field capacity values was estimated using data on the wilting point of crops in sandy loam soils from Crop Evapotranspiration, Guidelines for Computing Crop Water Requirements (Allen et al. 1998 [DIRS 157311], Table 19). That report (Allen et al. 1998 [DIRS 157311]) is a publication by the Food and Agriculture Organization of the United Nations (FAO). The FAO is one of the largest specialized agencies in the United Nations system and the lead agency for agriculture and rural development. Included in its many functions are collection, analysis, interpretation, and dissemination of information relating to nutrition, food, agriculture, forestry, and fisheries. The FAO serves as a clearing-house, providing farmers, scientists, government planners, traders, and non-governmental organizations with the information they need to make rational decisions on planning, investment, marketing, research, and training. A series of irrigation and drainage papers was written by experts in the various related fields of study and published by the FAO. Crop Evapotranspiration, Guidelines for Computing Crop Water Requirements (Allen et al. 1998 [DIRS 157311]), FAO Irrigation and Drainage Paper 56, describes comprehensive guidelines for determining crop water requirements. The FAO publications are considered sources of established fact data.

The data from the two references described above sufficiently represent the property of interest and are appropriate for intended use. The data are presented, further discussed, and used in Section 6.6.

\subsubsection{Irrigation Duration}

Duration of irrigation for field and garden crops was developed based on evaluation of information from several references that describe socioeconomic conditions in Amargosa Valley, history of settlement, as well as current land and water use. 


\subsubsection{2000 Census Population and Housing Data}

Information on housing type, housing tenure, and mobility of Amargosa Valley population was obtained from the most recent census. The data pertain to the residents of the Amargosa Valley census county division from the 2000 census conducted by the U.S. Bureau of the Census (2002 [DIRS 159728], Tables P47 and P49; 2002 [DIRS 177451], Tables P115, H6, H7, H15, H36, $\mathrm{H} 38$, and H39).

The 2000 census data are appropriate for use in this analysis and considered established fact as they are based on the most recent and comprehensive census of the Amargosa Valley population. The data are specific to the people who reside in the Amargosa Valley, consistent with the requirements of 10 CFR 63.312(b) [DIRS 173164]. The data were collected and summarized in accordance with the requirements of the Census Bureau for census data. The U.S. Bureau of the Census is the federal agency chartered to collect, analyze, and supply key economic and demographic data. Data from the Census Bureau are considered to be established fact. The 2000 Census data used in this analysis are identified and presented in Section 6.7.2 and used to develop parameter distribution in Sections 5.2 and 6.7.4.

\subsubsection{Dietary and Lifestyle Survey}

Information on lifestyle characteristics of the people who reside in the town of Amargosa Valley was obtained from a survey of the residents of the Yucca Mountain region (DTN: MO0010SPANYE00.001 [DIRS 154976]). This survey is described in The 1997 "Biosphere" Food Consumption Survey Summary Findings and Technical Documentation (DOE 1997 [DIRS 100332]). The objective of the survey was to collect dietary and socioeconomic information for biosphere modeling. Dietary and lifestyle data were collected from adults residing within 50 miles of Yucca Mountain. Nearly 13,000 adults were estimated to reside in that area at the time of the survey, with about 900 of them in the Amargosa Valley (DOE 1997 [DIRS 100332], p. vi). The survey sample consisted of 1,079 responses, with an Amargosa Valley sample of 195 (DOE 1997 [DIRS 100332], Table 2.3.1).

Data on residence tenure, type of housing units, and on home gardens are identified and described in Section 6.7.2 and were used in Sections 5.2 and 6.7.4 to develop distributions of irrigation duration. These data are appropriate because they are from a survey of the diet and living style of the people residing in the Amargosa Valley and are consistent with the requirements of 10 CFR 63.312(b) [DIRS173164].

\subsubsection{History of Settlement and Water Use in Amargosa Valley}

The report by Lee et al. (2005 [DIRS 177197], pp. iii, 27, 36, 54; Section 3.5; Figure 8) presents a summary of historic accounts, geologic treatises, and other key literature sources to identify factors that contributed to the development of local groundwater resources in Amargosa Valley during the past 150 years. This is a publication in the NUREG series prepared by the NRC staff (NUREG-1710, Vol. 1). The report is based on over 200 references from multiple sources and was reviewed by several individuals whose names are provided in the Acknowledgements section. Overall, the historical information compiled in the report can be considered established fact. Specifically, the report identifies the period of time when the first wells were drilled in 
Amargosa Valley and subsequently used for irrigation. It also contributes to the general understanding of the history of the region and social underpinnings of land and water use in Amargosa Valley.

In addition, several other references were used to corroborate the information included in the references presented in this section. The data are summarized, discussed, and used in Sections 5.2, 6.7.2, and 6.7.4.

\subsubsection{Time Span of a Generation}

The time span of a generation was characterized using the mean age of mother based on the Centers for Disease Control and Prevention National Vital Statistics report (Mathews and Hamilton 2002 [DIRS 177463]). These data can be considered established fact and were appropriate for intended use.

\subsection{CRITERIA}

The requirements that are applicable to this analysis are listed in Table 4.2-1 (BSC 2006 [DIRS 176938], Section 3.2). These project requirements are for compliance with applicable portions of 10 CFR Part 63 [DIRS 173273]. In addition to the requirements listed in Table 4.2-1, definitions of terms in 10 CFR 63.2 and description of concepts in 10 CFR 63.102 that are relevant to biosphere modeling are also applicable to this analysis.

Table 4.2-1. Requirements Applicable to This Analysis

\begin{tabular}{|l|c|}
\hline \multicolumn{1}{|c|}{ Requirement Title } & Related Regulation \\
\hline Requirements for Performance Assessment & 10 CFR 63.114 \\
\hline Required Characteristics of the Reference Biosphere & 10 CFR 63.305 \\
\hline Required Characteristics of the Reasonably Maximally Exposed Individual & 10 CFR 63.312 \\
\hline
\end{tabular}

Listed below are the acceptance criteria from Yucca Mountain Review Plan, Final Report (NRC 2003 [DIRS 163274]) that are applicable to this analysis. The list is based on meeting the requirements of 10 CFR 63.114, 10 CFR 63.305, and 10 CFR 63.312 [DIRS 173273] that relate in whole or in part to this analysis.

\section{Acceptance Criteria from Section 2.2.1.3.13: Redistribution of Radionuclides in Soil}

\section{Acceptance Criterion 2: Data Are Sufficient for Model Justification}

(1) Behavioral, hydrological, and geochemical values used in the license application are adequately justified (e.g., irrigation and precipitation rates, erosion rates, radionuclide solubility values, etc.). Adequate descriptions of how the data were used, interpreted, and appropriately synthesized into the parameters are provided.

(2) Sufficient data (e.g., field, laboratory, and natural analog data) are available to adequately define relevant parameters and conceptual models necessary for developing 
the abstraction of redistribution of radionuclides in soil in the total system performance assessment.

\section{Acceptance Criterion 3: Data Uncertainty Is Characterized and Propagated Through the Model Abstraction}

(1) Models use parameter values, assumed ranges, probability distributions, and bounding assumptions that are technically defensible, reasonably account for uncertainties and variabilities, do not result in an under-representation of the risk estimate, and are consistent with the characteristics of the reasonably maximally exposed individual in 10 CFR Part 63.

(2) The technical bases for the parameter values and ranges in the total system performance assessment abstraction are consistent with data from the Yucca Mountain region, e.g., Amargosa Valley survey studies of surface processes in the Fortymile Wash drainage basin; applicable laboratory testings; natural analogs; or other valid sources of data. For example, soil types, crop types, plow depths, and irrigation rates should be consistent with current farming practices, and data on the airborne particulate concentration should be based on the resuspension of appropriate material in a climate and level of disturbance similar to that which is expected to be found at the location of the reasonably maximally exposed individual, during the compliance time period.

(3) Uncertainty is adequately represented in parameters for conceptual models, process models, and alternative conceptual models considered in developing the total system performance assessment abstraction of redistribution of radionuclides in soil, either through sensitivity analyses, conservative limits, or bounding values supported by data, as necessary. Correlations between input values are appropriately established in the total system performance assessment.

\section{Acceptance Criteria from Section 2.2.1.3.14: Biosphere Characteristics}

\section{Acceptance Criterion 1: System Description and Model Integration Are Adequate}

(3) Assumptions are consistent between the biosphere characteristics modeling and other abstractions. For example, the U.S. Department of Energy should ensure that the modeling of features, events, and processes, such as climate change, soil types, sorption coefficients, volcanic ash properties, and the physical and chemical properties of radionuclides are consistent with assumption in other total system performance assessment abstractions.

\section{Acceptance Criterion 2: Data Are Sufficient for Model Justification}

(1) The parameter values used in the license application are adequately justified (e.g., behaviors and characteristics of the residents of the Town of Amargosa Valley, Nevada, characteristics of the reference biosphere, etc.) and consistent with the definition of the reasonably maximally exposed individual in 10 CFR Part 63 . 
Adequate descriptions of how the data were used, interpreted, and appropriately synthesized into the parameters are provided.

(2) Data are sufficient to assess the degree to which features, events, and processes related to biosphere characteristics modeling have been characterized and incorporated in the abstraction. As specified in 10 CFR Part 63, the U.S. Department of Energy should demonstrate that features, events, and processes, which describe the biosphere, are consistent with present knowledge of conditions in the region, surrounding Yucca Mountain. As appropriate, the U.S. Department of Energy sensitivity and uncertainty analyses (including consideration of alternative conceptual models) are adequate for determining additional data needs, and evaluating whether additional data would provide new information that could invalidate prior modeling results and affect the sensitivity of the performance of the system to the parameter value or model.

\section{Acceptance Criterion 3: Data Uncertainty Is Characterized and Propagated Through the Model Abstraction}

(1) Models use parameter values, assumed ranges, probability distributions, and bounding assumptions that are technically defensible, reasonably account for uncertainties and variabilities, do not result in an under-representation of the risk estimate, and are consistent with the definition of the reasonably maximally exposed individual in 10 CFR Part 63.

(2) The technical bases for the parameter values and ranges in the abstraction, such as consumption rates, plant and animal uptake factors, mass-loading factors, and biosphere dose conversion factors, are consistent with site characterization data, and are technically defensible.

(4) Uncertainty is adequately represented in parameter development for conceptual models and process-level models considered in developing the biosphere characteristics modeling, either through sensitivity analyses, conservative limits, or bounding values supported by data, as necessary. Correlations between input values are appropriately established in the total system performance assessment, and the implementation of the abstraction does not inappropriately bias results to a significant degree.

\subsection{CODES, STANDARDS, AND REGULATIONS}

No codes, standards, or regulations other than those identified in Section 4.2 and determined to be applicable were used in this analysis. 


\section{ASSUMPTIONS}

\subsection{UNDEFINED STANDARD DEVIATIONS FOR THE PARTITION COEFFICIENT DISTRIBUTIONS}

The data defining the parameters for the lognormal distribution of the partition coefficients are from Sheppard and Thibault (1990 [DIRS 109991], Tables 3, A-1, A-2, A-3, and A-4). For some soil types (sandy or loamy) and some elements of interest, there were insufficient data available for the authors to define an SD of the logarithm of the partition coefficient. In those cases where the SD is not provided, the mean value of the logarithm of the partition coefficient still provides an estimate for the partition coefficient value. However, the use of a single value for a given partition coefficient would not meet the requirement to incorporate the necessary variability and uncertainty. In these cases it was assumed that the SD of the logarithm of the partition coefficient could be approximated by the mean of the SDs of the logarithm of the partition coefficients for elements where data are available. This assumption is used in Section 6.3 to generate the parameters required to define the lognormal distribution representing the variability and uncertainty of the partition coefficients.

This assumption is reasonable as it attributes an average uncertainty about a measured mean of the logarithm of the partition coefficient. In addition, there is no distinct relationship between the SDs of the logarithms of the observed values and the means of the logarithms of the observed values (Sheppard and Thibault 1990 [DIRS 109991], Tables A-1, A-2, A-3, and A-4), which further justifies using the average SD. Using an average value for this SD allows reasonable uncertainty and variability associated with this parameter to be propagated through the biosphere model. This is a more realistic approach than using a fixed value while not attributing too little or excessive uncertainty to the parameter.

\subsection{UNDEFINED IRRIGATION DURATION}

Irrigation duration is the biosphere model parameter that quantifies how long the land that is used to grow garden and field crops was irrigated with contaminated water prior to the point in time for which the annual dose is calculated. The value of such a parameter has to be appropriate for the defined receptor, the reference biosphere, and has to reflect the current conditions in the region, as described in Section 6.7.1. The parameter value also has to be appropriate for the period of dose assessment, which can extend tens of thousands of years or more. The history of modern mechanized farming in the Southwest, including the Yucca Mountain region, spans a period of time that is less than a century. Therefore, irrigation duration cannot be determined based on the current or historical site-specific data.

The previous surface soil submodel of the biosphere model (BSC 2004 [DIRS 169460], Section 6.4.1) represented irrigation as a process occurring continuously until the equilibrium radionuclide concentration in surface soil was established. Such a representation did not account for the actual agricultural land use characteristics of Amargosa Valley. In this analysis, the long-term irrigation duration was estimated based on consideration of land management and sustainability of agriculture as well as social factors characteristic of the local population. Information used to develop this assumption is further described in Sections 6.7.2 and 6.7.3. 
The biosphere model considers five types of locally grown crops: leafy vegetables, other vegetables, fruit, grain, and forage crops (BSC 2004 [DIRS 169460], Section 6.3.1.6). Grain and forage are field crops, while vegetables and fruit that people consume are likely grown in home gardens. More than $90 \%$ of arable land in Amargosa Valley is planted in alfalfa, other hay, and grains (YMP 1999 [DIRS 158212], Tables 10 and 11; CRWMS M\&O 1998 [DIRS 103210], Tables 3-10 and 3-11; CRWMS M\&O 1997 [DIRS 101090], Tables 3-12 and 3-13). Therefore, these crops are produced in relatively large fields, while most vegetables and fruit are grown in home gardens. Consequently, irrigation duration was developed separately for field and for garden crops.

Irrigation Duration for Field Crops - There are many socioeconomic factors limiting irrigation duration of field crops. Although agricultural land is available, the quality of soils, availability of water in terms of access and appropriations, the cost of soil amendments, irrigation equipment, and electric power, as well as capital investment necessary to maintain the farm and irrigation infrastructure may become deciding factors in the extent and even the occurrence of farming.

The fluctuations in the area of land actively farmed and in the amount of water used annually in the Yucca Mountain region have been documented (YMP 1999 [DIRS 158212], Tables 10 and 11; CRWMS M\&O 1998 [DIRS 103210], Tables 3-10 and 3-11; CRWMS M\&O 1997 [DIRS 101090], Tables 3-12 and 3-13), which indicates that not all arable land is irrigated every year. The changing pattern of land use can also be seen in the satellite photos of the area (Lee et al. 2005 [DIRS 177197], Figure 8; Stonestrom et al. 2003 [DIRS 165862], Figure 2). Some of the existing agricultural fields may be taken out of production due to changing land ownership, aging, death, economics, as well as changing lifestyles, especially since most of the Amargosa Valley population is not employed in agriculture (Bureau of the Census 2002 [DIRS 159728], Table P49) and some who are involved in farming may only be involved on a part-time basis (Lee at al. 2005 [DIRS 177197], p. 53).

Considering these factors, it is not reasonable to expect that every plot of agricultural land would be irrigated for the few thousand years necessary for some for the radionuclides to approach equilibrium concentrations in surface soil. Further discussion of the local agricultural practices and related social limitations to continuous farming on the same plot of land for an extended period of time is provided in Sections 6.7.2 and 6.7.3.

On the basis of available information about the history of the settlement and agriculture in the region (see Section 6.7.3 for further discussion), a lower bound of 100 years for field crops irrigation duration is assumed. This value corresponds to the duration of the permanent settlement in Amargosa Valley, after the introduction of railroads in the early 1900s with ensuing general economic development of that part of Nevada (Lee et al. 2005 [DIRS 177197], p. 36; McCracken 1992 [DIRS 177198], Chapters 3 and 4). The first mechanically bored wells were drilled in alluvial deposits for local railroads in the first decade of the 20th century (Lee et al. 2005 [DIRS 177197], p. iii). The first irrigation well was drilled for the T\&T Ranch, an experimental farm located in Amargosa Valley, about 1917 (Lee et al. 2005 [DIRS 177197], p. iii). 
The higher bound of irrigation duration for field crops is assumed to be an order of magnitude higher, i.e., 1,000 years. This large range was assumed to account for uncertainty in this parameter resulting from a lack of long-term farming in the region. The higher bound is comparable with the persistence of many ancient world civilizations, including Greek, Roman, and Mesopotamian civilizations (Microsoft Encarta Encyclopedia 2006 [DIRS 177462]; [DIRS 177695]; [DIRS 177696]), much longer than some other civilizations, such as Aztec or Inca, and about one-tenth of the time since the first cultivation of grains in human history has began in the Middle East (Microsoft Encarta Encyclopedia 2006 [DIRS 177700]; [DIRS 177698]; [DIRS 177697]).

The lower bound of the distribution is based on the history of agriculture in Amargosa Valley and it is recommended that this value also be used as a mode of the triangular distribution of irrigation duration of field crops. The additional information presented in Section 6.7.3 suggests that the likelihood of a field being used decreases over time. A triangular distribution reflects such a trend, and is therefore appropriate for intended use. A triangular distributions ranging from 100 to 1,000 years also sufficiently represents uncertainty in the parameter value.

Irrigation Duration for Garden Crops-There are several factors that limit the time a home garden can be farmed. Some of the important factors include the collocation of the home garden and a home and the duration of tenancy of a home. It also needs to be recognized that there likely exists more mobility in home ownership and occupancy than in field use.

Almost $80 \%$ of dwellings in Amargosa Valley were manufactured homes (DTN: MO0010SPANYE00.001 [DIRS 154976]; see Excel file AV Data_Life Style.xls in Appendix A). Such structures typically would have a shorter lifetime than conventional homes and would not reasonably be expected to last more than a few generations.

There is a relatively high mobility among the population of Amargosa Valley, with all residents of tenant-occupied houses and over a half of residents of owner-occupied houses moving into their residence within a decade preceding the 2000 Census (Bureau of the Census 2002 [DIRS 177451], Table P115). Since most of the Amargosa Valley residents do not farm for a living, growing crops in home gardens is a lifestyle choice. The experts who were interviewed (Section 6.7.2) acknowledged a decrease in prevalence of home gardens in that area within the last decade. Housing in Amargosa Valley is further discussed in Section 6.7.3.

When people move to a new home, they would plant their home gardens within an easy access, in close proximity of their homes, and even if they moved to a new house on the same property, it is possible that a garden would be planted in a new location.

In consideration of the factors limiting persistence and thus irrigation of a home garden at the same location it was concluded that these factors have a societal and lifestyle dependency. Therefore, the duration of a generation was selected as a measure of time home gardens would be farmed. Generation is defined as an average span of time between the birth of parents and that of their offspring (Merriam-Webster 1993 [DIRS 100468], p. 485). From National Vital Statistics Reports, the mean age of mothers at first birth in 2000 was 24.9 years (Mathews and Hamilton 2002 [DIRS 177463], p. 2). 
Further discussion of these and other social limitations to continuous gardening on the same plot of land for an extended period of time is provided in Section 6.7.3.

A lower bound of 25 years, i.e., approximately one generation, is assumed for irrigation duration for garden crops. The same value should also be used as a mode of the triangular distribution of the parameter. Duration of 250 years, or 10 generations, is assumed as a higher bound. The additional information presented in Section 6.7.3 suggests that the likelihood of a garden being used decreases over time. A triangular distribution reflects such a trend and is, therefore, appropriate for intended use. A triangular distribution ranging from 25 to 250 years also sufficiently represents uncertainty in the parameter value. 


\section{SCIENTIFIC ANALYSIS DISCUSSION}

The processes represented in the biosphere model that are supported by this analysis are those representing radionuclide transport mechanisms associated with soil. This section describes the development of biosphere model parameters associated with these mechanisms. The description of radionuclide transport processes involving surface soil is presented in Section 6.1. Equations indicating where these soil-related parameters are used as inputs to environmental transport models were taken from Biosphere Model Report (BSC 2004 [DIRS 169460]).

To capture uncertainty within the biosphere model, this analysis develops the distributions of numerical values for parameters related to soil. After identifying specific elements of interest for the biosphere model, the subsequent sections define soil-related parameters and develop distributions for those parameters, which are used to model various environmental transport pathways involving surface soil. The distributions for soil bulk density, element-specific soil solid/liquid partition coefficients $\left(\mathrm{K}_{\mathrm{d}} \mathrm{S}\right)$, erosion rate, enhancement factors, and soil water content at field capacity are developed in Sections 6.2, 6.3, 6.4, 6.5, and 6.6, respectively. Section 6.7 contains a discussion of the potential for long-term irrigation in the Amargosa Valley area and a description and development of the distribution of irrigation duration.

The analysis considers two human exposure scenarios: groundwater and volcanic ash. The distributions for the six soil-related parameters developed in this report are representative of environmental conditions expected under present-day and future climates for the Amargosa Valley. For the reasons described below, in this analysis it is considered that climate changes predicted for the Yucca Mountain region (BSC 2004 [DIRS 170002]) would not affect the soil types for predicting the soil behavior.

The biosphere pathways must be consistent with arid or semi-arid conditions (10 CFR 63.305(d) [DIRS 173273]). Climate is one of the important factors affecting soil formation. Soils are usually more developed in areas with higher temperature and rainfall. This is in part related to the rate of weathering, which increases when the temperature and precipitation increase (Brady and Weil 1999 [DIRS 160019], Section 2.13). Temperatures in the Yucca Mountain region are predicted to be lower for the glacial transition period, and therefore thermally activated processes of soil generation would be retarded. For the climate in the arid to semi-arid range, the soil formation processes would not be significantly affected because the parent material and soil development process would remain the same. This consideration is in addition to the fact that the process of soil development is very slow (Brady and Weil 1999 [DIRS 160019], Section 2.16). The rate of soil erosion, a parameter developed in this report (Section 6.4), indicates that less than a tenth of a percent of surface soil would be removed annually. Therefore, for the climate change involved, the soils are not likely to evolve to the degree that the values of soil-related parameter distributions developed in this analysis would be no longer appropriate. Consequently, in this report, a single set of soil-related parameter values is developed that applies to the climatic conditions consistent with those supported by the biosphere model, i.e., arid to semi-arid conditions. 


\subsection{MODELING ENVIRONMENTAL TRANSPORT PATHWAYS INVOLVING SURFACE SOIL}

The environmental transport pathways of interest in this analysis include the pathways associated with radionuclide accumulation in, and removal from, the surface soil (the upper layer of the soil, down to the tilling depth, where all plant roots are assumed to be located) as well as some processes affecting radionuclide transport from soil to air by resuspension.

\subsubsection{Radionuclide Buildup in Surface Soil}

For the groundwater exposure scenario, surface soil is contaminated as a result of using contaminated groundwater for irrigation. Radionuclide concentrations in the soil would build up at a rate determined by the physical and chemical properties of the soil and the radionuclides. On land irrigated for a long time, radionuclide concentrations depend on the rate of accumulation and removal, and, with time, they would reach equilibrium concentrations when the rates of addition and removal are equal (BSC 2004 [DIRS 169460], Section 6.4.1).

Accumulation of radionuclides in the surface soil arises from the use of contaminated irrigated water. Radionuclides can be removed from the surface soil by leaching into the deep soil, surface soil erosion, crop harvest removal, and radioactive decay. Although crop harvesting may be an important mechanism for radionuclide removal on cultivated lands, this mechanism is not considered in the biosphere model because it is considered to compensate for the reintroduction of radionuclides into the soil when contaminated cow manure is used as fertilizer (BSC 2004 [DIRS 169460], Section 6.4.1.1).

When the radionuclide concentration in the groundwater and the crop irrigation rate are not time-dependent, the radionuclide concentration in surface soil is expressed as (BSC 2004 [DIRS 169460], Section 6.4.1.1):

$$
C S_{i}(t)=\frac{C w_{i} I R}{\lambda_{d, i}+\lambda_{l, i}+\lambda_{e}}\left[1-e^{-\left(\lambda_{d, i}+\lambda_{l, i}+\lambda_{e}\right) t}\right]
$$

where

$$
\begin{aligned}
C s_{i}(t)= & \text { activity concentration of radionuclide } i \text { in surface soil per unit area at time } \mathrm{t} \\
& \left(\mathrm{Bq} \mathrm{m}^{-2}\right) \\
i & =\text { primary radionuclide index, used for entire biosphere model } \\
t & \text { time variable }(\mathrm{yr}) \\
C w_{i}= & \text { activity concentration of radionuclide } i \text { in the groundwater }\left(\mathrm{Bq} \mathrm{m}{ }^{-3}\right) \\
I R(t)= & \text { annual average irrigation rate }\left(\mathrm{m} \mathrm{yr}^{-1}\right) \\
\lambda_{d, i}= & \text { radioactive decay constant for radionuclide } i\left(\mathrm{yr}^{-1}\right) ; \text { this can be calculated from } \\
& \text { radionuclide half-life using the conversion } \ln (2) / T_{d, i} \text {, where } T_{d, i} \text { is half-life of } \\
& \text { radionuclide } i(\mathrm{yr}) \\
\lambda_{l, i}= & \text { average annual leaching removal rate constant for radionuclide } i\left(\mathrm{yr}^{-1}\right) \\
\lambda_{e}= & \text { average annual surface soil erosion removal rate constant }\left(\mathrm{yr}^{-1}\right) .
\end{aligned}
$$


The process of leaching contaminants from the surface soil is evaluated in the biosphere model using an element-specific leaching removal rate constant. (The term leaching coefficient is also used for the leaching removal rate constant.) Leaching coefficients are calculated in the biosphere model as (BSC 2004 [DIRS 169460], Section 6.4.1.3):

$$
\lambda_{l, i}=\frac{O W}{d \times \theta\left(1+\frac{\rho}{\theta} K d_{i}\right)}
$$

where

$$
\begin{aligned}
O W= & \text { crop overwatering rate }\left(\mathrm{m} \mathrm{yr}^{-1}\right) \\
d= & \text { depth of surface soil }(\mathrm{m}) \\
\theta= & \text { volumetric water content of soil (dimensionless) } \\
\rho= & \text { solid-liquid partition coefficient for radionuclide } i \text { in surface soil } \\
& \left(\mathrm{Bq} \mathrm{kg}{ }^{-1} \text { solid }\right) /\left(\mathrm{Bq} \mathrm{m}{ }^{-3} \text { liquid }\right)=\left(\mathrm{m}^{3} \text { liquid } \mathrm{kg}^{-1} \text { solid }\right)
\end{aligned}
$$

and the other parameters are defined in Equations 6.1-1.

The rate of radionuclide removal from surface soils by erosion is quantified in the biosphere model using a surface soil erosion removal rate constant ( $\lambda e$ ) as (BSC 2004 [DIRS 169460], Section 6.4.1.4):

$$
\lambda_{e}=\frac{E R}{d \times \rho}
$$

where $E R$ is the annual average erosion rate for the surface soil $\left(\mathrm{kg} \mathrm{m}^{-2} \mathrm{yr}^{-1}\right)$ and the other parameters are defined in Equations 6.1-1 and 6.1-2.

Equation 6.1-1 describes the process of radionuclide buildup in surface soil under the conditions where radionuclide addition with irrigation water competes with radionuclide removal from surface soil by radioactive decay, leaching, and soil removal by erosion. With time, the system approaches asymptotically the equilibrium radionuclide concentration in surface soil. The equilibrium concentration in the soil, $C s_{i}$, is expressed as the ratio of the radionuclide addition rate to the removal rate:

$$
C s_{i}=\frac{C w_{i} I R}{\lambda_{d, i}+\lambda_{l, i}+\lambda_{e}}
$$

At any time $t$, radionuclide concentration in surface soil is at a fraction of equilibrium, which is given by the term $\left[1-e^{-\left(\lambda_{d, i}+\lambda_{l, i}+\lambda_{e}\right) t}\right]$ in Equation 6.1-1.

The activity concentration of a radionuclide in surface soil calculated from Equation 6.1-4 is given in units of activity per unit area $\left(\mathrm{Bq} \mathrm{m}^{-2}\right)$. It can be converted to activity concentration in Bq per unit mass of surface soil $\left(\mathrm{Bq} \mathrm{kg}^{-1}\right)$ using: 


$$
C s_{m, i}=\frac{C s_{i}}{\rho_{s}}
$$

where

$$
\begin{aligned}
& C s_{m, i}=\text { equilibrium activity concentration of radionuclide } i \text { in surface soil per unit mass } \\
& \left.(\mathrm{Bq} \mathrm{kg})^{-1}\right) \\
& C s_{i}=\text { equilibrium activity concentration of radionuclide } i \text { in surface soil per unit area } \\
& \left(\mathrm{Bq} \mathrm{m}^{-2}\right) \text { (defined in Equation 6.1-4) } \\
& \rho_{s} \quad=\operatorname{areal}\left(\text { surface) density of surface soil }\left(\mathrm{kg} \mathrm{m}^{-2}\right)\right. \text {. }
\end{aligned}
$$

Areal density of soil is calculated in the submodel using:

$$
\rho_{s}=\rho \times d
$$

The term $\lambda_{d, i}+\lambda_{l, i}+\lambda_{e}$ in Equation 6.1-1 can be replaced with one parameter, the effective removal constant, $\lambda_{\text {eff }, i}$. Thus, Equation 6.1-1 can be expressed as:

$$
C S_{i}=\frac{C w_{i} I R}{\lambda_{e f f, i}}\left(1-e^{-\lambda_{e f f, i} T_{i r}}\right)
$$

where

$$
\begin{aligned}
\lambda_{\text {eff }, i} & =\text { effective removal rate constant for radionuclide } i\left(\mathrm{yr}^{-1}\right) \\
T_{\text {irr }} & =\text { irrigation duration }(\mathrm{yr}) .
\end{aligned}
$$

The effective removal constant is an important parameter that determines the rate at which radionuclides approach equilibrium concentrations in the surface soil. For example, the time $(t)$ required for soil concentrations to reach $95 \%$ of the equilibrium value (i.e., $1-e^{-\lambda_{\text {ef } f, i} t}=0.95$ ) is equal to $\ln (20) / \lambda_{\text {effi, }}$. Although, theoretically, it takes an infinite amount of time to reach equilibrium, the time to reach a fixed percentage of the equilibrium value would be finite, and $95 \%$ is a close approximation to equilibrium. It takes about 10 to 2,000 years for the radionuclides considered in the model to reach the $95 \%$ equilibrium concentration in surface soils (BSC 2004 [DIRS 169460], Section 7.4.2.1). Long-lived isotopes of elements that bind readily to soil particles would not approach equilibrium concentrations for a few thousand years, whereas relatively short-lived or mobile radioisotopes would approach equilibrium concentrations after only a few years.

The previous revision of the biosphere model used an assumption that irrigation continued for a period of time sufficiently long for the radionuclide concentration in surface soil to be near equilibrium. Under this assumption, the fraction of equilibrium was equal to one. In Equation 6.1-7, the time variable, $t$, was replaced with the irrigation duration, $T_{i r}$. This parameter quantifies how long a field was irrigated prior to a point in time for which the dose assessment is done. 
In support of the surface soil submodel described above, this analysis develops in Sections 6.2, $6.3,6.4,6.6$, and 6.7 the following parameters: bulk soil density, $\rho$; element-specific partition coefficients, $K d_{i}$; erosion rate for the surface soil, $E R$; volumetric water content, $\theta$, and the irrigation duration, $T_{i r r}$.

\subsubsection{Soil Resuspension}

Resuspension is the process by which material deposited from the atmosphere onto the ground is subsequently returned to the atmosphere. In the biosphere model, radionuclide concentrations in the air are used to estimate inhalation exposure of the receptor and crop contamination by the deposition of resuspended particles onto plant surfaces. The receptor used in the biosphere model is the reasonably maximally exposed individual (RMEI), as defined in 10 CFR 636.312 [DIRS 173273]. Of interest to this analysis are the methods used to calculate radionuclide concentration in air for evaluation of inhalation exposure of the RMEI.

Concentrations of radionuclides in air inhaled by the RMEI would differ substantially depending on the activity and location of the RMEI. Therefore, the reference biosphere was divided into indoor and outdoor environments. In the outdoor environment, the RMEI was considered to be actively disturbing the soil or inactive relative to soil disturbance. In the indoor environment, the RMEI was considered to be either active or inactive (i.e., asleep). Concentrations of radionuclides in air were determined for each environment (BSC 2004 [DIRS 169460], Section 6.4.2.1) using the following equation (BSC 2004 [DIRS 169460], Section 6.4.2):

$$
C a_{h, i, n}=f_{\text {enhance, } n} C s_{m, i} S_{n}
$$

where

$$
\begin{aligned}
& C a_{h, i, n}=\text { activity concentration of radionuclide } i \text { in air from soil resuspension for the } \\
& \text { assessment of human inhalation exposure }(h) \text { in environment } n\left(\mathrm{~Bq} / \mathrm{m}^{3}\right) \\
& f_{\text {enhance }}=\text { enhancement factor for the activity concentration of suspended particulates } \\
& \text { (dimensionless), which accounts for differences between activity } \\
& \text { concentrations of surface soil and suspended particles } \\
& C s_{m, i}=\text { activity concentration of radionuclide } i \text { in the surface soil per unit of mass (m) } \\
& (\mathrm{Bq} / \mathrm{kg}) \\
& S_{n} \quad=\text { average annual concentration of TSP in air (mass loading) for evaluation of } \\
& \text { inhalation exposure for environment } n\left(\mathrm{~kg} / \mathrm{m}^{3}\right) \\
& n=\text { index of environments (described above). }
\end{aligned}
$$

This analysis develops in Section 6.5 distributions of numerical values of the enhancement factor for the four receptor environments described above.

\subsection{SOIL BULK DENSITY}

The soil bulk density, $\rho$, is one of the parameters that describes the physical characteristics of the surface soil. This parameter is used in several parts of the surface soil submodel of the biosphere model. It is used to calculate the areal density of surface soil (Equation 6.1-6), to determine the 
leaching removal rate constant, $\lambda_{l}$, of radionuclides from surface soil as a result of overwatering (Equation 6.1-2), and to determine the surface soil erosion removal constant, $\lambda_{e}$ (Equation 6.1-3).

Consistent with the requirement in 10 CFR 63.305(a) [DIRS 173273], the soils and their characteristics should reflect the present knowledge of the conditions in the region surrounding the Yucca Mountain site. The NRCS identified several soil series as being present in the Amargosa Valley region (USDA 2004 [DIRS 173916], Parts I and II). The soil series occurring in the agricultural areas in Amargosa Valley was considered, based on the NRCS soil survey.

Properties of the Amargosa Valley soils are described in Soil Survey of Nye County, Nevada, Southwest Part (USDA 2004 [DIRS 173916], Parts I and II). The soils where almost all farming occurs in Amargosa Valley are identified by the following map symbols: 2054, 2070, 2152, 2153, and 2451 (USDA 2004 [DIRS 173916], Part I, Maps 40, 41, 46, and 47). The descriptions and selected physical properties of these soils are presented below. The farmed soils in Amargosa Valley generally have a high content of rock fragments, such as gravel and cobble. The most abundant soil texture class for the soil fraction (obtained by separating out the coarse fragments) of farmed soils in Amargosa Valley is sandy loam with a relatively large fraction of rock fragments such as pebbles (gravel) and cobbles (Table 6.2-1). Sandy loams have 0\% to $20 \%$ clay, $0 \%$ to $50 \%$ silt, and $43 \%$ to $85 \%$ sand (BSC (2006 [DIRS 177101], Table 6-5). Additional information about soil categorization with respect to grain sizes and on soil textural classes properties can be found in Inhalation Exposure Input Parameters for the Biosphere Model (BSC (2006 [DIRS177101], Section 6.1.4).

Table 6.2-1 provides a summary of map symbols, soil series and percent composition of each soil series within a map unit, as well as a brief description of the soil series. Table 6.2-2 summarizes physical properties of the soil series occurring in Amargosa Valley, including thickness and bulk density of soil layers of interest to agriculture and horticulture, clay and organic matter content, as well as the T factor and wind erodibility group. It should be noted that density is given as the moist bulk density, which is defined (USDA 2004 [DIRS 173916], Part II, p. 24) as being the oven dry weight of soil per unit volume sampled at field capacity of moisture. Thus, the parameter represents the actual soil content (i.e., solids excluding water) measured under conditions prevailing in irrigated fields and, as such, is the appropriate parameter to represent soil density. Soil thickness, bulk density, and clay content for each soil series are given in Table 6.2-2 for the two uppermost soil layers. These two layers extend from a depth of approximately $0.35 \mathrm{~m}$ (14 inches for Commski) up to $1.5 \mathrm{~m}$ (60 inches for Arizo and Yermo). From the report Agricultural and Environmental Input Parameters for the Biosphere Model (BSC 2004 [DIRS 169673], Table 7.1-1), this minimum thickness is greater than the maximum tillage depth considered. Therefore, the density data in Table 6.2-2 can form the basis to estimate the moist bulk density of the soil. 
Table 6.2-1. Major Types of Agricultural Soils Occurring in Amargosa Valley

\begin{tabular}{|c|c|c|c|}
\hline Map Unit & $\begin{array}{l}\text { Soil } \\
\text { Series }\end{array}$ & $\begin{array}{l}\text { Percent of } \\
\text { Map Unit }\end{array}$ & Soil Series Texture and Description \\
\hline \multirow{2}{*}{$\begin{array}{l}\quad 2054 \\
\text { Yermo, hot- } \\
\text { Yermo-Arizo } \\
\text { association }\end{array}$} & Yermo & 70 & $\begin{array}{l}\text { Very gravelly sandy loam; the Yermo series consists of deep, } \\
\text { well-drained soils that formed in alluvium from mixed rocks. }\end{array}$ \\
\hline & Arizo & 15 & $\begin{array}{l}\text { Very gravelly sandy loam; the Arizo series consists of very deep, } \\
\text { excessively drained soil that form in alluvium derived from mixed } \\
\text { rocks. }\end{array}$ \\
\hline $\begin{array}{l}2070 \\
\text { Shamock }\end{array}$ & Shamock & 90 & $\begin{array}{l}\text { Gravelly fine sandy loam; the Shamock series consists of } \\
\text { moderately deep over a duripan well drained soils that formed in } \\
\text { alluvium derived from mixed rocks. }\end{array}$ \\
\hline $\begin{array}{l}2152 \\
\text { Arizo }\end{array}$ & Arizo & 85 & Very gravelly sandy loam (see description above) \\
\hline \multirow{3}{*}{$\begin{array}{c}2153 \\
\text { Arizo-Corbilt- } \\
\text { Commski } \\
\text { association }\end{array}$} & Arizo & 35 & Very gravelly sandy loam (see description above) \\
\hline & Commski & 25 & $\begin{array}{l}\text { Very gravelly fine sandy loam; the Commski series consists of very } \\
\text { deep, well-drained soils that formed in alluvium derived from } \\
\text { limestone. }\end{array}$ \\
\hline & Corbilt & 25 & $\begin{array}{l}\text { Gravelly fine sandy loam; the Corbilt series consists of very deep, } \\
\text { well drained soils that formed in alluvium derived from mixed rocks. }\end{array}$ \\
\hline \multirow{2}{*}{$\begin{array}{c}2451 \\
\text { Sanwell- } \\
\text { Sanwell, warm- } \\
\text { Yermo } \\
\text { association }\end{array}$} & Sanwell & 65 & $\begin{array}{l}\text { Gravelly fine sandy loam; the Sanwell series consists of very deep, } \\
\text { well-drained soils that form in coarse lacustrine sediments. }\end{array}$ \\
\hline & Yermo & 20 & Very gravelly sandy loam (see description above) \\
\hline
\end{tabular}

Source: USDA 2004 [DIRS 173916], Part I, Detailed Soil Map Units, Classification of the Soils, Taxonomic Units and their Properties; and Maps 40, 41, 46, and 47.

NOTE: Only the major soil series for a given map unit are listed, consistent with the description of soil properties in USDA 2004 [DIRS 173916], Part II.

From inspection of the density values in Table 6.2-2, the lower and upper values of soil density were $1.3 \mathrm{~g} \mathrm{~cm}^{-3}$ and $1.7 \mathrm{~g} \mathrm{~cm}^{-3}$ respectively. For stochastic modeling, it is recommended that the distribution of density be triangular over this range with a mode at the mid-point $1.5 \mathrm{~g} \mathrm{~cm}^{-3}$. If a deterministic value is required, then the moist soil density can be taken as $1.5 \mathrm{~g} \mathrm{~cm}^{-3}$ (the mid-point of the range).

It should be noted that the bulk density ranges for the other minor constituents of soils units occurring in Amargosa Valley (USDA 2004 [DIRS 173916], Part I), not shown in Table 6.2-2, are consistent with the values for the soil series within those units (USDA 2004 [DIRS 173916], Part II, Table 12). This indicates that the moist bulk density ranges for Amargosa Valley soils are consistent among soil series. 
Table 6.2-2. Physical Properties of Soils in Amargosa Valley

\begin{tabular}{|c|c|c|c|c|c|c|c|c|c|c|c|}
\hline \multirow[b]{2}{*}{ Soil Series } & \multicolumn{2}{|c|}{ Depth, in } & \multicolumn{2}{|c|}{$\begin{array}{c}\text { Clay Content Range, } \\
\%\end{array}$} & \multicolumn{2}{|c|}{$\begin{array}{c}\text { Moist Bulk Density } \\
\text { Range, } \mathrm{g} / \mathrm{cm}^{3}\end{array}$} & \multicolumn{2}{|c|}{$\begin{array}{l}\text { Available Water } \\
\text { Capacity, in/in }\end{array}$} & \multirow{2}{*}{$\begin{array}{c}\begin{array}{c}\text { Organic } \\
\text { Matter, \% }\end{array} \\
\text { Maximum }\end{array}$} & \multirow[b]{2}{*}{$\begin{array}{c}\text { T Factor }^{\mathrm{a}} \\
\text { tons/acre/yr }\end{array}$} & \multirow{2}{*}{$\begin{array}{l}\text { Wind } \\
\text { Erodibility } \\
\text { Group }\end{array}$} \\
\hline & $\begin{array}{l}\text { Lower } \\
\text { Limit }\end{array}$ & $\begin{array}{l}\text { Upper } \\
\text { Limit }\end{array}$ & $\begin{array}{l}\text { Lower } \\
\text { Limit }\end{array}$ & $\begin{array}{l}\text { Upper } \\
\text { Limit }\end{array}$ & $\begin{array}{l}\text { Lower } \\
\text { Limit }\end{array}$ & $\begin{array}{l}\text { Upper } \\
\text { Limit }\end{array}$ & $\begin{array}{l}\text { Lower } \\
\text { Limit }\end{array}$ & $\begin{array}{l}\text { Upper } \\
\text { Limit }\end{array}$ & & & \\
\hline \multirow[t]{2}{*}{ Arizo } & 0 & 8 & 5 & 12 & 1.40 & 1.55 & 0.05 & 0.07 & \multirow[t]{2}{*}{0.5} & \multirow[t]{2}{*}{5} & \multirow[t]{2}{*}{5} \\
\hline & 8 & 60 & 0 & 5 & 1.45 & 1.65 & 0.04 & 0.06 & & & \\
\hline \multirow[t]{2}{*}{ Corbilt } & 0 & 4 & 5 & 10 & 1.35 & 1.50 & 0.06 & 0.09 & \multirow[t]{2}{*}{0.5} & \multirow[t]{2}{*}{4} & \multirow[t]{2}{*}{5} \\
\hline & 4 & 32 & 5 & 10 & 1.35 & 1.55 & 0.11 & 0.13 & & & \\
\hline \multirow[t]{2}{*}{ Shamock } & 0 & 4 & 3 & 8 & 1.50 & 1.70 & 0.10 & 0.12 & \multirow[t]{2}{*}{0.8} & \multirow[t]{2}{*}{2} & \multirow[t]{2}{*}{4} \\
\hline & 4 & 37 & 5 & 10 & 1.55 & 1.70 & 0.09 & 0.11 & & & \\
\hline \multirow[t]{2}{*}{ Yermo } & 0 & 6 & 8 & 18 & 1.40 & 1.60 & 0.06 & 0.08 & \multirow[t]{2}{*}{0.5} & \multirow[t]{2}{*}{5} & \multirow[t]{2}{*}{5} \\
\hline & 6 & 60 & 8 & 18 & 1.40 & 1.60 & 0.06 & 0.08 & & & \\
\hline \multirow[t]{2}{*}{ Commski } & 0 & 5 & 10 & 18 & 1.40 & 1.60 & 0.06 & 0.08 & \multirow[t]{2}{*}{0.5} & \multirow[t]{2}{*}{5} & \multirow[t]{2}{*}{5} \\
\hline & 5 & 14 & 5 & 15 & 1.40 & 1.60 & 0.04 & 0.06 & & & \\
\hline \multirow[t]{2}{*}{ Sanwell } & 0 & 9 & 5 & 10 & 1.40 & 1.60 & 0.10 & 0.13 & \multirow[t]{2}{*}{0.5} & \multirow[t]{2}{*}{5} & \multirow[t]{2}{*}{4} \\
\hline & 9 & 16 & 5 & 10 & 1.30 & 1.50 & 0.08 & 0.12 & & & \\
\hline
\end{tabular}

Source: USDA 2004 [DIRS 173916], Part II, Table 12.

a $T$ Factor is an estimate of the maximum average annual rate of soil erosion by wind or water that can occur without affecting crop productivity over a sustained period (Troeh et al. 1980 [DIRS 110012], Section 6-1). The rate is in tons per acre per year. This parameter is only applicable to the surface layer that is available for erosion. 


\subsection{PARTITION COEFFICIENT}

By definition, the partition coefficient is the ratio of the mass of the solute in the solid phase per unit mass of the solid phase to the concentration of the solute in the solution at equilibrium (Freeze and Cherry 1979 [DIRS 101173], Section 9.2). Synonyms for partition coefficient with this definition include $\mathrm{K}_{\mathrm{d}}$, sorption coefficient, and distribution coefficient. The dimensions of the partition coefficient are volume per mass, with units typically given in $\mathrm{L} \mathrm{kg}^{-1}$.

Partition coefficients are used in the biosphere model for the groundwater exposure scenario to calculate the leaching rate constant, as described in Section 6.1. The objective of this section is to identify appropriate distributions for the elemental partition coefficients for the range of soils found in the Amargosa Valley. Information on the soils farmed in the region surrounding the Yucca Mountain site is presented in Section 6.2.

The partition coefficients are the only element-specific parameters developed in this analysis. The biosphere model was constructed for radionuclides screened in for the TSPA (BSC 2004 [DIRS 169460], Section 6.1.3). This list of radionuclides is used in the analysis to identify the elements for which partition coefficients are required. Elements identified as being potentially important to TSPA for time up to 20,000 years are: actinium (Ac), americium (Am), carbon (C), cesium $(\mathrm{Cs})$, iodine $(\mathrm{I})$, neptunium $(\mathrm{Np})$, protactinium $(\mathrm{Pa})$, plutonium $(\mathrm{Pu})$, radium $(\mathrm{Ra})$, strontium (Sr), technetium (Tc), thorium (Th), and uranium (U). Elements identified as being potentially important to TSPA for times beyond 20,000 years are chlorine $(\mathrm{Cl})$, lead $(\mathrm{Pb})$, selenium (Se), and tin ( $\mathrm{Sn})$. Distributions of partition coefficients were generated for all of these elements.

It should be noted that the biosphere model does not use partition coefficients that were used in the modeling of radionuclide transport in the unsaturated zone or the saturated zone. The partition coefficients used to calculate BDCFs are applicable to surface soils and differ from the coefficients used to model the transport of radionuclides through the saturated and unsaturated zones. This was done because the sorptive properties of the media in the geosphere (e.g., tuffaceous rocks and alluvium) and the geochemical environment differ from those of the surface soil in the biosphere.

\subsubsection{Data Review}

The element specific partition coefficients used in this analysis are those recommended by Sheppard and Thibault (1990 [DIRS 109991]) and presented in Tables A-1, A-2, A-3, and A-4 of that reference for sandy soil, loamy soil, clayey soil, and organic soil, respectively.

Tables 6.3-1 through 6.3-4 provide partition coefficient data for the four soil textures as given by Sheppard and Thibault (1990 [DIRS 109991]) and the 17 elements defined to be of interest to TSPA. 
Table 6.3-1. Element Specific Partition Coefficients for Sandy Soil

\begin{tabular}{|c|c|c|c|c|c|}
\hline \multirow[b]{2}{*}{ Element } & \multirow{2}{*}{$\begin{array}{c}\text { Number of } \\
\text { Observations }\end{array}$} & \multirow{2}{*}{$\begin{array}{c}\lambda^{\mathrm{a}} \\
\ln \left(\mathrm{L} \mathrm{kg}^{-1}\right)\end{array}$} & \multirow{2}{*}{$\begin{array}{c}\zeta^{b} \\
\ln \left(L g^{-1}\right)\end{array}$} & \multicolumn{2}{|c|}{ Measured Range, $\mathbf{L} \mathbf{~ k g}^{-1}$} \\
\hline & & & & Minimum & Maximum \\
\hline Actinium (Ac) & 0 & $6.1^{\mathrm{c}}$ & ND & ND & ND \\
\hline Americium (Am) & 29 & 7.6 & 2.6 & 8.2 & 300,000 \\
\hline Carbon $(C)$ & 3 & 1.1 & 0.8 & 1.7 & 7.1 \\
\hline Chlorine $(\mathrm{Cl})$ & 0 & ND & ND & ND & ND \\
\hline Cesium (Cs) & 81 & 5.6 & 2.5 & 0.2 & 10,000 \\
\hline lodine $(\mathrm{I})$ & 22 & 0.04 & 2.2 & 0.04 & 81 \\
\hline Neptunium (Np) & 16 & 1.4 & 1.7 & 0.5 & 390 \\
\hline Protactinium $(\mathrm{Pa})$ & 0 & $6.3^{c}$ & ND & ND & ND \\
\hline Lead $(\mathrm{Pb})$ & 3 & 5.6 & 2.3 & 19 & 1,405 \\
\hline Plutonium (Pu) & 39 & 6.3 & 1.7 & 27 & 36,000 \\
\hline Radium (Ra) & 3 & 6.2 & 3.2 & 57 & 21,000 \\
\hline Selenium (Se) & 3 & 4.0 & 0.4 & 36 & 70 \\
\hline Tin $(S n)$ & 0 & $4.9^{c}$ & ND & ND & ND \\
\hline Strontium (Sr) & 81 & 2.6 & 1.6 & 0.05 & 190 \\
\hline Technetium (Tc) & 19 & -2.0 & 1.8 & 0.01 & 16 \\
\hline Thorium (Th) & 10 & 8.0 & 2.1 & 207 & 150,000 \\
\hline Uranium (U) & 24 & 3.5 & 3.2 & 0.03 & 2,200 \\
\hline
\end{tabular}

Source: Sheppard and Thibault 1990 [DIRS 109991], Table A-1.

a $\lambda$ is the mean of the natural logarithms of the observed values.

${ }^{b} \zeta$ is the SD of the natural logarithms of the observed values.

c Default values for $\lambda$ have been predicted using soil-to-plant concentration ratios when no partition coefficient data have been reported as detailed by Sheppard and Thibault (1990 [DIRS 109991], p. 472).

NOTE: $\quad$ ND $=$ no data provided in source reference.

Table 6.3-2. Element Specific Partition Coefficients for Loamy Soil

\begin{tabular}{|c|c|c|c|c|c|}
\hline \multirow[b]{2}{*}{ Element } & \multirow{2}{*}{$\begin{array}{c}\text { Number of } \\
\text { Observations }\end{array}$} & \multirow{2}{*}{$\begin{array}{c}\lambda^{a} \\
\ln \left(L \mathrm{~kg}^{-1}\right)\end{array}$} & \multirow{2}{*}{$\begin{array}{c}\zeta^{b} \\
\ln \left(L^{k} g^{-1}\right)\end{array}$} & \multicolumn{2}{|c|}{ Measured Range, $\mathbf{L ~ k g}^{-1}$} \\
\hline & & & & Minimum & Maximum \\
\hline Actinium (Ac) & 0 & $7.3^{\mathrm{c}}$ & ND & ND & ND \\
\hline Americium (Am) & 20 & 9.2 & 1.4 & 400 & 48,309 \\
\hline Carbon $(\mathrm{C})$ & 0 & $2.9^{\mathrm{c}}$ & ND & ND & ND \\
\hline Chlorine $(\mathrm{Cl})$ & 0 & ND & ND & ND & ND \\
\hline Cesium (Cs) & 54 & 8.4 & 1.3 & 560 & 61,287 \\
\hline lodine (I) & 33 & 1.5 & 2.0 & 0.1 & 43 \\
\hline Neptunium (Np) & 11 & 3.2 & 1.2 & 1.3 & 79 \\
\hline Protactinium $(\mathrm{Pa})$ & 0 & $7.5^{\mathrm{c}}$ & ND & ND & ND \\
\hline Lead $(\mathrm{Pb})$ & 3 & 9.7 & 1.4 & 3,500 & 59,000 \\
\hline Plutonium (Pu) & 21 & 7.1 & 1.2 & 100 & 5,933 \\
\hline Radium (Ra) & 3 & 10.5 & 3.1 & 1,262 & 530,000 \\
\hline Selenium (Se) & 1 & 5.0 & ND & ND & ND \\
\hline $\operatorname{Tin}(S n)$ & 0 & $6.1^{\mathrm{c}}$ & ND & ND & ND \\
\hline Strontium (Sr) & 43 & 3.0 & 1.7 & 0.01 & 300 \\
\hline
\end{tabular}


Table 6.3-2. Element Specific Partition Coefficients for Loamy Soil (Continued)

\begin{tabular}{|c|c|c|c|c|c|}
\hline \multirow[b]{2}{*}{ Element } & \multirow{2}{*}{$\begin{array}{c}\text { Number of } \\
\text { Observations }\end{array}$} & \multirow{2}{*}{$\begin{array}{c}\lambda^{a} \\
\ln \left(L \mathrm{~kg}^{-1}\right)\end{array}$} & \multirow{2}{*}{$\begin{array}{c}\zeta^{b} \\
\ln \left(L^{k g^{-1}}\right)\end{array}$} & \multicolumn{2}{|c|}{ Measured Range, $\mathbf{L ~ k g}^{-1}$} \\
\hline & & & & Minimum & Maximum \\
\hline Technetium (Tc) & 10 & -2.3 & 1.1 & 0.01 & 0.4 \\
\hline Thorium (Th) & 0 & $8.1^{\mathrm{c}}$ & ND & ND & ND \\
\hline Uranium $(U)$ & 8 & 2.5 & 3.3 & 0.2 & 4,500 \\
\hline
\end{tabular}

Source: Sheppard and Thibault 1990 [DIRS 109991], Table A-2.

${ }^{a} \lambda$ is the mean of the natural logarithms of the observed values.

${ }^{b} \zeta$ is the SD of the natural logarithms of the observed values.

${ }^{c}$ Default values for $\lambda$ have been predicted using soil-to-plant concentration ratios when no partition coefficient data have been reported as detailed by Sheppard and Thibault (1990 [DIRS 109991], p. 472).

NOTE: $\quad$ ND $=$ no data provided in source reference.

Table 6.3-3. Element Specific Partition Coefficients for Clayey Soil

\begin{tabular}{|c|c|c|c|c|c|}
\hline \multirow[b]{2}{*}{ Element } & \multirow{2}{*}{$\begin{array}{c}\text { Number of } \\
\text { Observations }\end{array}$} & \multirow{2}{*}{$\begin{array}{c}\lambda^{\mathrm{a}} \\
\ln \left(\mathrm{L} \mathrm{kg}^{-1}\right)\end{array}$} & \multirow{2}{*}{$\begin{array}{c}\zeta^{b} \\
\ln \left(\mathrm{L} \mathrm{kg}^{-1}\right)\end{array}$} & \multicolumn{2}{|c|}{ Measured Range, $\mathrm{L} \mathrm{kg}^{-1}$} \\
\hline & & & & Minimum & Maximum \\
\hline Actinium $(\mathrm{Ac})$ & 0 & $7.8^{\mathrm{c}}$ & ND & ND & ND \\
\hline Americium (Am) & 11 & 9.0 & 2.6 & 25 & 400,000 \\
\hline Carbon $(C)$ & 0 & $0.8^{\mathrm{c}}$ & $\mathrm{ND}$ & ND & ND \\
\hline Chlorine $(\mathrm{Cl})$ & 0 & ND & ND & ND & ND \\
\hline Cesium (Cs) & 28 & 7.5 & 1.6 & 37 & 31,500 \\
\hline lodine (I) & 8 & 0.5 & 1.5 & 0.2 & 29 \\
\hline Neptunium (Np) & 4 & 4.0 & 3.8 & 0.4 & 2,575 \\
\hline Protactinium $(\mathrm{Pa})$ & 0 & $7.9^{\mathrm{c}}$ & ND & ND & ND \\
\hline Lead $(\mathrm{Pb})$ & 0 & $6.3^{\mathrm{c}}$ & ND & ND & ND \\
\hline Plutonium $(\mathrm{Pu})$ & 18 & 8.5 & 2.1 & 316 & 190,000 \\
\hline Radium (Ra) & 8 & 9.1 & 1.3 & 696 & 56,000 \\
\hline Selenium (Se) & 14 & 4.7 & 0.5 & 36 & 246 \\
\hline $\operatorname{Tin}(\mathrm{Sn})$ & 0 & $6.5^{\mathrm{c}}$ & $\mathrm{ND}$ & ND & ND \\
\hline Strontium (Sr) & 24 & 4.7 & 2.0 & 3.6 & 32,000 \\
\hline Technetium (Tc) & 4 & 0.2 & 0.06 & 1.16 & 1.32 \\
\hline Thorium (Th) & 5 & 8.6 & 2.6 & 244 & 160,000 \\
\hline Uranium (U) & 7 & 7.3 & 2.9 & 46 & $3,951,000$ \\
\hline
\end{tabular}

Source: Sheppard and Thibault 1990 [DIRS 109991], Table A-3.

${ }^{a} \lambda$ is the mean of the natural logarithms of the observed values.

${ }^{b} \zeta$ is the SD of the natural logarithms of the observed values.

${ }^{c}$ Default values for $\lambda$ have been predicted using soil-to-plant concentration ratios when no partition coefficient data have been reported as detailed by Sheppard and Thibault (1990 [DIRS 109991], p. 472).

NOTE: $\quad$ ND = no data provided in source reference. 
Table 6.3-4. Element Specific Partition Coefficients for Organic Soil

\begin{tabular}{|c|c|c|c|c|c|}
\hline \multirow[b]{2}{*}{ Element } & \multirow{2}{*}{$\begin{array}{c}\text { Number of } \\
\text { Observations }\end{array}$} & \multirow{2}{*}{$\begin{array}{c}\lambda^{\mathrm{a}} \\
\ln \left(\mathrm{L} \mathrm{kg}^{-1}\right)\end{array}$} & \multirow{2}{*}{$\begin{array}{c}\zeta^{b} \\
\ln \left(L g^{-1}\right)\end{array}$} & \multicolumn{2}{|c|}{ Measured Range, $\mathbf{L ~ k g}^{-1}$} \\
\hline & & & & Minimum & Maximum \\
\hline Actinium (Ac) & 0 & $8.6^{\mathrm{C}}$ & ND & ND & ND \\
\hline Americium (Am) & 5 & 11.6 & 1.7 & 6,398 & 450,000 \\
\hline Carbon (C) & 0 & $4.2^{\mathrm{c}}$ & ND & ND & ND \\
\hline Chlorine $(\mathrm{Cl})$ & 0 & ND & ND & ND & ND \\
\hline Cesium (Cs) & 9 & 5.6 & 3.6 & 0.4 & 145,000 \\
\hline lodine $(\mathrm{I})$ & 9 & 3.3 & 2.0 & 1.4 & 368 \\
\hline Neptunium (Np) & 3 & 7.1 & 0.4 & 857 & 1,900 \\
\hline Protactinium $(\mathrm{Pa})$ & 0 & $8.8^{\mathrm{C}}$ & ND & ND & ND \\
\hline Lead $(\mathrm{Pb})$ & 6 & 10.0 & 0.5 & 9,000 & 31,590 \\
\hline Plutonium $(\mathrm{Pu})$ & 7 & 7.5 & 2.6 & 60 & 62,000 \\
\hline Radium (Ra) & 0 & $7.8^{c}$ & ND & ND & ND \\
\hline Selenium (Se) & 4 & 5.1 & 0.5 & 105 & 310 \\
\hline $\operatorname{Tin}(\mathrm{Sn})$ & 0 & $7.4^{\mathrm{c}}$ & ND & ND & ND \\
\hline Strontium (Sr) & 12 & 5.0 & 1.8 & 8 & 4,800 \\
\hline Technetium (Tc) & 24 & 0.4 & 1.8 & 0.02 & 340 \\
\hline Thorium (Th) & 3 & 11.4 & 4.6 & 1,579 & $1.30 \mathrm{E}+07$ \\
\hline Uranium (U) & 6 & 6.0 & 2.5 & 33 & 7,350 \\
\hline
\end{tabular}

Source: Sheppard and Thibault 1990 [DIRS 109991], Table A-3.

${ }^{a} \lambda$ is the mean of the natural logarithms of the observed values.

${ }^{b} \zeta$ is the SD of the natural logarithms of the observed values.

${ }^{c}$ Default values for $\lambda$ have been predicted using soil-to-plant concentration ratios when no partition coefficient data have been reported as detailed by Sheppard and Thibault (1990 [DIRS 109991], p. 472).

NOTE: $\quad$ ND $=$ no data provided in source reference.

Sheppard and Thibault (1990 [DIRS 109991], p. 471) defined their texture categories of soil as follows:

The mineral soils were categorized by texture into sand, clay, and loam. The soils that contained $\geq 70$ percent sand-sized particles were classified as sand soils, and those containing $\geq 35$ percent clay-sized particles were classified as clay soils. Loam soils had an even distribution of sand-, clay-, and silt-sized particles or consisted of up to 80 percent silt-sized particles. Organic soils contained $>30$ percent organic matter and were either classic peat or muck soils, or the litter horizon of a mineral soil.

Inspection of Tables 6.3-1 through 6.3-4 indicates that, for a given element and a given soil, the measured range of the partition coefficient is large, in many cases spanning several orders of magnitude. While a large portion of the variability between the results of independent measurements can be attributed to soil variation between the experimental locations, there is also known to be appreciable variability at specific sites, as discussed in Section 4.1.2.4. Thus, even for a given location, it would be expected that any measured partition coefficients would be subject to significant variability over an irrigated field. This variability should be taken into account when assessing biosphere modeling. The use of broad distributions for the partition coefficients ensures that this variability is taken into account. 
The maximum organic matter content for Amargosa Valley soils is less than $0.8 \%$ (Table 6.2-3), and therefore the native soils are not classified as organic in texture (i.e., they do not contain more than $30 \%$ organic matter). The upper limit of the fractional clay content for Amargosa Valley soils is $18 \%$ (Table 6.2-2), and therefore the native soils are not classified as clay in texture (i.e., they do not contain $35 \%$ or more of clay-sized particles). As a consequence, the data in Tables 6.3-3 and 6.3-4 are not applicable to the soils in Amargosa Valley.

\subsubsection{Development of Parameter Distribution}

The authors of the review article from which the values were obtained (Sheppard and Thibault 1990 [DIRS 109991], p. 472) indicated that partition coefficients are lognormally distributed. Therefore, they elected to derive the mean and standard deviation of the logarithm of the parameter. Thus, for given elements and soils considered in this analysis, the uncertainty and variability in partition coefficient distributions can be represented by lognormal distributions.

As noted previously, for a given element and soil, the measured range of the partition coefficient is large, in many cases spanning several orders of magnitude (Tables 6.3-1 to 6.3-4). The use of the lognormal distribution can only be considered an approximation because no statistical justification was provided for universally using this distribution, other than that such a distribution can embrace a wide range of non-negative values. Justification of a particular distribution is a potential concern especially for elements with few reported measurements of the partition coefficient. The lognormal distribution is consistent with observations and captures the large degree of variability known to exist in partition coefficient values.

No attempt was made in this analysis to derive any time dependency of the partition coefficients, consistent with 10 CFR 63.305(a) [DIRS 173273], which requires that features, events, and processes be consistent with the present knowledge of the conditions in the region surrounding the Yucca Mountain site. Sheppard and Thibault (1990 [DIRS 109991], p. 472) stated that if a researcher reported a time series of partition coefficient values, they used only the partition coefficient values for the longest time because those values would most closely approximate equilibrium (i.e., late time) conditions. The use of the partition coefficient for the longest time period is the best representation of the long periods of continuing irrigation to be modeled (Section 6.7). Furthermore, the mathematical model of the leaching process used in Biosphere Model Report (BSC 2004 [DIRS 169460], Section 6.4.1.3) is consistent with the use of a constant leaching removal rate, which implies that a time-independent partition coefficient is appropriate.

The soils in Amargosa Valley that are farmed are classified as sandy loams (Table 6.2-1; based on USDA 2004 [DIRS 173916], Part II, Table 11). The qualifiers of gravelly, very gravelly, and cobbly refer to the size and fraction of rock fragments within the soil (see USDA 1993 [DIRS 160546], pp. 32 to 35 and 141 to 144, including Table 3-11). These qualifiers do not affect the soil texture but impact tillage and possibly restrict crop types. Soil Survey Manual (USDA 1993 [DIRS 160546], pp. 137 to 140) presents a soil texture scale that starts at sand and transitions sequentially through loamy sand, sandy loam, loam, clay loam, and silty clay loam before embracing clay combinations. The textures of Amargosa Valley soils are between sand and loam with a tendency to be more like loam than sand. 
Sheppard and Thibault (1990 [DIRS 109991], p. 477) reported examining the effect of $\mathrm{pH}$ on partition coefficients for the elements studied. Although they expected to see some dependence, no such effect was observed. The natural soils in and around the Amargosa Valley are alkaline (USDA 2004 [DIRS 173916], Part II, Table 13). However, continuous farming with soil augmentation, fertilizer use, and raising alfalfa (legumes) can change $\mathrm{pH}$. The variations implicit in the partition coefficient distributions are considered sufficiently broad to accommodate $\mathrm{pH}$ uncertainty and variability.

The partition coefficient values should reasonably account for uncertainty and variability, and not result in an under-representation of the dose estimate for the defined receptor. The soil types present at the possible location of the receptor fall between the categories of soil types (i.e., sand and loam) for which partition coefficient data are available. Therefore, the partition coefficients presented in Tables 6.3-1 and 6.3-2 are considered reasonable to represent Amargosa Valley soils. To select between the two data sets so that risk is not underestimated requires further consideration. An increase in the value of the partition coefficient causes a greater increase in radionuclide concentration in the soil (if there is sufficient elapsed time for the build-up process to attain near equilibrium conditions). The additional activity resident in the soil can increase predicted dose. To ensure that the dose risk is not underestimated, the partition coefficient data for a given element was taken from the data set (sand or loam) that has the higher expected value (i.e., mean) for the partition coefficient using the lognormal distribution.

It is not immediately apparent from inspection of the parameters of the lognormal distribution based on the mean and SD of the logarithms of the variable (i.e., partition coefficient) which of two distributions have the greater expected value (mean). For a lognormal distribution of variable $x$, where $\lambda$ is the mean value of the natural logarithm of the variable, $\ln (x)$, and $\zeta$ is the $\mathrm{SD}$ of $\ln (x)$, then the arithmetic mean, $\mu$, of the variable $x$ is being given by (GoldSim Technology Group 2003 [DIRS 166227], Appendix B):

$$
\mu=\exp \left(\lambda+0.5 \varsigma^{2}\right)
$$

Using Equation 6.3-1 and the values for the logarithmic mean and SDs in Tables 6.3-1 and 6.3-2, Table 6.3-5 was constructed showing the arithmetic mean for the individual elemental partition coefficients. Table 6.3-5 also shows which soil type has the larger arithmetic mean and provides the logarithmic parameters for that lognormal distribution.

The SD of the partition coefficient was not available for all elements. One option for the analysis would be to use a fixed value for the partition coefficient. In light of the data and discussion presented earlier in this section, this approach is not considered justifiable. It was therefore assumed (Section 5.1) that, for elements without information on partition coefficient variability, it is reasonable to express the variability using an average of the SDs for all other elements for the same soil type. This assumption is only required for actinium, carbon, protactinium, selenium, and tin. Using an average SD, based on other elements for which values are available, as a surrogate for SD for those radionuclides for which data are not available, is considered reasonable for incorporation of variability and uncertainty.

In Table 6.3-5, for the cases where the SD of the logarithm of the partition coefficient is unavailable (i.e., for elements $\mathrm{Ac}, \mathrm{C}, \mathrm{Pa}, \mathrm{Se}$, and $\mathrm{Sn}$ ), loam soils have the greater arithmetic mean 
partition coefficient. The arithmetic mean of the column titled " $\mathrm{SD} \ln \left(\mathrm{K}_{\mathrm{d}}\right)$ " for loam soils is 1.77 (hand calculation). This value is rounded up to 1.8 and is used to estimate the SD for those elements where a value is not provided.

The data for the lognormal distributions presented in Table 6.3-5 are in terms of the mean, $\lambda$, and $\mathrm{SD}, \zeta$, of the natural logarithm of the reported partition coefficients. This convention was followed here as it was the one used by the authors of the paper presenting the data (Sheppard and Thibault 1990 [DIRS 109991], p. 472). However, an alternative way to define the parameters of a lognormal distribution is to use the GM and GSD (GoldSim Technology Group 2003 [DIRS 166227], Appendix B). The relationships between the GM and the GSD and $\lambda$ and $\zeta$ are:

$$
\begin{gathered}
G M=\exp (\lambda) \\
G S D=\exp (\zeta)
\end{gathered}
$$

The values of the parameters used to specify the lognormal distributions representing the uncertainty and variability of the elemental partition coefficients to be used in the biosphere model are summarized Table 6.3-6. The parameter values in Table 6.3-6 are provided in terms of GM and GSD for a lognormal distribution. The $99 \%$ confidence interval for a lognormal distribution is approximately $2.576 \times \mathrm{SD}$ logarithmically above and below the GM, i.e., $\mathrm{GM} \times \mathrm{GSD}^{ \pm 2.576}$. The $95 \%$ confidence interval for a lognormal distribution is approximately $1.96 \times$ GSD logarithmically above and below the GM, i.e., GM $\times G^{ \pm 1.96}$. These values were considered as a lower and higher bound of the probability distribution functions for the partition coefficients (see Excel file Kd Bounds.xls in Appendix A), to realistically represent the range of measured values. In most cases, the $95 \%$ bounds represented better the range of the measured partition coefficients, except for technetium, cesium, and chlorine, for which $99 \%$ confidence interval bounds were used. These values are also provided in Table 6.3-6 as a low and high bound of the probability distribution functions for the partition coefficients. The measured maxima and minima of the partition coefficients are also provided in Table 6.3-6. For technetium, the measured maximum partition coefficient exceeds the upper bound by about $14 \%$. However, this value is still considered to not under-represent the risk to the receptor because it is by a factor of 35 higher than the maximum measured for loamy soils (Table 6.3-2). As noted previously, the soils where farming occurs in Amargosa Valley are sandy loams, and their texture is more loam-like than sand-like. 
Table 6.3-5. Logarithmic Parameters and the Associated Arithmetic Means of the Partition Coefficients for the Elements of Concern

\begin{tabular}{|c|c|c|c|c|c|c|c|c|c|}
\hline \multirow[b]{2}{*}{ Element } & \multicolumn{3}{|c|}{ Sand } & \multicolumn{3}{|c|}{ Loam } & \multicolumn{3}{|c|}{ Selected Case } \\
\hline & Mean $\ln \left(K_{d}\right)^{a}$ & $S D \ln \left(K_{d}\right)^{a}$ & $\begin{array}{l}\text { Arithmetic } \\
\text { Mean K } \\
\text { L kg }^{-1}\end{array}$ & Mean $\ln \left(K_{d}\right)^{b}$ & $S D \ln \left(K_{d}\right)^{b}$ & $\begin{array}{l}\text { Arithmetic } \\
\text { Mean K } \\
\text { L kg }^{-1}\end{array}$ & $\begin{array}{c}\text { Soil } \\
\text { Type }\end{array}$ & Mean $\ln \left(K_{d}\right)$ & $S D \ln \left(K_{d}\right)$ \\
\hline Actinium (Ac) & 6.1 & - & $4.46 \times 10^{2}$ & 7.3 & - & $1.48 \times 10^{3}$ & loam & 7.3 & 一 \\
\hline Americium (Am) & 7.6 & 2.6 & $5.87 \times 10^{4}$ & 9.2 & 1.4 & $2.64 \times 10^{4}$ & sand & 7.6 & 2.6 \\
\hline Carbon $(\mathrm{C})$ & 1.1 & 0.8 & 4.14 & 2.9 & 一 & $1.82 \times 10^{1}$ & loam & 2.9 & 一 \\
\hline Cesium (Cs) & 5.6 & 2.5 & $6.15 \times 10^{3}$ & 8.4 & 1.3 & $1.04 \times 10^{4}$ & loam & 8.4 & 1.3 \\
\hline Chlorine $(\mathrm{Cl})$ & \multicolumn{3}{|c|}{ No Data } & \multicolumn{3}{|c|}{ No Data } & \multicolumn{3}{|c|}{ No Data } \\
\hline lodine (I) & 0.04 & 2.2 & $1.17 \times 10^{1}$ & 1.5 & 2.0 & $3.31 \times 10^{1}$ & loam & 1.5 & 2.0 \\
\hline Lead $(\mathrm{Pb})$ & 5.6 & 2.3 & $3.81 \times 10^{3}$ & 9.7 & 1.4 & $4.35 \times 10^{4}$ & loam & 9.7 & 1.4 \\
\hline Neptunium (Np) & 1.4 & 1.7 & $1.72 \times 10^{1}$ & 3.2 & 1.2 & $5.04 \times 10^{1}$ & loam & 3.2 & 1.2 \\
\hline Protactinium $(\mathrm{Pa})$ & 6.3 & - & $5.45 \times 10^{2}$ & 7.5 & 一 & $1.81 \times 10^{3}$ & loam & 7.5 & 一 \\
\hline Plutonium (Pu) & 6.3 & 1.7 & $2.31 \times 10^{3}$ & 7.1 & 1.2 & $2.49 \times 10^{3}$ & loam & 7.1 & 1.2 \\
\hline Radium (Ra) & 6.2 & 3.2 & $8.25 \times 10^{4}$ & 10.5 & 3.1 & $4.43 \times 10^{6}$ & loam & 10.5 & 3.1 \\
\hline Selenium (Se) & 4.0 & 0.4 & $5.91 \times 10^{1}$ & 5.0 & 一 & $1.48 \times 10^{2}$ & loam & 5.0 & - \\
\hline Strontium (Sr) & 2.6 & 1.6 & $4.84 \times 10^{1}$ & 3 & 1.7 & $8.52 \times 10^{1}$ & loam & 3.0 & 1.7 \\
\hline Technetium (Tc) & -2.0 & 1.8 & $6.84 \times 10^{-1}$ & -2.3 & 1.1 & $1.84 \times 10^{-1}$ & sand & -2.0 & 1.8 \\
\hline Thorium (Th) & 8.0 & 2.1 & $2.70 \times 10^{4}$ & 8.1 & - & $3.29 \times 10^{3}$ & sand & 8.0 & 2.1 \\
\hline $\operatorname{Tin}(\mathrm{Sn})$ & 4.9 & 一 & $1.34 \times 10^{2}$ & 6.1 & 一 & $4.46 \times 10^{2}$ & loam & 6.1 & - \\
\hline Uranium (U) & 3.5 & 3.2 & $5.54 \times 10^{3}$ & 2.5 & 3.3 & $2.82 \times 10^{3}$ & sand & 3.5 & 3.2 \\
\hline
\end{tabular}

a Data taken from Table 6.3-1.

${ }^{\mathrm{b}}$ Data taken from Table 6.3-2.

NOTE: $\quad \mathrm{K}_{\mathrm{d}}=$ partition coefficient; units are $\mathrm{L} \mathrm{kg}^{-1}$. 
Table 6.3-6. Lognormal Distribution Parameters for Partition Coefficients

\begin{tabular}{|c|c|c|c|c|c|c|}
\hline \multirow[b]{2}{*}{ Element } & \multicolumn{6}{|c|}{ Parameter Values for a Lognormal Distribution } \\
\hline & GM, L kg ${ }^{-1}$ & GSD & $\underset{\mathrm{L} \mathrm{kg}^{-1}}{\operatorname{Minimum}}{ }^{\mathrm{a}}$ & $\underset{\mathrm{L} \mathrm{kg}^{-1}}{\operatorname{Maximum}}{ }^{\mathrm{a}}$ & $\begin{array}{c}\text { Low Bound } \\
\mathrm{L} \mathrm{kg}^{-1}\end{array}$ & $\begin{array}{l}\text { High Bound } \\
\text { L kg }^{-1}\end{array}$ \\
\hline Actinium (Ac) & $1.5 \times 10^{3}$ & $6.0^{c}$ & Not provided & Not provided & $4.3 \times 10^{1}$ & $5.0 \times 10^{4}$ \\
\hline Americium (Am) & $2.0 \times 10^{3}$ & $1.4 \times 10^{1}$ & 8.2 & $3.0 \times 10^{5}$ & $1.2 \times 10^{1}$ & $3.3 \times 10^{5}$ \\
\hline Carbon (C) & $1.8 \times 10^{1}$ & 6.0 & $1.7^{\mathrm{d}}$ & $7.1^{d}$ & $5.3 \times 10^{-1}$ & $6.2 \times 10^{2}$ \\
\hline Cesium (Cs) & $4.4 \times 10^{3}$ & 3.7 & $5.6 \times 10^{2}$ & $6.1 \times 10^{4}$ & $1.6 \times 10^{2}$ & $1.3 \times 10^{5}$ \\
\hline Chlorine $(\mathrm{Cl})$ & $1.4 \times 10^{-1}$ & $6.0^{\mathrm{C}}$ & Not provided & Not provided & $1.3 \times 10^{-3}$ & $1.4 \times 10^{1}$ \\
\hline lodine (I) & 4.5 & 7.4 & 0.1 & $4.3 \times 10^{1}$ & $8.9 \times 10^{-2}$ & $2.3 \times 10^{2}$ \\
\hline Lead $(\mathrm{Pb})$ & $1.6 \times 10^{4}$ & 4.1 & $3.5 \times 10^{3}$ & $5.9 \times 10^{4}$ & $1.0 \times 10^{3}$ & $2.5 \times 10^{5}$ \\
\hline Neptunium (Np) & $2.5 \times 10^{1}$ & 3.3 & 1.3 & $7.9 \times 10^{1}$ & 2.3 & $2.6 \times 10^{2}$ \\
\hline Protactinium $(\mathrm{Pa})$ & $1.8 \times 10^{3}$ & $6.0^{c}$ & Not provided & Not provided & $5.3 \times 10^{1}$ & $6.2 \times 10^{4}$ \\
\hline Plutonium (Pu) & $1.2 \times 10^{3}$ & 3.3 & $1.0 \times 10^{2}$ & $5.9 \times 10^{3}$ & $1.2 \times 10^{2}$ & $1.3 \times 10^{4}$ \\
\hline Radium (Ra) & $3.6 \times 10^{4}$ & $2.2 \times 10^{1}$ & $1.3 \times 10^{3}$ & $5.3 \times 10^{5}$ & $8.3 \times 10^{1}$ & $1.6 \times 10^{7}$ \\
\hline Selenium (Se) & $1.5 \times 10^{2}$ & $6.0^{\mathrm{C}}$ & $3.6 \times 10^{1 d}$ & $7.0 \times 10^{1 \mathrm{~d}}$ & 4.4 & $5.1 \times 10^{3}$ \\
\hline Strontium (Sr) & $2.0 \times 10^{1}$ & 5.5 & $1.0 \times 10^{-2}$ & $3.0 \times 10^{2}$ & $7.2 \times 10^{-1}$ & $5.6 \times 10^{2}$ \\
\hline Technetium (Tc) & $1.4 \times 10^{-1}$ & 6.0 & $1.0 \times 10^{-2}$ & $1.6 \times 10^{1}$ & $1.3 \times 10^{-3}$ & $1.4 \times 10^{1}$ \\
\hline Thorium (Th) & $3.0 \times 10^{3}$ & 8.2 & $2.1 \times 10^{2}$ & $1.5 \times 10^{5}$ & $4.9 \times 10^{1}$ & $1.8 \times 10^{5}$ \\
\hline Tin (Sn) & $4.5 \times 10^{2}$ & $6.0^{\mathrm{c}}$ & Not provided & Not provided & $1.3 \times 10^{1}$ & $1.5 \times 10^{4}$ \\
\hline Uranium (U) & $3.3 \times 10^{1}$ & $2.5 \times 10^{1}$ & $3.0 \times 10^{-2}$ & $2.2 \times 10^{3}$ & $6.3 \times 10^{-1}$ & $1.8 \times 10^{4}$ \\
\hline
\end{tabular}

a Values for the selected soil type from Table 6.3-1 or Table 6.3-2.

${ }^{b}$ Low and high bounds were calculated in Excel worksheet Kd Bounds.x/s (Appendix A) for the $95 \%$ confidence interval of a lognormal distribution except for cesium, technetium, and chlorine, for which $99 \%$ confidence interval was used.

${ }^{c}$ Estimated using an average standard deviation for other elements for which values were available.

${ }^{d}$ Range for sandy soils; range for loams was not provided in the source reference.

The source reference (Sheppard and Thibault 1990 [DIRS 109991]) does not include partition coefficients for chlorine. Chlorine ions $\left(\mathrm{Cl}^{-}\right)$are highly mobile within a soil environment and move rapidly by leaching. It can be assumed that when chlorine enters the soil in irrigation water as chloride ions, it would remain present as chloride ions, either in soil water or weakly ion-exchanged. The partition coefficient for chlorine can be estimated because there is an inverse correlation between partition coefficient values and soil-to-plant concentration ratios (Sheppard and Thibault 1990 [DIRS 109991], p. 472), i.e., a large value for the partition coefficient implies a low value for the soil-to-plant concentration ratio. In $A$ Review and Analysis of Parameters for Assessing Transport of Environmentally Released Radionuclides Through Agriculture, Baes et al. (1984 [DIRS 103766]) reported the (dimensionless) soil-to-plant transfer concentration ratios (called transfer factors in the biosphere model) for vegetative portions of food crops for many elements. Included were values for chlorine (transfer factor $=70)$ and technetium (transfer factor $=9.5)($ Baes et al. 1984 [DIRS 103766], p. 10). The soil-to-plant transfer concentration ratios for these two elements are larger than the values for most of the other elements, thereby indicating a small value for the partition coefficient and high mobility of these elements in the environment. Because of these similarities, the partition coefficient distribution for technetium was used as a surrogate of that of chlorine. 
Sheppard and Thibault (1990 [DIRS 109991], p. 472) state that there is an inverse relationship between the two parameters of approximate form $C R \propto K_{d}^{-2}$, where $C R$ is the concentration ratio and $K_{d}$ is the partition coefficient. The correlation coefficient between the partition coefficient and the soil-to-plant transfer factor is evaluated and reported in Environmental Transport Input Parameters for the Biosphere Model (BSC 2004 [DIRS 169672], Section 6.2.1.5), where it was determined to be -0.8 . This topic is not discussed further here.

\subsection{EROSION RATE}

The erosion removal rate is required by the biosphere model to calculate the surface soil erosion removal rate constant, as given by Equation 6.1-3.

Erosion is one of the mechanisms of radionuclide removal from surface soil that is considered in the biosphere model for the groundwater exposure scenario and influences the level of equilibrium radionuclide concentration in surface soil, especially for those radionuclides that do not get effectively removed from the surface soil via other mechanisms.

\subsubsection{Leaching and Soil Erosion as Competing Removal Processes}

For the Amargosa Valley, where farming and gardening practices rely on irrigation with potentially contaminated water, any dose assessment must consider processes that occur in the soil compartment of the biosphere. For some elements, the soil has a high affinity for atoms of those elements. This attachment of atoms to soil particles is described by the partition coefficient, as defined in Section 4.1.2. If water contaminated with an element in solution is mixed with uncontaminated soil, some of the atoms of that element are removed from the water and become attached to the soil particles. The partition coefficient is a simple linear representation of this reversible process.

Where an element has a large partition coefficient, prolonged irrigation with contaminated water can lead to relatively high concentrations of the element on particles of soil. This is especially so in the arid to semi-arid conditions around Yucca Mountain, where evapotranspiration rather than percolation is the major mechanism of water removal from surface soil. Such a loss of water to the atmosphere leaves any radionuclides introduced by the irrigation water behind in the soil. These radionuclides, now resident in the soil, can be transported to the receptor and contribute to the receptor's dose.

Radionuclide buildup due to continuing irrigation is limited by competing processes that remove radioactivity from the soil. Baes and Sharp (1983 [DIRS 109606], p. 18) identify radioactive decay, harvesting, and leaching as examples of such processes. Another transport mechanism that can result in removal is erosion of the soil by wind and water. To put the accumulation process into perspective, an analysis was conducted that evaluated time required to reach $50 \%$ and $95 \%$ equilibrium radionuclide concentration in surface soil assuming that leaching was the only removal process. Table 6.4-1 reproduces the values of elemental partition coefficients (see Section 6.2), the corresponding leaching removal rate constant, as well as the time required to reach $50 \%$ and $95 \%$ equilibrium. 
The leaching removal rate constant was calculated using Equation 6.1-2 and the following average values of the remaining parameters:

- Partition coefficient, $K d_{i}$ (Table 6.3-6)

- Average overwatering rate, $O W=0.079 \mathrm{~m} \mathrm{yr}^{-1}$ (BSC 2004 [DIRS 169673], Table 7.1-1)

- Average depth of surface soil, $d=0.175$ m (BSC 2004 [DIRS 169673], Table 7.1-1)

- Average volumetric water content, $\theta=0.23$ (Section 6.6)

- Average soil density, $\rho=1,500 \mathrm{~kg} \mathrm{~m}^{-3}$ (Section 6.2).

Time required to reach $50 \%$ and $95 \%$ equilibrium concentration in surface soil was calculated by making the term in brackets in Equation 6.1-1, representing the fraction of equilibrium, equal to 0.5 and 0.95, respectively, and solving for $t$. Calculations are shown in Excel spreadsheet Time to Equilibrium.xls (Appendix A).

For erosion to have an effect on radionuclide accumulation in soil comparable with leaching, a reasonable fraction of the topsoil would have to be removed by erosion in the time required for the $50 \%$ or $95 \%$ buildup by leaching, shown in Table $6.4-1$.

Table 6.4-1. Time Required to Reach 50\% and 95\% Equilibrium Concentration in Surface Soil Assuming Leaching Is the Only Removal Mechanism

\begin{tabular}{|c|c|c|c|c|c|}
\hline Element & $\begin{array}{l}\text { Mean Partition } \\
\text { Coefficient } \\
\text { L kg }^{\mathrm{a}}\end{array}$ & $\begin{array}{c}\text { Mean Partition } \\
\text { Coefficient } \\
\mathrm{m}^{3} \mathrm{~kg}^{-1}\end{array}$ & $\begin{array}{l}\text { Leaching Removal } \\
\text { Rate Constant } \\
\text { yr }^{-1}\end{array}$ & $\begin{array}{c}\text { Time to } 50 \% \\
\text { Equilibrium }^{c} \\
y r\end{array}$ & $\begin{array}{c}\text { Time to } 95 \% \\
\text { Equilibrium }^{\mathrm{d}} \\
\mathrm{yr}\end{array}$ \\
\hline Actinium $(\mathrm{Ac})$ & $1.5 \times 10^{3}$ & 1.5 & $2.01 \times 10^{-4}$ & 3,455 & 14,933 \\
\hline Americium (Am) & $2.0 \times 10^{3}$ & 2.0 & $1.50 \times 10^{-4}$ & 4,607 & 19,910 \\
\hline Carbon $(C)$ & $1.8 \times 10^{1}$ & $1.8 \times 10^{-2}$ & $1.66 \times 10^{-2}$ & 42 & 181 \\
\hline Cesium (Cs) & $4.4 \times 10^{3}$ & 4.4 & $6.84 \times 10^{-5}$ & 10,134 & 43,800 \\
\hline Chlorine $(\mathrm{Cl})$ & $1.4 \times 10^{-1}$ & $1.4 \times 10^{-4}$ & 1.03 & 1 & 3 \\
\hline lodine (I) & 4.5 & $4.5 \times 10^{-3}$ & $6.47 \times 10^{-2}$ & 11 & 46 \\
\hline Lead $(\mathrm{Pb})$ & $1.6 \times 10^{4}$ & $1.6 \times 10^{1}$ & $1.88 \times 10^{-5}$ & 36,851 & 159,268 \\
\hline Neptunium (Np) & $2.5 \times 10^{1}$ & $2.5 \times 10^{-2}$ & $1.20 \times 10^{-2}$ & 58 & 250 \\
\hline Protactinium $(\mathrm{Pa})$ & $1.8 \times 10^{3}$ & 1.8 & $1.67 \times 10^{-4}$ & 4,146 & 17,919 \\
\hline Plutonium (Pu) & $1.2 \times 10^{3}$ & 1.2 & $2.51 \times 10^{-4}$ & 2,764 & 11,947 \\
\hline Radium (Ra) & $3.6 \times 10^{4}$ & $3.6 \times 10^{1}$ & $8.36 \times 10^{-6}$ & 82,915 & 358,352 \\
\hline Selenium (Se) & $1.5 \times 10^{2}$ & $1.5 \times 10^{-1}$ & $2.00 \times 10^{-3}$ & 346 & 1,495 \\
\hline Strontium (Sr) & $2.0 \times 10^{1}$ & $2.0 \times 10^{-2}$ & $1.49 \times 10^{-2}$ & 46 & 201 \\
\hline Technetium (Tc) & $1.4 \times 10^{-1}$ & $1.4 \times 10^{-4}$ & 1.03 & 1 & 3 \\
\hline Thorium (Th) & $3.0 \times 10^{3}$ & 3.0 & $1.00 \times 10^{-4}$ & 6,910 & 29,864 \\
\hline Tin $(S n)$ & $4.5 \times 10^{2}$ & $4.50 \times 10^{-1}$ & $6.69 \times 10^{-4}$ & 1,037 & 4,481 \\
\hline Uranium (U) & $3.3 \times 10^{1}$ & $3.3 \times 10^{-2}$ & $9.08 \times 10^{-3}$ & 76 & 330 \\
\hline
\end{tabular}

Source: Excel spreadsheet Time to Equilibrium.x/s (Appendix A).

a From Table 6.3-6.

${ }^{\mathrm{b}}$ Calculated using Equation 6.1-2 and average values of parameters, as described in the text.

${ }^{c}$ Calculated by making the term in brackets in Equation 6.1-1 equal to 0.5 and solving it for $t$.

d Calculated by making the term in brackets in Equation 6.1-1 equal to 0.95 and solving it for $t$. 


\subsubsection{Data Review}

In this section the discussion of the erosion process is continued with consideration of site-specific conditions. Soil erosion arises from the removal of soil particles by moving fluid, water (fluvial erosion), or air (eolian erosion). Fluvial erosion comprises sheet and rill erosion. The term sheet and rill erosion is defined in Appendix 3 of Summary Report, 1997 National Resources Inventory (Revised December 2000) (USDA 2000 [DIRS 160548]) as the removal of layers of soil from the land surface by the action of rainfall and runoff. This type of erosion occurs when rainfall exceeds infiltration. In sheet erosion, a surface film of water forms, which facilitates removal of a uniform thin layer of soil by raindrop splash or water run-off. Rill erosion results from a concentration of this surface water into deeper, faster-flowing channels. Sheet and rill erosion are the first stage in water erosion. Wind erosion also involves the removal of soil particles by a moving fluid. In this case, the fluid is air, rather than water as with the sheet and rill erosion. Wind erosion affects primarily arid and semiarid regions because soils in such regions are frequently exposed or bared of vegetation. In both types of erosion, i.e., water and wind, the finer particles are typically lost first, which leads to the loss of the organic matter and nutrients that are generally attached to those particles, and thus decreases the productivity of the soil.

Summary Report, 1997 National Resources Inventory (Revised December 2000) (USDA 2000 [DIRS 160548]) includes estimates of fluvial and eolian erosion for the United States. Table 6.4-2 provides the estimated annual average sheet and rill erosion on non-federal land in Nevada (USDA 2000 [DIRS 160548], Table 10). The values for wind erosion are given in Table 6.4-3 (USDA 2000 [DIRS 160548], Table 11).

Table 6.4-2. Estimated Average Annual Sheet and Rill Erosion on Non-Federal Land in Nevada by Year

\begin{tabular}{|c|c|c|c|c|}
\hline Year & $\begin{array}{c}\text { Cultivated } \\
\text { Cropland }\end{array}$ & $\begin{array}{c}\text { Non-cultivated } \\
\text { Cropland }\end{array}$ & Total Cropland & Pastureland \\
\hline 1982 & 0.2 & 0.0 & 0.1 & 0.0 \\
\hline 1987 & 0.2 & 0.0 & 0.1 & 0.0 \\
\hline 1992 & 0.2 & 0.0 & 0.1 & 0.1 \\
\hline 1997 & 0.2 & 0.0 & 0.1 & 0.1 \\
\hline
\end{tabular}

Source: USDA 2000 [DIRS 160548], Table 10.

${ }^{\text {a }}$ All units in ton acre $^{-1} \mathrm{yr}^{-1}$.

Table 6.4-3. Estimated Average Annual Wind Erosion on Non-Federal Land in Nevada by Year

\begin{tabular}{|c|c|c|c|c|}
\hline Year & $\begin{array}{c}\text { Cultivated } \\
\text { Cropland }\end{array}$ & $\begin{array}{c}\text { Non-cultivated } \\
\text { Cropland }\end{array}$ & Total Cropland & Pastureland \\
\hline 1982 & 11.4 & 1.0 & 5.2 & 1.2 \\
\hline 1987 & 24.5 & 0.9 & 5.2 & 1.3 \\
\hline 1992 & 19.3 & 1.1 & 6.1 & 1.2 \\
\hline 1997 & 20.8 & 1.0 & 4.4 & 1.3 \\
\hline
\end{tabular}

Source: USDA 2000 [DIRS 160548], Table 11.

a All units in ton acre ${ }^{-1} \mathrm{yr}^{-1}$. 
The estimated erosion values are tabulated by land usage. The categories of land use are defined in Summary Report, 1997 National Resources Inventory (Revised December 2000) (USDA 2000 [DIRS 160548], Appendix 3) and are as follows:

Cropland. A land cover/use category that includes areas used for the production of adapted crops for harvest. Two subcategories of cropland are recognized: cultivated and noncultivated. Cultivated cropland comprises land in row crops or close-grown crops and also other cultivated cropland, for example, hayland or pastureland that is in a rotation with row or close-grown crops. Noncultivated cropland includes permanent hayland and horticultural cropland.

Pastureland. A land cover/use category of land managed primarily for the production of introduced forage plants for livestock grazing. Pastureland cover may consist of a single species in a pure stand, a grass mixture, or a grass-legume mixture. Management usually consists of cultural treatments: fertilization, weed control, reseeding or renovation, and control of grazing. For the National Resources Inventory, this category includes land that has a vegetative cover of grasses, legumes, and/or forbs, regardless of whether or not it is being grazed by livestock.

Although the erosion rates presented in Tables 6.4-2 and 6.4-3 are displayed for the years when National Resources Inventories were conducted (1982, 1987, 1992, and 1997), the data do not pertain to the actual erosion occurring during a particular year. Erosion rates are estimated average annual (or expected) rates based upon the cropping practices, management practices, and inherent resource conditions that occur at each National Resources Inventory sample site. Climatic factors used in the erosion predictions were based upon long-term average conditions and not upon one year's actual event (USDA 2000 [DIRS 160548], p. 5).

The data presented in Tables 6.4-2 and 6.4-3 suggest that 1 ton acre $^{-1} \mathrm{yr}^{-1}$ (2.24 metric ton hectare $\mathrm{yr}^{-1}$ from USDA 2000 [DIRS 160548], p. 8) of soil loss, due to combined water and wind erosion, is reasonable for non-cultivated land. This value is used to put the erosion process into perspective with the competing process of leaching. As one metric ton is $10^{3} \mathrm{~kg}$ and one hectare is $10^{4} \mathrm{~m}^{2}, 1$ ton acre $\mathrm{yr}^{-1}$ is equivalent to $2.24 \times 10^{-1} \mathrm{~kg} \mathrm{~m}^{-2} \mathrm{yr}^{-1}$. For the average surface soil thickness of $0.25 \mathrm{~m}$ (based on BSC 2004 [DIRS 169673], Table 7.1-1) and the average soil density of $1500 \mathrm{~kg} / \mathrm{m}^{3}$ (Section 6.2 ), the areal soil density is $375 \mathrm{~kg} / \mathrm{m}^{2}$. Thus, if soil were to be eroded at an annual rate of one ton per acre, this would correspond to a radionuclide fractional removal rate of $6.0 \times 10^{-4} \mathrm{yr}^{-1}$ (i.e., $2.24 \times 10^{-1} \mathrm{~kg} \mathrm{~m}^{-2} \mathrm{yr}^{-1}$ per $375 \mathrm{~kg} \mathrm{~m}^{-2}$ ). At this rate of removal, erosion losses would be insignificant compared to leaching losses for chlorine, iodine, neptunium, strontium, technetium, and uranium (approximately $\mathrm{K}_{\mathrm{d}} \leq 50 \mathrm{~L} \mathrm{~kg} \mathrm{~kg}^{-1}$ ) in Table 6.4-1. However, for the highly sorbing elements, such as protactinium, plutonium, and thorium, this erosion loss rate exceeds the loss from leaching and erosion would be the more dominant removal mechanism.

The purpose of developing distributions for the partition coefficients and erosion rates is to take into account the coupling of the uncertainties in these parameters and the propagation of that uncertainty to the BDCFs. 
The textbook Soil and Water Conservation for Productivity and Environmental Protection (Troeh et al. 1980 [DIRS 110012], Section 6-1) states that erosion cannot be prevented but that it is possible and necessary to reduce erosion losses to tolerable rates. The book then presents the concept of the tolerable soil loss, T. This factor is an estimate of the maximum average annual rate of soil erosion (by wind, water, or both) that can occur without affecting crop productivity over a sustained period. Tolerable soil loss for the soil series occurring in Amargosa Valley is given in Table 6.2-2 in units of ton acre ${ }^{-1} \mathrm{yr}^{-1}$ (USDA 2004 [DIRS 173916], Part II, Table 12). With the exception of the Shamock soil (T factor of 2 ton $\mathrm{acre}^{-1} \mathrm{yr}^{-1}$ ), it is reasonable to say that the typical soils in the Amargosa Valley area could tolerate annual erosion losses of about four to five tons per acre before production would be affected. It is conceivable that some future users, using poor conservation practices, would accept losses at a higher rate for many years before production is impacted. Such use is considered non-representative of a farmer who has to work in an arid (or in the future semi-arid) climate where irrigation presents a significant expense and requires attention to watering needs. In the absence of an alternative upper limit for soil removal, the highest $\mathrm{T}$ value of 5 ton $\mathrm{acre}^{-1} \mathrm{yr}^{-1}$ is taken as the limit.

Both fluvial and eolian soil erosion mechanisms are complex and are dependent on soil characteristics, crop type, slope, vegetation cover, and erosion control practices in addition to the prevailing meteorological conditions. Troeh (1980 [DIRS 110012], Section 1-2.1) indicates that erosion from either process is generally intermittent with the possibility of months or years passing without much soil being lost. During unfavorable meteorological conditions, especially when the soil is in a vulnerable condition such as when plant cover is at a minimum, a significant fraction of the annual loss can be removed in only a few days.

Inspection of the values given in Tables 6.4-2 and 6.4-3 indicates that wind erosion dominates the soil removal process.

\subsubsection{Estimate of Lower Loss Limit for Erosion}

The lower limit of soil loss due to erosion was based on the average soil loss by erosion on noncultivated cropland in Nevada. The sheet and rill erosion on non-cultivated cropland in Nevada is listed as zero (USDA 2000 [DIRS 160548], Table 10), so effectively the erosion of noncultivated cropland is caused by wind. From Table 6.4-3, the average value of wind erosion for non-cultivated cropland in Nevada is 1 ton $\mathrm{acre}^{-1} \mathrm{yr}^{-1}$. Using the conversion factor introduced in Section 6.3.1, this is equivalent to the surface soil loss rate of $2.24 \times 10^{-1} \mathrm{~kg} \mathrm{~m}^{-2} \mathrm{yr}^{-1}$.

\subsubsection{Estimate of Upper Loss Limit for Erosion}

The upper limit of soil erosion rate was calculated based on the average values of sheet, rill, and wind erosion for different types of cropland and for pastureland for Nevada (Tables 6.4-2 and 6.4-3) as well as the consideration of tolerance factor for the Amargosa Valley soils. The upper limit of the erosion rate is a limiting factor for radionuclide buildup in soil only for elements that have high partition coefficients and, therefore, for which leaching is not a very effective removal mechanism. Using an average soil erosion rate based on statewide data to estimate an upper limit value for Amargosa Valley provides a degree of conservatism in predicting the receptor doses from the pathways that include radionuclides in surface soil. Even as an upper limit, the rate of erosion is sufficiently low that the mean residence time of a 
contaminant in the surface soil (defined as a reciprocal of the erosion removal rate constant) is of the order of a few hundred years. As discussed in Section 6.4.2, the process of erosion is erratic over time and is dependent on agricultural practices and land stewardship.

As shown by the data presented in Tables 6.4-2 and 6.4-3, the annual average erosion rate depends on land use, with erosion rates higher on cultivated land (i.e., lands subject to regular disturbance such as plowing) than on uncultivated land. Thus, the upper limit of annual soil loss requires some knowledge of land use.

The major crop in the Amargosa Valley is alfalfa hay (Table 6.4-4), a perennial crop that does not need annual soil disturbing activities. In addition, other hay contributes from approximately $3 \%$ to $30 \%$ of the alfalfa area. Thus, the most appropriate data are those for non-cultivated croplands, with some consideration being given to the cultivated category (Tables 6.4-2 and 6.4-3). This is a conservative approach because the soil erosion rate is generally the lowest for non-cultivated croplands from among the categories of land use, and thus a contaminant would remain in the soil longer. Note that no credit is taken for the replanting of the alfalfa crop, which occurs about once every seven years. During the future climates there may be more annual, cultivated crops, such as winter and spring wheat, barley, and peas (e.g., see BSC 2004 [DIRS 169673], Table A-3). Thus, erosion rates based primarily on non-cultivated croplands are reasonable for estimates of soil loss for the future climate.

Table 6.4-4. Acres Planted in Amargosa Valley

\begin{tabular}{|c|c|c|c|c|}
\hline \multirow[t]{2}{*}{ Crop $^{a}$} & \multicolumn{4}{|c|}{ Year } \\
\hline & $1996^{b}$ & $1997^{b}$ & $1998^{c}$ & $1999^{c}$ \\
\hline Alfalfa Hay & 1,747 & 1,822 & 1,278 & 1,360 \\
\hline Other Hay & 51 & 68 & 634 & 313 \\
\hline Barley & 17 & 32 & 34 & \\
\hline Oats & 45 & & & \\
\hline Pistachios & 92 & 80 & 98 & 98 \\
\hline Fruit Trees & 2 & 8 & 18 & 16 \\
\hline Grapes & 8 & 10 & 10 & 11 \\
\hline Garlic & 5 & 5 & 0.3 & 0.3 \\
\hline Onions & 5 & & & \\
\hline
\end{tabular}

a Commercial agricultural crop production during spring in Radiological Monitoring Program Grid cells 408, 409, 508 , and 509.

b Source: CRWMS M\&O 1997 [DIRS 101090], Tables 3-12 and 3-13.

c Source: YMP 1999 [DIRS 158212] Tables 10 and 11.

As discussed above, soil removal is the only important mechanism of radionuclide removal from surface soil for those radionuclides that have a large partition coefficient and then only if long times are involved.

As listed in Table 6.4-2, Summary Report, 1997 National Resources Inventory (USDA 2000 [DIRS 160548], p. 78) provides the estimated average annual sheet and rill erosion in Nevada for cultivated cropland as being 0.2 ton $\mathrm{acre}^{-1} \mathrm{yr}^{-1}$ for all the years given, with estimated margins of error of 0.05 ton acre $^{-1} \mathrm{yr}^{-1}$. It is stated in the report (USDA 2000 [DIRS 160548], p. 76) that "The margin of error is approximately twice the estimated standard error, and can be used 
to construct a 95\% confidence interval for the estimate." The estimated wind erosion is between 11.4 and 24.5 ton acre $^{-1} \mathrm{yr}^{-1}$ for the years given (Table 6.4-3).

For the present-day conditions in Nevada, only wind erosion has any significant effect on soil loss. Taking the average rate of loss by wind erosion from Table 6.4-3 for both cultivated cropland $\left(\approx 19\right.$ ton acre $\left.^{-1} \mathrm{yr}^{-1}\right)$ and non-cultivated cropland $\left(\approx 1\right.$ ton $\left.\mathrm{acre}^{-1} \mathrm{yr}^{-1}\right)$, and weighting by the percentages of crop in each category (using average alfalfa acreage for non-cultivated cropland and average acreage for other crops for cultivated cropland), gives approximately 5 ton acre $\mathrm{yr}^{-1}$. This is in good agreement with the tolerance factor for most of the soil series present in Amargosa Valley and can be used as the estimate of the upper limit of erosion soil loss. Using the tolerance factor of 5 ton $\operatorname{acre}^{-1} \mathrm{yr}^{-1}\left(1.1 \mathrm{~kg} \mathrm{~m}^{-2} \mathrm{yr}^{-1}\right)$ as an upper limit for soil erosion allows for possible inaccuracies from using statewide estimates for specific locations. The $\mathrm{T}$ Factor is an upper limit of sustainable soil loss, and therefore any sampled value would be lower.

Furthermore, the surface soil model, as developed in Biosphere Model Report (BSC 2004 [DIRS 169460], Section 6.4.1), considers that the surface soil is mixed over the root zone. This mixing implies frequent (annual) tillage, where the estimated soil loss rate is that for cultivated land.

\subsubsection{Recommended Distribution and Parameters for the Annual Rate of Soil Erosion}

The recommended distribution for the annual erosion rate is triangular with a lower limit at $0.2 \mathrm{~kg} \mathrm{~m}^{-2} \mathrm{yr}^{-1}$ (the value developed in Section 6.4 .3 rounded to the nearest tenth of $\mathrm{kg} \mathrm{m}^{-2} \mathrm{yr}^{-1}$ ), and an upper limit at $1.1 \mathrm{~kg} \mathrm{~m}^{-2} \mathrm{yr}^{-1}$ (developed in Section 6.4.4). Because of the lack for detailed site- and climate-specific information, the mode is conservatively taken to be coincident with the lower limit. If a single deterministic value is required to estimate the erosion rate, then the mode of the distribution of $0.2 \mathrm{~kg} \mathrm{~m}^{-2} \mathrm{yr}^{-1}$ should be used.

\subsection{ENHANCEMENT FACTOR FOR RESUSPENSION}

Resuspension of contaminated soil is potentially important for the groundwater and volcanic ash exposure scenarios. One of the parameters used to calculate resuspension of contaminated soil is the enhancement factor, which is discussed in this section.

\subsubsection{Characteristics of the Radionuclide Resuspension Process}

\subsubsection{Radionuclide Concentration in Soil and in Suspended Particulates}

The activity per unit mass of resuspended particles is not necessarily identical to the activity per unit mass of underlying soil that is the source of suspended particulates because of the non-uniform distribution of activity with particle size and the preferential resuspension of smaller particles. In order to avoid modeling radionuclide concentration as equal for soil and suspended particles when using the mass-loading approach for resuspension, Burley (1990 [DIRS 177220], Section 5.4.4) introduced the concept of an enhancement factor. The enhancement factor is the ratio of airborne particle activity concentration $\left(\mathrm{Bq} \mathrm{kg}^{-1}\right)$ to surface soil activity concentration $\left(\mathrm{Bq} \mathrm{kg}^{-1}\right)$. In Biosphere Model Report (BSC 2004 [DIRS 169460], Equation 6.4.2-2), this enhancement factor is used as shown in Equation 6.1-8. 
Differences in activity concentration between resuspended particles and soil are caused by differences in the particle size distribution of aerosol mass and activity as compared to particle size distribution of mass and activity in the soil from which the aerosols originate. The particle size distribution of airborne particulates can be influenced by a multitude of factors, including soil surface conditions and local resuspension mechanisms (Shinn et al. 1997 [DIRS 177223], p. 248).

The enhancement factor used in the biosphere model is receptor environment-specific and exposure scenario-specific. The biosphere model was developed for two exposure scenarios corresponding to two types of radionuclide release from the repository to the environment. These are the groundwater exposure scenario and the volcanic ash exposure scenario. Enhancement factors should be representative of these scenarios and also of the conditions in the receptor environments. The biosphere model considers two outdoor and two indoor environments. In the active outdoors environment, surface soil is actively disturbed. This environment is representative of conditions that occur when a person is outdoors in the contaminated environment conducting dust-generating activities. It encompasses potentially contaminated locations outdoors where the RMEI would conduct activities that would resuspend soil, including dust-generating activities while working (e.g., plowing, excavating, livestock operations), driving on unpaved roads, and performing other outdoor recreational activities (e.g., gardening, landscaping, riding horses, riding motorbikes, and walking on uncompacted soil). Because dust concentrations decrease rapidly after dust-disturbing activities cease, this category is limited to the conditions during and shortly after dust-generating activities. In the other outdoor environment (inactive outdoors) there is no active disturbance of soil surface. Two indoor environments are active and inactive (asleep) indoors.

\subsubsection{Particle Size Distribution of Suspended Particulates}

Airborne particulate matter does not consist of a single pollutant but rather is a mixture of many kinds of pollutants (EPA 1996 [DIRS 160121], p. 3-188). An important characteristic of particle size distributions of atmospheric aerosols is their multimodal nature (EPA 1996 [DIRS 160121], p. 3-4). Atmospheric aerosols described in terms of TSP usually have two major particle size fractions referred to as the fine mode and a coarse mode. The measurements indicate that these two modes have different chemical composition and are generated by different processes (EPA 1996 [DIRS 160121], p. 3-6). Of interest to this analysis are atmospheric aerosols in the coarse mode because this mode includes soil dust (EPA 1996 [DIRS 160121], p. 3-6; Lundgren and Burton 1995 [DIRS 177699], pp. 131 and 138). The fine mode contains particles from combustion sources and particles that result from condensation of vapors formed from chemical reactions.

TSP that originates from undisturbed soil has been found to be approximately lognormally distributed with MMAD of 2 to $6 \mu \mathrm{m}$ (Shinn 1998 [DIRS 177230], p. 3; NCRP 1999 [DIRS 155894], p. 67 and 68; also see references in Table 6.5-1). The reported geometric standard deviation of TSP distributions varies from about 2 to 6 and more (see Table 6.5-1). In the absence of measurements, a GSD of the lognormal distribution of about 5 is recommended (NCRP 1999 [DIRS 155894], p. 68). It needs to be recognized that the measured median aerodynamic diameter (MAD) of a particle size distribution (as opposed to the true MAD) may be affected by the type of sampler that was used to collect samples. Aerosol sampling is particle 
size-dependent and the characteristics of the particle size distribution inferred from the collected sample reflect particle-size selective sampling (EPA 2004 [DIRS 175978], Figure 2-8).

During soil disturbances, e.g., during mechanical soil disturbances or very strong winds, another mode in a distribution of suspended soil particles occurs with a MAD of $15 \mu \mathrm{m}$ or more (NCRP 1999 [DIRS 155894], p. 67; Shinn 1998 [DIRS 177230], p. 3; (EPA 1996 [DIRS 160121], Section 3.7.6.1). This component is transient and residence times in air of particulates suspended as a result of mechanical soil disturbance are only on the order of seconds due to gravitational settling (NCRP 1999 [DIRS 155894], p. 67; DTN: MO0603UCCF01JS.001 [DIRS 176759], worksheets containing DustScan data; Pinnick et al. 1985 [DIRS 159577], pp. 103 and 104).

In a series of experiments involving numerous farming activities at three experimental farms near Davis, California, and dust levels ranging from $0.7 \mathrm{mg} \mathrm{m}^{-3}$ to almost $100 \mathrm{mg} \mathrm{m}^{-3}$, an MMAD of $49 \mu \mathrm{m}$ was estimated for all operations (Nieuwenhuijsen et al. 1998 [DIRS 150855], pp. 36 and 38). This was higher than the MMAD measured during other studies reviewed in that publication; for example, other researchers measured MMAD varying from 12 to $20 \mu \mathrm{m}$ during various agricultural operations (Nieuwenhuijsen et al. 1998 [DIRS 150855], p. 38).

For sandy soils in New Mexico, heavy vehicle traffic on unpaved roadways generated very dusty conditions with mass loading typically on the order of hundreds of $\mathrm{mg} \mathrm{m}^{-3}$ (Pinnick et al. 1985 [DIRS 159577], Table 3). The distribution of suspended particle sizes spanned three orders of magnitude, from a fraction of a micrometer to hundreds of micrometers, and was a bimodal with modal mass median diameters of about $8 \mu \mathrm{m}$ and $90 \mu \mathrm{m}$ (Pinnick et al. 1985 [DIRS 159577], pp. 99 to 100). The geometric standard deviation of the modes ranged from 1.50 to 2.20 (Pinnick et al. 1985 [DIRS 159577], Table 3). Under dusty conditions, the majority of the suspended mass typically belongs to the larger particle size mode (Pinnick et al. 1985 [DIRS 159577], p. 104 and Table 3).

Artificial dust-raising experiments conducted at the sites of British nuclear tests in Australia identified two main fractions to the particle size distribution of suspended radioactive material. These fractions had MAD of 5 to $6 \mu \mathrm{m}$ and more than $11 \mu \mathrm{m}$ (Johnston et al. 1992 [DIRS 177227], p. 632).

It needs to be recognized that the particle size distribution of atmospheric aerosols generated during soil disturbance is a function of time. While freshly generated coarse mode aerosol may have an MMAD of $20 \mu \mathrm{m}$, with time the large particles will rapidly settle out, leaving a distribution enriched with smaller-size particles (EPA 1996 [DIRS 160121], Section 3.7.6.1). This process is a source of uncertainty in both the measured distributions and in the characteristics of airborne aerosols in the reference biosphere.

Size distributions of suspended particulate matter described in the literature are often represented by a lognormal distribution. Such a representation is only a mathematical approximation of the true distribution. The actual distributions may contain minor modes in addition to the dominant mode, as was identified during the measurements at Maralinga, Australia (Shinn 2003 [DIRS 177226], p. 7 and Appendix 2). Also, the fact that experimental data are best fit by a lognormal or a normal distribution does not necessarily imply that the functional representation 
is valid across the whole rage of the ordinate (in this case, a lognormal distribution representing probability of particle sizes in the range from zero to infinity) because extreme values may not be physically possible to occur, even with small probabilities.

\subsubsection{Particle Size Distribution of Suspended Activity}

The analysis of suspended radioactivity generally involves consideration of the particle size distribution of TSP as well as how the activity is distributed among suspended particles of different sizes. The particle size distribution of suspended radionuclides depends on the physical and chemical form of a contaminant in the soil. Thus, distribution of radionuclides introduced into surface soil in the aqueous phase in irrigation water would be different from the distribution in the soil of radioactive waste particles that were deposited during a volcanic eruption.

When radionuclides are sorbed onto the grains of soil, activity on a particle is proportional to the surface area available for sorption. Small particles have a larger surface-to-volume ratio than large particles and this ratio increases in inverse proportion to the particle size. This is particularly important for elements such as plutonium, americium, or thorium, which have high sorption coefficients (Table 6.3-3). The size of suspended soil particles is generally smaller than the average size of soil particles, and thus, on average, suspended soil particles have larger available surface area, and consequently activity, per unit mass than that of soil.

When radionuclides are present in the soil in the form of small particles either attached to soil aggregates or separate from soil grains, a different distribution of suspended activity may be expected. In many experiments, plutonium activity in the air was found to be approximately lognormally distributed across particles diameters with MAD in the range from 2 to $6 \mu \mathrm{m}$ and GSD between 2 and 3.6 (Shinn 1992 [DIRS 160115], p. 1190). The distribution of suspended plutonium activity differed from the distribution of suspended soil particles, which typically had much broader distribution with a GSD of over 6 . Shinn attributes this to plutonium bounding to a particularly narrow range of the soil particles available for suspension. This effect was observed in the experiments at the Nevada Test Site and at the Savanna River Project (Shinn et al. 1989 [DIRS 177231], p. 776; Shinn et al. 1982 [DIRS 177224], pp. 1135 and 1136). The MAD for the plutonium size distribution was much lower than that for the suspended particulate matter $(1.2 \mu \mathrm{m}$ versus $5.5 \mu \mathrm{m}$ at the Nevada Test Site and $3.0 \mu \mathrm{m}$ versus $10 \mu \mathrm{m}$ at Savanna River) and the distribution of plutonium activity was narrower than the distribution of suspended soil particles.

At Palomares, Spain, broad particle size distributions were measured with MAD ranging from 3.3 to 3.7 for both mass and activity. Particle size distributions were approximately lognormally distributed with a GSD of approximately 3.5, which is the type of distribution commonly found in plutonium-containing aerosols (Shinn 2002 [DIRS 177225], p. 7).

Because of the different physical form, and thus different resuspension characteristics, of radionuclides released to the environment in groundwater and in volcanic ash, the enhancement factors were developed separately for the groundwater and volcanic ash exposure scenarios, as described in the following sections. 


\subsubsection{Enhancement Factor for the Volcanic Ash Exposure Scenario}

Enhancement factors for the volcanic ash exposure scenario are developed in this section based primarily on experimental measurements taken where plutonium particles were deposited during intentional or accidental explosions. Aerodynamic behavior of plutonium particles is expected to be similar to that of waste particles of the same size because of similar density. However, the particle size, chemical properties, and radionuclides involved may be different between the particles of waste and particles of plutonium. These differences contribute to uncertainty in the enhancement factor. The following sections discuss the behavior of plutonium in soil, present a review of the enhancement factor measurements, and develop distributions of the enhancement factor values for the biosphere model.

\subsubsection{Plutonium Behavior in Soil}

When deposited on soil, plutonium attaches itself to the larger, less mobile particles of soil or soil aggregates as a result of adhesive forces between the plutonium particles and the soil substrate (Burley 1990 [DIRS 177220], pp. 5-3 and 5-7; Shinn 1998 [DIRS 177230], p. 2). Analyses of plutonium at the Nevada Test Site indicated that $\mathrm{PuO}_{2}$ was bound to coarse soil particles in the size range from 5 to $20 \mu \mathrm{m}$, while hydrated $\mathrm{PuO}_{2}$ was bound to smaller particles in the size range from 2 to $5 \mu \mathrm{m}$ (Burley 1990 [DIRS 177220], p. 5-3). Although generally considered insoluble, plutonium oxide can undergo dissolution in a neutral aqueous phase producing plutonium ions until the formation of a hydrated coating inhibits further dissolution (Burley 1990 [DIRS 177220], p. 5-7). Plutonium ions formed during the dissolution can become sorbed onto the soil; however, the extent of plutonium sorption on soil is limited by competing reactions because plutonium reacts with other agents present in aqueous phase and forms soluble complexes (Burley 1990 [DIRS 177220], p. 5-7). When plutonium was released to soil in soluble form, it was shown to react rapidly with soil and form strong chemical bonds; such plutonium would not be readily separated from soil by natural processes (Burley 1990 [DIRS 177220], p. 5-8).

In experiments on the behavior of plutonium particles from atmospheric deposition, it was found that plutonium becomes attached to soil aggregates and does not readily migrate into the soil (Shinn 1998 [DIRS 177230], p. 2). This was particularly the case in the Nevada Test Site plutonium profiles in the soil, where most plutonium activity was contained in the top 2 to $3 \mathrm{~cm}$ of topsoil (Anspaugh et al. 1975 [DIRS 151548], Figure 5). Similar results were obtained in Australia (Johnston et al. [DIRS 177227], p. 635 to 636). At the Nevada test site, surface soil was well mixed in the first few centimeters due to geophysical processes such as raindrop impact and freezing-thawing, and biological factors such as plant root growth (Shinn et al. 1997 [DIRS 177222], Methods).

\subsubsection{Measurements of Enhancement Factor-Data Review and Analysis of Data Applicability}

Generally, the processes governing resuspension are very complex to model and difficult to predict (Burley 1990 [DIRS 177220], p. 5-4; Shinn 1992 [DIRS 160115], p. 1188). At the time Burley proposed the concept of an enhancement factor, there were virtually no measurements of such a parameter. Using data on the distribution of mass and plutonium activity with particle 
size in four samples of soil from Rocky Flats, Burley (1990 [DIRS 177220], Table 5-4) calculated that the enhancement factor would vary from 1.06 to 2.34 with a mean of 1.49 . Since then, there have been several measurements of enhancement factors in diverse environments: the Nevada Test Site (Shinn et al. 1989 [DIRS 177231]; Shinn et al. 1997 [DIRS 177222]), California (Shinn 1998 [DIRS 177230]), Palomares, Spain (Shinn 2002 [DIRS 177225]), Maralinga, Australia (Johnston et al. 1992 [DIRS 177227]; Shinn 2003 [DIRS 177226]), the Marshall Islands (Shinn et al. 1997 [DIRS 177223]), Johnston Atoll (Shinn et al. 1994 [DIRS 177228]), the Savannah River Site, South Carolina (Shinn et al. 1982 [DIRS 177224]), and Chernobyl (Kashparov et al. 1994 [DIRS 177229]). Most experiments investigated resuspension of particles of plutonium intentionally or unintentionally dispersed in the environment.

Many measurements of the enhancement factor were carried out in arid climates at the Nevada Test Site; Tonopah Test Range, Nevada; at Maralinga, Australia; and at Palomares, Spain. These three sites are similar in that they receive low rainfall, have sparse vegetative ground cover, and have high summer temperatures. Most measurements were of aged plutonium (older than several months, and usually much longer) that was initially deposited by high explosive detonation as high-fired plutonium oxide particles (Church et al. 2000 [DIRS 177310], Introduction). The plutonium particles were thus created through a high-temperature process and rapidly oxidized to an insoluble, very stable chemical state (Church et al. 2000 [DIRS 177310], Introduction). Such airborne releases of plutonium are generally in the oxide form and contain a substantial fraction of particles in the respirable size range (Burley 1990 [DIRS 177220], p. 5-3). The radiological impact to people from that chemical form of plutonium occurs primarily when particles of plutonium become resuspended and inhaled.

The enhancement factor measurements are summarized in Table 6.5-1. Most measurements were taken where plutonium had been deposited on the soil surface. Plutonium resuspension and enhancement in airborne particulates was measured, primarily by Shinn and coworkers, in a variety of environments. Enhancement factors typically ranged from about 0.2 to less than 4 . The experiments showed that for cultivated fields that were cleared of vegetation, topsoil mixed by farm implements, and bare soil that had settled for one week or more, the enhancement factors were less than unity (Shinn 1992 [DIRS 160115], p. 1188). 
Table 6.5-1. Summary of Enhancement Factor Measurements

\begin{tabular}{|c|c|c|c|c|c|c|}
\hline Location & $\begin{array}{l}\text { Atmospheric } \\
\text { Mass Loading, } \\
\mu^{-3} \mathrm{~m}^{-3}\end{array}$ & MAD, $\mu \mathrm{m}$ & $\begin{array}{c}\text { Activity } \\
\text { Concentration } \\
\text { in Soil, Bq kg }{ }^{-1}\end{array}$ & $\begin{array}{c}\text { Activity } \\
\text { Concentration } \\
\text { in Air, Bq kg }\end{array}$ & $\begin{array}{l}\text { Enhancement } \\
\text { Factor }\end{array}$ & $\begin{array}{l}\text { Reference and Experimental } \\
\text { Conditions/Comments }\end{array}$ \\
\hline \multicolumn{7}{|c|}{ Nevada Test Site and Tonopah Test Range } \\
\hline $\begin{array}{l}\text { Double Tracks Site before } \\
\text { cleanup }\end{array}$ & 5.9 & & 4,520 & & 0.69 & \multirow{4}{*}{$\begin{array}{l}\text { Church et al. } 2000 \\
\text { [DIRS 177310], Table } 2 \\
\text { Plutonium-contaminated soil } \\
\text { from plutonium dispersion } \\
\text { experiments }\end{array}$} \\
\hline $\begin{array}{l}\text { Double Tracks Site after } \\
\text { cleanup }\end{array}$ & $\begin{array}{l}8.2 \text { (during } \\
\text { cleanup) } \\
4.8 \text { (after } \\
\text { cleanup) }\end{array}$ & & 1,400 & & 0.69 & \\
\hline $\begin{array}{l}\text { Clean Slate Site before } \\
\text { cleanup }\end{array}$ & 3.5 & & 4,810 & & 0.69 & \\
\hline Clean Slate Site after cleanup & 7.1 & & 570 & & 0.69 & \\
\hline Cleanup site before cleanup & 41 & \multirow{5}{*}{$\begin{array}{l}\text { MAD = } 5.5 \\
\text { (both mass and } \\
\text { activity) } \\
\text { GSD = 8.5 }\end{array}$} & $\begin{array}{l}20,000 \text { SW plot } \\
9,800 \text { NE plot }\end{array}$ & & 1.03 & \multirow{5}{*}{$\begin{array}{l}\text { Shinn et al. } 1989 \\
\text { [DIRS } 177231 \text { ], Table } 4 \text { and } \\
\text { pp. } 772 \text { and } 776\end{array}$} \\
\hline Cleanup site during cleanup & 88 & & & & 2.00 & \\
\hline $\begin{array}{l}\text { Cleanup site after } 60 \% \\
\text { cleanup }\end{array}$ & 39 & & & & 3.71 & \\
\hline After soil stabilized & 41 & & & & 1.20 & \\
\hline Upwind, background & 42 & & & & & \\
\hline $\begin{array}{l}\text { Clean Slate } 3 \text { Site } \\
\text { averages for almost } \\
\text { 10-month-long measurement } \\
\text { campaign }\end{array}$ & $\begin{array}{l}13.6 \\
\text { average from } \\
\text { Table } 1 \text { of the } \\
\text { source } \\
\text { reference }\end{array}$ & $\begin{array}{l}\text { MMAD }=3.7 \\
(2.80 \text { to } 5.51) \\
G S D=2.79 \\
\text { AMAD assumed } \\
\text { the same as } \\
\text { MMAD }\end{array}$ & 385 & & $\begin{array}{l}0.13 \text { to } 1.61 \\
0.69 \\
\text { average from } \\
\text { Table } 1 \text { of the } \\
\text { source } \\
\text { reference }\end{array}$ & $\begin{array}{l}\text { Shinn et al. } 1997 \\
\text { [DIRS 177222], Table } 1 \text { and } \\
\text { Results }\end{array}$ \\
\hline Area 5, Site D & & & & & 0.87 & \multirow{2}{*}{$\begin{array}{l}\text { Shinn } 1992 \text { [DIRS 160115], } \\
\text { p. } 1188\end{array}$} \\
\hline Area 11, Site D & & & & & 1.04 & \\
\hline
\end{tabular}


Table 6.5-1. Summary of Enhancement Factor Measurements (Continued)

\begin{tabular}{|c|c|c|c|c|c|c|}
\hline Location & $\begin{array}{l}\text { Atmospheric } \\
\text { Mass Loading, } \\
\mu \mathrm{gg} \mathrm{m}^{-3}\end{array}$ & MAD, $\mu \mathrm{m}$ & $\begin{array}{c}\text { Activity } \\
\text { Concentration } \\
\text { in Soil, } \mathbf{B q ~ k g}^{-1}\end{array}$ & $\begin{array}{c}\text { Activity } \\
\text { Concentration } \\
\text { in Air, Bq kg }\end{array}$ & $\begin{array}{l}\text { Enhancement } \\
\text { Factor }\end{array}$ & $\begin{array}{l}\text { Reference and Experimental } \\
\text { Conditions/Comments }\end{array}$ \\
\hline \multicolumn{7}{|c|}{ Maralinga and Emu, South Australia } \\
\hline $\begin{array}{l}\text { Taranaki West (FW site) } \\
\text { Control site, stable, never } \\
\text { ploughed or otherwise } \\
\text { disturbed }\end{array}$ & 14 & $\begin{array}{l}\text { MMAD }=4.0 \\
\text { AMAD }=4.7\end{array}$ & & 1,000 & 2 & \multirow{5}{*}{$\begin{array}{l}\text { Shinn } 2003 \text { [DIRS 177226], } \\
\text { Tables } 1,2 \text {, and } 3 \\
\text { Plutonium-contaminated soil, } \\
\text { site of former nuclear tests } \\
1953 \text { to } 1963 \text {. }\end{array}$} \\
\hline $\begin{array}{l}\text { Taranaki North, Lot } 19 \\
\text { Cleaned but not stabilized }\end{array}$ & 28 & $\begin{array}{l}\text { MMAD }=3.0 \\
\text { AMAD }=2.8\end{array}$ & & 2,200 & \multirow[t]{2}{*}{2} & \\
\hline $\begin{array}{l}\text { Taranaki North, Lot } 18 \\
\text { Uncleaned, recontaminated }\end{array}$ & 47 & $\begin{array}{l}\text { MMAD }=3.2 \\
\text { AMAD }=6.9\end{array}$ & & 2,300 & & \\
\hline $\begin{array}{l}\text { Taranaki Northeast } \\
\text { Cleaned site }\end{array}$ & 14 & $\begin{array}{l}\text { MMAD }=4.6 \\
A M A D=3.7\end{array}$ & & 2,300 & $\begin{array}{l}\text { Average value } \\
\text { not provided; } \\
6 \text { during storm }\end{array}$ & \\
\hline $\begin{array}{l}\text { TM- } 100 \\
\text { Undisturbed control site; not a } \\
\text { typical result }\end{array}$ & 21 & $\begin{array}{l}\text { MMAD }=1.0 \\
A M A D=2.9\end{array}$ & & 16.7 & $\begin{array}{l}0.0003 \text { (not } \\
\text { typical) }\end{array}$ & \\
\hline $\begin{array}{l}\text { Various sites at Maralinga } \\
\text { and Emu }\end{array}$ & & & & & $\begin{array}{l}0.3 \text { to } 20 \\
\text { Average } 4.2\end{array}$ & $\begin{array}{l}\text { Johnston et al. } 1992 \\
\text { [DIRS } 177227 \text {, Table } 4 \\
\text { Of } 20 \text { enhancement factor } \\
\text { values given, } 18 \text { were } 6 \text { or } \\
\text { less, one was } 10 \text { and one was } \\
\text { 20; authors note large } \\
\text { uncertainty (p. 637). }\end{array}$ \\
\hline \multicolumn{7}{|c|}{ Palomares, Spain } \\
\hline Upwind from Plot 2-1 & 70 & $\begin{array}{l}\text { MAD = } 3.7 \text { (both } \\
\text { mass and } \\
\text { activity) }\end{array}$ & $\begin{array}{l}440 \text { (taken from } \\
\text { Church et al } \\
2000 \\
\text { [DIRS 177310], } \\
\text { Table 2) }\end{array}$ & 120 & 0.28 & \multirow{2}{*}{$\begin{array}{l}\text { Shinn } 2002 \text { [DIRS 177225], } \\
\text { Tables } 1 \text { and 2, p. } 5 \\
\text { Plutonium contamination as a } \\
\text { result of military aircraft } \\
\text { accident in 1966; detonation of } \\
\text { conventional explosives } \\
\text { caused release of fissile } \\
\text { material upon impact }\end{array}$} \\
\hline Downwind from Plot 2-1 & & $\begin{array}{l}\text { MMAD }=3.6 \\
\text { MGSD }=3.7 \\
\text { AMAD }=3.3 \\
\text { AGSD }=3.4\end{array}$ & & & & \\
\hline
\end{tabular}


Table 6.5-1. Summary of Enhancement Factor Measurements (Continued)

\begin{tabular}{|c|c|c|c|c|c|c|}
\hline Location & $\begin{array}{l}\text { Atmospheric } \\
\text { Mass Loading, } \\
\mu_{\mathrm{g} \mathrm{m} \mathrm{m}}^{-3}\end{array}$ & MAD, $\mu \mathrm{m}$ & $\begin{array}{c}\text { Activity } \\
\text { Concentration } \\
\text { in Soil, } \mathbf{B q ~ k g}^{-1}\end{array}$ & $\begin{array}{c}\text { Activity } \\
\text { Concentration } \\
\text { in Air, Bq kg }\end{array}$ & $\begin{array}{l}\text { Enhancement } \\
\text { Factor }\end{array}$ & $\begin{array}{l}\text { Reference and Experimental } \\
\text { Conditions/Comments }\end{array}$ \\
\hline \multicolumn{7}{|c|}{ Savanna River, South Carolina } \\
\hline Field 1 & $\begin{array}{l}43 \text { (average } \\
\text { from Table 2) }\end{array}$ & $\begin{array}{l}\text { AMAD }=2.2 \text { to } \\
3.0\end{array}$ & $\begin{array}{l}121 \text { (average } \\
\text { from Table 3) }\end{array}$ & $\begin{array}{l}25.5 \text { (average } \\
\text { from Table 3) }\end{array}$ & 0.21 (average) & \multirow{3}{*}{$\begin{array}{l}\text { Shinn et al. } 1982 \\
\text { [DIRS } 177224] \text {. Tables 2, 3, } \\
\text { pp. } 1135 \text { to } 1136 \text {, and } 1140 \\
\text { Bare soil near chemical } \\
\text { separation facility, where } \\
\text { releases of plutonium occurred } \\
\text { from } 1967 \text { through } 1974 \\
\text { Activity concentration } \\
\text { converted from Ci } \mathrm{g}^{-1} \text { to Bq } \\
\mathrm{kg}^{-1} \text { using } 1 \mathrm{Ci} \mathrm{g}^{-1}=3.7 \mathrm{E} 13 \\
\mathrm{~Bq} \mathrm{~kg}^{-1}\end{array}$} \\
\hline Field 2 & $\begin{array}{l}79 \text { (average } \\
\text { from Table 2) }\end{array}$ & $\begin{array}{l}\text { AMAD }=3.0 \text { to } \\
4.2\end{array}$ & $\begin{array}{l}26 \text { (average } \\
\text { from Table 3) }\end{array}$ & $\begin{array}{l}11.7 \text { (average } \\
\text { from Table 3) }\end{array}$ & 0.46 (average) & \\
\hline All data & & $\begin{array}{l}\text { AMAD }=3.0 \\
A G S D=2.1 \\
\text { MMAD }=10 \\
\text { broad mass } \\
\text { distribution }\end{array}$ & & & & \\
\hline \multicolumn{7}{|c|}{ Marshall Islands } \\
\hline $\begin{array}{l}\text { Bikini — bare soil, disturbed } \\
\text { phase, May } 6-8\end{array}$ & $\begin{array}{l}136 \text { to } 167 \\
\text { depending on } \\
\text { distance to } \\
\text { shore }\end{array}$ & $\begin{array}{l}\text { MAD }=2.0 \\
\text { GSD }=2.2 \\
\text { (similar for mass } \\
\text { loading and Pu; } \\
\text { approximated } \\
\text { from Table 3) }\end{array}$ & 570 & 1,800 & 3.1 & $\begin{array}{l}\text { Shinn et al. } 1997 \\
\text { [DIRS } 177223 \text { ], Tables } 2 \text { to } 4 \\
\text { Plutonium-contaminated soil; } \\
\text { study conducted in 1978; } \\
\text { nuclear tests conducted in the } \\
\text { Pacific Test Range until } 1958\end{array}$ \\
\hline $\begin{array}{l}\text { Bikini_bare soil, stable } \\
\text { phase, May } 10-11\end{array}$ & 23 & $\begin{array}{l}M A D=2.4 \\
G S D=3.1\end{array}$ & 570 & 540 & 0.96 & \multirow{4}{*}{$\begin{array}{l}\text { No significant difference } \\
\text { between aerosol plutonium } \\
\text { activity and aerosol mass } \\
\text { concentration (from p. 256, } \\
\text { Conclusions). } \\
\text { Pulses of nominal 10-second } \\
\text { duration for road with traffic }\end{array}$} \\
\hline $\begin{array}{l}\text { Bikini_bare soil, stable } \\
\text { phase, May } 12-16\end{array}$ & 18 & $\begin{array}{l}\mathrm{MAD}=2.4 \\
\mathrm{GSD}=3.1\end{array}$ & 570 & 390 & 0.69 & \\
\hline Bikini—coconut grove & 21 & & 300 & 120 & 0.41 & \\
\hline Bikini-road with traffic & $\begin{array}{l}41 \\
100 \text { for passing } \\
\text { motor vehicles } \\
26 \text { for bicycle of } \\
\text { foot traffic } \\
\end{array}$ & & 150 & 380 & 2.5 & \\
\hline
\end{tabular}


Table 6.5-1. Summary of Enhancement Factor Measurements (Continued)

\begin{tabular}{|c|c|c|c|c|c|c|}
\hline Location & $\begin{array}{l}\text { Atmospheric } \\
\text { Mass Loading, } \\
\mu_{\mathrm{gg} \mathrm{m}}^{-3}\end{array}$ & MAD, $\mu \mathrm{m}$ & $\begin{array}{c}\text { Activity } \\
\text { Concentration } \\
\text { in Soil, Bq kg }\end{array}$ & $\begin{array}{c}\text { Activity } \\
\text { Concentration } \\
\text { in Air, Bq kg }\end{array}$ & $\begin{array}{l}\text { Enhancement } \\
\text { Factor }\end{array}$ & $\begin{array}{l}\text { Reference and Experimental } \\
\text { Conditions/Comments }\end{array}$ \\
\hline Enjebi-vegetated field & & & 900 & 400 & 0.45 & \multirow{4}{*}{$\begin{array}{l}\text { Shinn et al. 1997 } \\
\text { [DIRS 177223], Table } 8\end{array}$} \\
\hline Enjebi_downwind from road & & & 1,300 & 730 & 0.56 & \\
\hline Enjebi-garden, freshly tilled & & & 900 & 4,000 & 4.41 & \\
\hline $\begin{array}{l}\text { Enjebi-garden, } 1 \text { week after } \\
\text { tilled }\end{array}$ & & & 900 & 2,300 & 2.55 & \\
\hline \multicolumn{7}{|c|}{ Johnston Atoll } \\
\hline Spoils pile & 178 & $\begin{array}{l}\text { MMAD }=3.25 \\
\text { AMAD }=3.59\end{array}$ & & & & \multirow{4}{*}{$\begin{array}{l}\text { Shinn et al. } 1994 \text { [DIRS } \\
\text { 177228], Results; Table } 1 \\
\text { Plutonium contaminated soil } \\
\text { Measurements were taken for } \\
\text { one month in } 1992 \text { during } \\
\text { operation of a soil sorting } \\
\text { system } \\
\text { No significant difference } \\
\text { between AMAD and MMAD for } \\
\text { resuspended plutonium } \\
\text { GSD of } 10 \text { does nor reflect the } \\
\text { true shape of a distribution }\end{array}$} \\
\hline Plant area & 93 & $\begin{array}{l}\text { MMAD }=3.98 \\
\text { AMAD }=3.64\end{array}$ & & & & \\
\hline Clean pile & 79 & $\begin{array}{l}\text { MMAD }=3.26 \\
\text { AMAD }=2.62\end{array}$ & & & & \\
\hline $\begin{array}{l}\text { Work areas (spoils pile, plant } \\
\text { area, and clean pile) }\end{array}$ & 109 & $\begin{array}{l}\text { MMAD = } 3.5 \\
\text { AMAD = } 3.3 \\
\text { GSD }=10 \\
\text { "widely- } \\
\text { dispersed" } \\
\text { distribution over } \\
0.1 \text { to } 10 \mu \mathrm{m} \\
\end{array}$ & $\begin{array}{l}44 \\
50 \text { (from earlier } \\
\text { measurements } \\
\text { at the same site) }\end{array}$ & 135 & $\begin{array}{l}3.0 \\
2.7\end{array}$ & \\
\hline \multicolumn{7}{|c|}{ Chernobyl } \\
\hline $\begin{array}{l}\text { Agricultural areas } \\
\text { contaminated by nuclear } \\
\text { power plant accident; } \\
\text { measurements inside and } \\
\text { outside tractor cabs }\end{array}$ & 300 to 203,000 & & & & $\begin{array}{l}6.4 \text { (average) } \\
\text { Not represent- } \\
\text { ative of TSP } \\
\text { because of } \\
\text { size-selective } \\
\text { sampling; hot } \\
\text { particles present }\end{array}$ & $\begin{array}{l}\text { Kashparov et al. } 1994 \\
\text { [DIRS } 177229] \text {, Tables } 1 \text { and } 2 \\
\text { Enhancement factor } \\
\text { represents average of several } \\
\text { measurements of }{ }^{137} \mathrm{Cs} \text { and } \\
{ }_{144} \mathrm{Ce} \text { concentrations; } \mathrm{PM}_{10} \\
\text { fraction was measured. }\end{array}$ \\
\hline \multicolumn{7}{|c|}{ California } \\
\hline Garden plot & & & & & 0.73 & $\begin{array}{l}\text { Shinn } 1998 \text { [DIRS 177230], } \\
\text { Table } 1 \mathrm{~A}\end{array}$ \\
\hline
\end{tabular}

\footnotetext{
${ }^{a}$ Calculated in Excel file Distributions of Enhancement Factors.xls (Appendix A).
}

NOTE: $A M A D=$ activity median aerodynamic diameter; $M G S D$ = mass geometric standard deviation; 
In soil that had recently been disturbed, the availability of plutonium for resuspension was increased by breaking plutonium particle bindings with soil particles, and enhancement factors were greater than unity, but never more than about 10 (Shinn 1992 [DIRS 160115], p. 1189). For instance, when the pebble cover of desert pavement at one location at the Nevada Test Site was removed, the enhancement factor increased 2.2 times, which indicates that desert pavement was effective in preventing or limiting resuspension.

Long-term resuspension potential of plutonium particles, and thus the enhancement factor, was influenced by the physical and chemical form of plutonium, soil characteristics, vegetative cover, meteorological conditions, and also by human activities. Long-term measurements at the Nevada Test Site demonstrated that the enhancement factor varies over time, depending on the environmental conditions and availability of plutonium particles for resuspension (Shinn 1997 [DIRS 177222], Table 1). This concept is also addressed in the article by Shinn (1992 [DIRS 160115]) and displayed in Figure 1 of that report.

Near a chemical separation facility at Savanna River, South Carolina, where low-level releases of plutonium occurred from 1967 through 1974, the enhancement factor was found to be less than one (0.21 and 0.46) (Shinn et al. 1982 [DIRS 177224], p. 1140). Enhancement factors less than one were also measured at numerous other contaminated sites (see Table 6.5-1). However, Shinn also reports that there exist data for the Hanford Site in Washington state that show enhancement factors greater than one for comparable soil contamination (Shinn et al. 1982 [DIRS 177224], p. 1140).

Measurements of the enhancement factor in Southern Australia at the sites of British nuclear tests resulted in values typically greater than unity (Shinn 2003 [DIRS 177226], Table 2; Johnston et al. 1992 [DIRS 177227], Table 4).

Where there are no measurements of the enhancement factor, the following values are recommended: 0.7 for undisturbed surface soil; 4 for in the case where soil is recently disturbed, and 0.01 for a nuclear detonation site (NCRP 1999 [DIRS 155894], p. 66). The enhancement factor for nuclear detonation is not applicable to this analysis. In these kinds of events, plutonium that was released to the environment is contained in small glass-like beads mixed into the soil, which results in enhancement factors that are two to three orders of magnitude less than unity (Shinn 1992 [DIRS 160115], p. 1188).

The measured values of enhancement factor summarized in Table 6.5-1 are plotted in a histogram (Figure 6.5-1). The graph contains all (65) measured values of the enhancement factor included in the references listed in Table 6.5-1 (see Excel file Distributions of Enhancement Factors.xls in Appendix A). The individual data points represent various experimental conditions, especially with respect to the measurement duration, because some measurements extended over long periods, while others were shorter-term; many data points represent averages of several measurements. Nevertheless, the data points displayed in Figure 6.5-1 have been treated as equal.

Figure 6.5-1 shows that over half of the measured values were less than or equal to unity and about half showed an enhancement of radionuclide concentration in suspended particulates compared to that of soil from which they originated. The average enhancement factor for all 
measurements is 2.2. Measurements that resulted in the enhancement factor exceeding unity usually involved recently disturbed soil, such as during contaminated site cleanup (Shinn et al. 1989 [DIRS 177231], Table 4); during a storm (Shinn 2003 [DIRS 177226], Table 2); in presumably high dust conditions (Johnston et al. 1992 [DIRS 177227]); after recent soil disturbance and by the road with traffic (Shinn et al. 1997 [DIRS 177223], Table 4); and by the work area where contaminated soil was being sorted (Shinn et al. 1994 [DIRS 177228], Results).

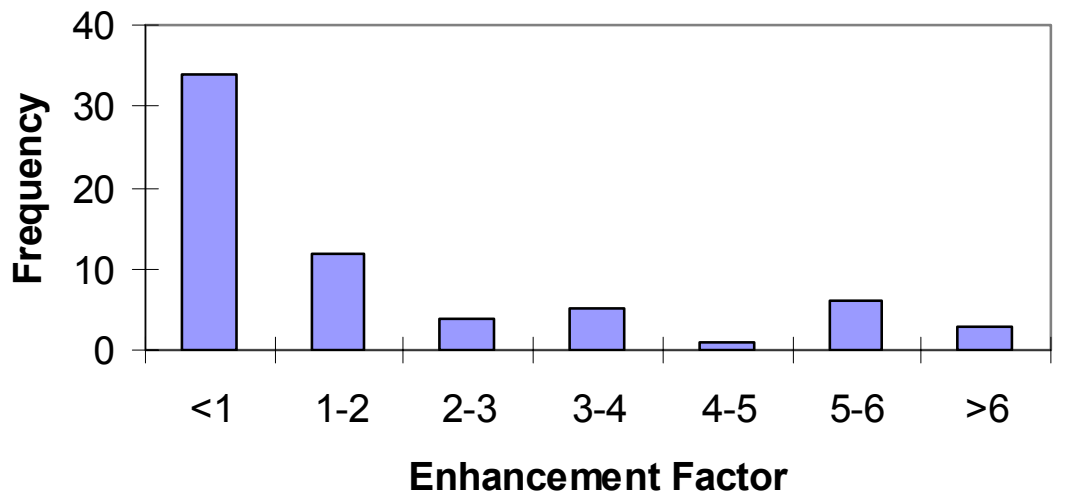

Source: Plot produced in Excel file Distributions of Enhancement Factors.xls (Appendix A).

Figure 6.5-1. Distribution of Measured Enhancement Factors

Most enhancement factors presented in Table 6.5-1 concern plutonium particles that were dispersed in the environment during an explosion. As noted earlier, in these experiments plutonium was mostly present in the form of plutonium oxide particles attached to soil particles or soil aggregates. Most experiments were conducted many years, even decades, after the original plutonium dispersion took place, so some fraction of plutonium would have dissolved and plutonium ions formed during the dissolution would have become sorbed onto the soil, as explained in Section 6.5.2.1. The enhancement factor is thus influenced by the distribution of plutonium sorbed on various sized soil particles as well as the particle-size-dependent manner in which plutonium particles were attached to soil aggregates or soil grains.

Also, most measurements of the enhancement factor summarized in Table 6.5-1 were taken while the atmospheric mass loading was $100 \mu \mathrm{g} \mathrm{m}^{-3}$ or less, and usually much less, regardless of whether the soil surface was undisturbed or disturbed. The results presented in the references as representative of disturbed soil surface usually were obtained where the soil surface had been disturbed within a relatively short time before a measurement, and not during surface disturbing activities. This is quite different from the conditions referred to in the biosphere model as the active outdoors environment, which apply to the situation when the soil disturbance is ongoing and a person is directly exposed to elevated mass loading. As noted earlier, such elevated levels of mass loading are transient and rapidly decrease after the disturbance ceases. 


\subsubsection{Development of Parameter Distribution}

In the volcanic ash exposure scenario, particles of fuel are dispersed in the environment as a result of a volcanic eruption followed by atmospheric dispersion and deposition on the ground of contaminated volcanic ash (BSC 2004 [DIRS 174067], Section 6.5.1). In this scenario, small particles of spent fuel are attached to larger particles of volcanic ash. In this respect, particles of fuel behave like particles of plutonium from the experiments described in the previous sections involving plutonium dispersal by high explosives. The density of plutonium oxide is comparable to the density of uranium oxide from spent fuel, so particles of similar size would have similar aerodynamic properties because aerodynamic diameter scales with the square root of particle density (NCRP 1997 [DIRS 160260], Section 5.1.1).

The mass loading that persisted during the measurements of enhancement factor was in the range from 0.0035 to $0.109 \mathrm{mg} \mathrm{m}^{-3}$ (Table 6.5-1), which coincides with the mass loading associated with the receptor environments other than the active outdoors environment. (The mass loading in the report by Kashparov et al. (1994 [DIRS 177229], Table 2) was higher; however, the atmospheric dust measurements were made with a $\mathrm{PM}_{10}$ sampler and the enhancement factors are not fully comparable with the other results presented in this section.) The mass loading for the active outdoors environment used in the biosphere model for the volcanic ash scenario range from 1 to $15 \mathrm{mg} \mathrm{m}^{-3}$; the mass loading for the other receptor environments is much lower (BSC 2006 [DIRS 177101], Section 7.1).

The contamination studied during the enhancement factor measurements was in the form of residual microscopic particles of plutonium in the soil (Shinn 2003 [DIRS 177226], p. 2). When the soil was undisturbed, the enhancement factor was typically less than one (Table 6.5-1) but was found to increase with soil disturbance when plutonium bindings with soil aggregates were broken. It was observed that disturbance affected the availability of plutonium for resuspension (Shinn 1992 [DIRS 160115], p. 1189). It needs to be recognized again that the conditions described in the references that were reviewed as pertaining to disturbed soil do not necessarily imply that dust-generating activities were occurring when the measurements were taken, but rather that there was an increased potential for resuspension of the contaminant arising from a prior soil disturbance.

The measured enhancement factors that have been reported in the references cited in Section 6.5.2.2 were divided into two broad categories, "undisturbed conditions" and "disturbed conditions," based on the descriptions of experimental conditions, and are summarized in Tables 6.5-2 and 6.5-3, respectively. The undisturbed soil conditions refer to the situation when there were no active soil-disturbing activities occurring at the time of measurements. For the undisturbed conditions, the enhancement factor is generally less than one; the geometric mean is 0.6 and the geometric standard deviation is 2.0. For the disturbed soil conditions, there is an increase of radionuclide concentration in airborne particulates and the enhancement factor is greater than 1. The geometric mean for these data is 2.9 and the geometric standard deviation is 1.8 (see Excel spreadsheet Distribution of Enhancement Factors.xls in Appendix A). 
Table 6.5-2. Measured Values of the Enhancement Factor under Undisturbed Soil Conditions

\begin{tabular}{|c|c|c|}
\hline Source & Location/Conditions & $f_{\text {enhance }}$ \\
\hline Shinn 1998 [DIRS 177230], Table 1A & California garden plot & 0.73 \\
\hline \multirow[t]{3}{*}{ Shinn et al. 1982 [DIRS 177224], p. 1140} & Savanna River: & \\
\hline & Field 1 & 0.21 \\
\hline & Field 2 & 0.46 \\
\hline \multirow[t]{5}{*}{ Shinn et al. 1997 [DIRS 177223], Table 8} & Marshall Islands: & \\
\hline & Bikini, coconut grove & 0.41 \\
\hline & Bikini, stabilized bare field & $0.82^{a}$ \\
\hline & Enjebi, vegetated field & 0.45 \\
\hline & Enjebi, downwind of road & 0.56 \\
\hline \multirow[t]{3}{*}{ Shinn 1992 [DIRS 160115], p. 1188} & Nevada Test Site: & \\
\hline & Area 5 , Site D & 0.87 \\
\hline & Area 11, Site D & 1.04 \\
\hline \multirow[t]{13}{*}{ Shinn et al. 1997 [DIRS 177222], Table 1} & Tonopah, near the Nevada Test Site: & \\
\hline & 18 Oct to $14 \mathrm{Nov}$ & 0.21 \\
\hline & 14 Nov to $11 \mathrm{Dec}, 1990$ & 1.54 \\
\hline & 13 Mar to 2 Apr, 1991 & 0.13 \\
\hline & $2 \mathrm{Apr}$ to $17 \mathrm{Apr}, 1991$ & 0.20 \\
\hline & 17 Apr to 1 May, 1991 & 1.61 \\
\hline & 1 May to 15 May, 1991 & 0.59 \\
\hline & 15 May to 30 May, 1991 & 1.16 \\
\hline & 30 May to 12 Jun, 1991 & 0.38 \\
\hline & 12 Jun to 26 Jun, 1991 & 0.48 \\
\hline & 26 Jun to 10 Jul, 1991 & 0.68 \\
\hline & $10 \mathrm{Jul}$ to $24 \mathrm{Jul}, 1991$ & 0.65 \\
\hline & $24 \mathrm{Jul}$ to 7 Aug, 1991 & 0.66 \\
\hline Shinn 2002 [DIRS 177225], Table 1 & Palomares, Spain & 0.28 \\
\hline Shinn 2003 [DIRS 177226], Table 2 & Maralinga, Taranaki West, never ploughed & 2 \\
\hline \multirow[t]{3}{*}{ Shinn et al. 1989 [DIRS 177223], Table 4} & Nevada Test Site: & \\
\hline & Cleanup site, before cleanup & 1.03 \\
\hline & Cleanup site, after site stabilization & 1.20 \\
\hline Church et al. 2000 [DIRS 177310], Table 2 & Nevada Test Site, before and after cleanup & 0.69 \\
\hline
\end{tabular}

${ }^{\mathrm{a}}$ This value is an average for the two periods of measurement provided in Table 6.5-1 from the same reference. 
Table 6.5-3. Measured Values of the Enhancement Factor under Disturbed Soil Conditions

\begin{tabular}{|c|c|c|}
\hline Source & Location/Conditions & $\begin{array}{l}\text { Enhancement } \\
\text { Factor }\end{array}$ \\
\hline \multirow[t]{6}{*}{ Shinn 1992 [DIRS 160115], Table 2} & Nevada Test Site: & \\
\hline & Soil thawing in spring time & 6.5 \\
\hline & Wildfire, removing grasses & 3.5 \\
\hline & Raked off desert pavement & 2.2 \\
\hline & Bikini: & \\
\hline & Bulldozer blading of soil & 3.9 \\
\hline \multirow{2}{*}{$\begin{array}{l}\text { Shinn } 1992 \text { [DIRS 160115], Table } 2 \\
\text { (continued) }\end{array}$} & South Carolina: & \\
\hline & Soil dried, eroded 2 weeks & 0.8 \\
\hline \multirow[t]{4}{*}{ Shinn et al. 1989 [DIRS 177231], Table 4} & Nevada Test Site: & \\
\hline & During cleanup trial & 2.0 \\
\hline & After $60 \%$ cleanup & 3.7 \\
\hline & After stabilized & 1.2 \\
\hline Kashparov et al. 1994 [177229], Table 2 & $\begin{array}{l}\text { Chernobyl - Average of several measurements } \\
\text { inside and outside tractor cabs, }{ }^{137} \mathrm{Cs} \text { and }{ }^{144} \mathrm{Ce} \text {; } \\
\text { atmospheric dust particles are reported to be } \\
\text { less than } 10 \mu \mathrm{m} \text { in diameter (presumably } \mathrm{PM}_{10} \\
\text { fraction) }\end{array}$ & $6.4^{\mathrm{a}}$ \\
\hline $\begin{array}{l}\text { Shinn et al. } 1994 \text { [DIRS 177228], Section } \\
\text { titled Results, 4th paragraph }\end{array}$ & Johnston Atoll & 2.7 \\
\hline \multirow[t]{3}{*}{ Shinn 2003 [DIRS 177226], Table 2} & Maralinga: & \\
\hline & $\begin{array}{l}\text { Taranaki, Northeast, cleaned, but not } \\
\text { stabilized }\end{array}$ & 2 \\
\hline & $\begin{array}{l}\text { Taranaki, North, cleaned, but not } \\
\text { stabilized, during storm }\end{array}$ & 6 \\
\hline $\begin{array}{l}\text { Johnston et al. } 1992 \text { [DIRS 177227], } \\
\text { Table } 4\end{array}$ & $\begin{array}{l}\text { Maralinga, several trials with artificial dust raising } \\
\text { experiments }\end{array}$ & $4.2^{\mathrm{a}}$ \\
\hline \multirow{3}{*}{$\begin{array}{l}\text { Shinn et al. } 1997 \text { [DIRS 177223], } \\
\text { Tables } 4 \text { and } 8\end{array}$} & Marshall Islands: & \\
\hline & Field, freshly tilled & 3.1 \\
\hline & Road with traffic & 2.5 \\
\hline
\end{tabular}

${ }^{a}$ Calculated from the data in reference in Excel file Distribution of Enhancement Factors.xls (Appendix A).

The data from Tables 6.5-2 and 6.5-3 are displayed in Figure 6.5-2. The graph, produced using a logarithmic scale, indicates that the data are reasonably well fit with a lognormal distribution (see Mathcad file EFs for Undisturbed and DisturbedSoil.mcd in Appendix A).

Many of the data points in Tables 6.5-2 and 6.5-3 were taken either on or near the Nevada Test Site or under conditions that are similar to the Amargosa Valley. Therefore these data can be considered representative of the local conditions. The measurements were taken many years following the radionuclide deposition, so the effect of weathering is already factored in. The data sets also include the results of measurements carried out in the regions where precipitation is greater than in Amargosa Valley. Generally, there is no systematic difference in the enhancement factor value between the sites having different precipitation levels, and the range of enhancement factor being based on data from various locations is considered to include variations expected from climate change. 


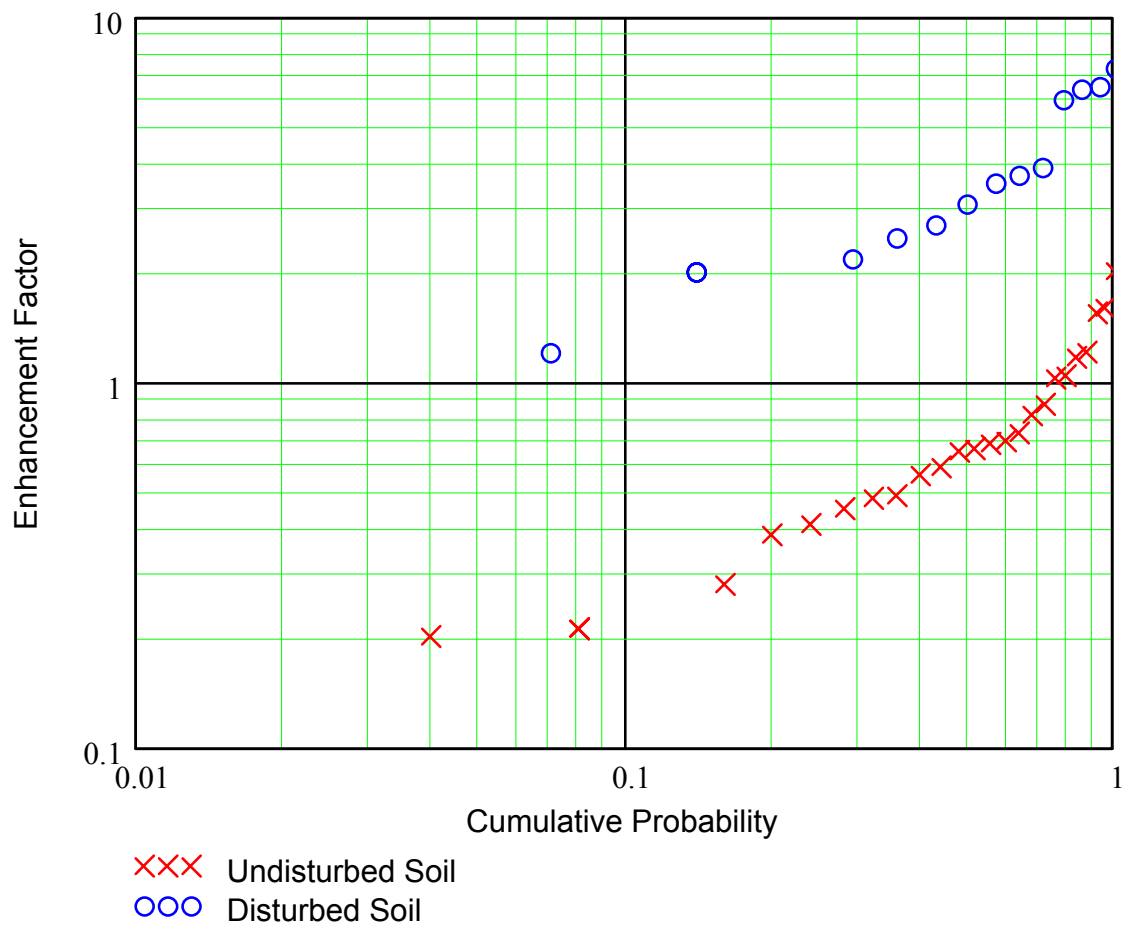

Source: Figure produced in Mathcad file EFs for Undisturbed and DisturbedSoil.mcd (Appendix A).

Figure 6.5-2. Graph of Enhancement Factors for Undisturbed and Disturbed Soil Conditions

The source of radionuclides for the volcanic scenario is contaminated ash that results when particles of the waste are attached to larger particles of ash (BSC 2005 [DIRS 174067], Section 6.5.1) that are released during an extrusive volcanic event and deposited on the soil surface. After the ash-waste mixture has been incorporated into the soil and weathered, a fraction of radionuclides would dissolve and adsorb to the soil grain surfaces. In most experiments described above, enhancement factors were measured on aged plutonium deposits, so the process of radionuclide sorption may have been already occurring to some degree. However, the magnitude of this effect is not known. In addition, the field measurements took place up to a few decades after the plutonium deposition event. The time scale for biosphere modeling is much longer. During this timeframe a larger fraction of contaminant may undergo dissolution and subsequent soil adsorption. This possible lack of representativeness for analogue measurements of the conditions in the Yucca Mountain region is a source of uncertainty when experimental results are used to develop the distributions of enhancement factors for the volcanic ash exposure scenario.

As demonstrated in Section 6.5.3, when radionuclides are adsorbed to soil grains, the enhancement factor is greater than unity for undisturbed soil conditions due to the particle size-dependent radionuclide concentration in soil and particle size-dependent resuspension, the effect opposite to that observed in experiments involving plutonium particles. To account for the uncertainty of that effect in the volcanic scenario, it is recommended that the mean value and bounds for the lognormal distribution calculated from the enhancement factor for undisturbed soil conditions (Table 6.5-2) be doubled, i.e., the geometric mean of 1.2 be used with a GSD 
of 2.0. It is also recommended that the high and low bounds for the lognormal distribution be taken at the $95 \%$ confidence interval, i.e., at $\mathrm{GM} \times \mathrm{GSD}^{ \pm 1.96}$, in this case at 0.3 and 4.6.

Although the mass loading levels during the field measurements of enhancement factor were typically much lower than those used in the biosphere model for the active outdoors environment, it is recommended that the distribution based on the measured enhancement factors for the disturbed soil be used. This is because soil disturbance would affect bindings of the particles of contaminant with particles of soil and would increase availability of contaminant particles for resuspension. Consequently, an enhancement effect would be observed during soil disturbance. It needs to be recognized that, with time, dissolution of waste particles and soil adsorption of radionuclides contained in the waste would take place. When this occurs, contaminant distribution in soil changes as radionuclides adsorb to the available surface of soil particles. This process is discussed in detail Section 6.5.3, where it is shown that, due to the particle size effect, the enhancement factors can range from values of less than one for disturbed soil conditions to about six for conditions with no active soil disturbance.

The initial distribution of particles of waste in soil and the subsequent evolution of contaminant distribution in soil relative to those for analogue measurements are sources of uncertainty in the enhancement factor. This is because the results of field measurements may not be fully representative of the conditions in the Yucca Mountain region or of the analysis timeframe. However, when the full range of measured values is used to develop a distribution of the enhancement factor, this range is considered sufficient to account for such an uncertainty. Based on the experimental data (Table 6.5-3), it is recommended that a lognormal distribution be used to represent the enhancement factor for the active outdoor environment. The enhancement factor measurements under disturbed soil conditions have a geometric mean of 2.9 and a GSD of 1.8. The lower and upper bounds for the $95 \%$ confidence interval of a lognormal distribution with these statistics are at 0.9 and 9.4. The high bound is much higher than most measured enhancement factor values. However, there were individual measurements at Maralinga (Johnston et al. 1992 [DIRS 177227], Table 4) that had relatively high enhancement factors, with one value being as high as 20 .

Soil-disturbing activities occur in the receptor environment that is categorized in Biosphere Model Report (BSC 2004 [DIRS 169460], Section 6.4.2.1) as active outdoors $(n=1)$. In the other receptor environments within the contaminated area (inactive outdoors $(n=2)$ and both active indoors $(n=3)$ and indoor asleep $(n=4))$ the soil is assumed to be undisturbed. The fifth category of $n=5$ applies to time spent outside areas of contamination where the enhancement factor does not apply.

\subsubsection{Enhancement Factor for the Groundwater Exposure Scenario}

As can be seen from Section 6.5.2.2, there were many measurements of the enhancement factor for resuspension of plutonium particles. This is not the case if a contaminant was deposited on the ground in the aqueous phase. The following section contains an analysis of the enhancement factor in such circumstances. 


\subsubsection{Radionuclide Enhancement as a Result of Particle Size Selective Resuspension of Soil Particles}

In the groundwater exposure scenario, radionuclides are introduced into the soil in the aqueous phase via irrigation water. As noted before, radionuclide sorption onto grains of soil is different from the way plutonium particles attach themselves to the soil. Radionuclide sorption is a process that occurs on the surface of the grains and is responsible for radionuclide buildup in soil (see Section 6.3 for discussion). Radionuclide sorption is element-dependent and is quantified in the biosphere model by the partition coefficient (Section 6.3).

Radionuclide sorption as a surface process is evident from the values of partition coefficients for different soil textural classes (Tables 6.3-1 to 6.3-3). Partition coefficients for sandy soils are the lowest, followed by the partition coefficients for loamy soils, and then clayey soils. Sandy soils have the largest-size grains, while clays have the finest particles, and thus largest available total grain surface area per unit mass. As a result, concentrations of radionuclides per unit mass of soil resulting from a unit radionuclide concentration in water in equilibrium with that soil would be greater for soils with finer particles.

This tendency was observed in measurements of how concentrations of naturally occurring radionuclides $\left({ }^{40} \mathrm{~K},{ }^{238} \mathrm{U}\right.$, and $\left.{ }^{232} \mathrm{Th}\right)$ were distributed among small (less than $\left.20 \mu \mathrm{m}\right)$ and large soil particles for several different soil types (Jasinska et al. 1980 [DIRS 177363]). The experimental results showed that the majority of radionuclides were attached to or captured by fractions of soil with diameter less than $20 \mu \mathrm{m}$ (Jasinska et al. 1980 [DIRS 177363], p. 417 to 418) and that the concentration of radionuclides increases as the fraction of particles smaller than $20 \mu \mathrm{m}$ increases.

The process of radionuclide concentration enhancement for resuspended particulates has been recognized in several radiological assessments (BIOPROTA 2005 [DIRS 177377], Sections 2 and 5). It was attributed to the fact that smaller soil particles that get suspended have a higher surface-to-volume ratio than large particles, which are less likely to become airborne. It was also noted that this ratio increases in inverse proportion to the linear dimensions of the particle (BIOPROTA 2005 [DIRS 177377], Section 5). This relationship implies that the radionuclide concentration of sorbed radionuclides is proportional to the surface area available for sorption.

Agricultural land in the reference biosphere, i.e., as represented in the biosphere model, is used for tens or hundreds of years (Section 6.7). Agricultural land use involves irrigation, tilling, disking and other practices necessary to maintain productivity. These practices would affect soil structure, i.e., the way individual grains of soil bind together and form soil aggregates. Over time, these practices would increase the likelihood that individual soil grains are affected by radionuclide sorption because soil would be mixed and broken down and individual soil particles would be equally likely to be wetted by irrigation water. Thus, it can be postulated that the amount of sorbed radionuclides is proportional to the available surface area of the soil grains. The enhancement factor would then be calculated as the ratio of the available surface area per unit mass of suspended particulates to the available surface area per unit mass of underlying soil.

The analysis presented in the following sections develops the surface-to-mass ratio for surface soil and for resuspended particles, based on the data for Amargosa Valley soils. The surface-to- 
mass ratio of resuspended particulates is examined for various particle size distributions that can be associated with dusty environments (active outdoors) as well as with the environments that have low mass loading.

\subsubsection{Particle Size Distribution for Amargosa Valley Soils}

Soil particles cover a relatively wide range of particles sizes. The proportion of soil separates of different particles sizes in the uppermost layer of the soil series present in Amargosa Valley is given in Table 6.5-4 in terms of mass percentages. The data for particles passing designated sieves for clay particles in the topsoil layer were taken from the Soil Survey of Nye County, Southwest Part (USD 2004 [DIRS 173916], Part II, Tables 11 and 12). The percentage of particles passing designated sieves is the percentage of the soil fraction less than 3 inches (7.62 $\mathrm{mm}$ ) in diameter. The percentage of clay is based on soil material that is less than $2 \mathrm{~mm}$ in diameter. Table 6.5-4 also shows the cumulative percentages of soil fractions normalized to the $2 \mathrm{~mm}$ particles, which are used in the subsequent analyses. This was done by dividing the fractions for sieve \#40 and sieve \#200 by the sieve \#10 fraction (see Excel file Soil Separates.xls in Appendix A).

A method for estimating the particle size distribution from the clay, silt, and fine plus very fine sand mass fractions was developed by Skaggs et al. (2001 [DIRS 177368]). Clay particles are less than $2 \mu \mathrm{m}$ in diameter; silt has particles in the 2 to $50 \mu \mathrm{m}$ range; fine and very fine sand are particles with diameters from 50 to $250 \mu \mathrm{m}$ (Skaggs et al. 2001 [DIRS 177368], p. 1038). The fractions are defined in the standard terms used by the U.S. Department of Agriculture, i.e., as fractions of the soil that is less than $2 \mathrm{~mm}$ in diameter (USDA 2004 [DIRS 173916], Part II, p. 23). There is a good agreement between the estimated and fitted distributions for most soil types, including sandy loams, the predominant soil type in Amargosa Valley (Skaggs et al. 2001 [DIRS 177368], p. 1041).

The cumulative particle size distribution is estimated using the following equation based on the empirical methods (Skaggs et al. 2001 [DIRS 177368], p. 1039):

$$
P(x ; c l, s i, f v f s)=\frac{1}{1+\left(\frac{1}{c l}-1\right) \exp \left[-u\left(\frac{x}{2}-1\right)^{c}\right]}
$$

where

$$
\begin{array}{ll}
x & =\text { diameter of soil particles }(\mu \mathrm{m}) \\
c l & =\text { clay mass fraction }(x \leq 2 \mu \mathrm{m}) \\
s i & =\text { silt mass fraction }(2 \mu \mathrm{m}<x \leq 50 \mu \mathrm{m}) \\
f v f s & =\text { fraction of fine plus very fine sand }(50 \mu \mathrm{m}<x \leq 250 \mu \mathrm{m}) .
\end{array}
$$


Table 6.5-4. Percentage of Soil Separates in Farmed Soils Occurring in Amargosa Valley

\begin{tabular}{|c|c|c|c|c|c|c|c|c|c|c|c|c|c|c|c|}
\hline \multirow[b]{2}{*}{ Soil Series } & \multicolumn{3}{|c|}{$\begin{array}{c}\text { Sieve \#4 } \\
(4.76 \text { to } 7.62 \mathrm{~mm})^{a, b}\end{array}$} & \multicolumn{3}{|c|}{$\begin{array}{l}\text { Sieve \#10 } \\
(<2 \mathrm{~mm})^{\mathrm{a}, \mathrm{b}}\end{array}$} & \multicolumn{3}{|c|}{$\begin{array}{c}\text { Sieve \#40 } \\
(<0.42 \mathrm{~mm})^{\mathrm{a}, \mathrm{b}}\end{array}$} & \multicolumn{3}{|c|}{$\begin{array}{c}\text { Sieve \#200 } \\
(<0.074 \mathrm{~mm})^{\mathrm{a}, \mathrm{b}}\end{array}$} & \multicolumn{3}{|c|}{$\begin{array}{c}\text { Clay } \\
(<0.002 \mathrm{~mm})^{c}\end{array}$} \\
\hline & Min & Max & Avg & Min & Max & Avg & Min & Max & Avg & Min & Max & Avg & Min & Max & Avg \\
\hline Corbilt & 30 & 55 & 42.5 & 25 & 50 & 37.5 & 15 & 35 & 25 & 10 & 25 & 17.5 & 5 & 10 & 7.5 \\
\hline Yermo & 35 & 55 & 45 & 30 & 50 & 40 & 15 & 45 & 30 & 10 & 30 & 20 & 8 & 18 & 13 \\
\hline Arizo & 30 & 55 & 42.5 & 25 & 50 & 37.5 & 20 & 40 & 30 & 10 & 20 & 15 & 5 & 12 & 8.5 \\
\hline Shamock & 55 & 80 & 67.5 & 50 & 75 & 62.5 & 35 & 55 & 45 & 25 & 40 & 32.5 & 3 & 8 & 5.5 \\
\hline Commski & 35 & 55 & 45 & 25 & 50 & 37.5 & 20 & 40 & 30 & 10 & 30 & 20 & 10 & 18 & 14 \\
\hline Sanwell & 65 & 80 & 72.5 & 60 & 75 & 67.5 & 45 & 60 & 52.5 & 25 & 40 & 32.5 & 5 & 10 & 7.5 \\
\hline Average & & & 52.5 & & & 47.1 & & & 35.4 & & & 22.9 & & & 9.3 \\
\hline $\begin{array}{l}\text { Percentages } \\
\text { normalized to } \\
<2 \mathrm{~mm} \text { soil }\end{array}$ & & & $\mathrm{N} / \mathrm{A}$ & & & 100 & & & 75 & & & 48 & & & 9 \\
\hline
\end{tabular}

Source: USD 2004 [DIRS 173916], Part II, Tables 11 and 12.

a Particle sizes for different sieve numbers were taken from USD 2004 [DIRS 173916], Part II, p. 23.

${ }^{\mathrm{b}}$ Percentages apply to soil that is less than $7.62 \mathrm{~mm}$ in diameter.

${ }^{c}$ These values are percentages in soil that is less than $2 \mathrm{~mm}$ in diameter.

NOTE: $\quad$ Averages were calculated in Excel file Soil Separates.xls (Appendix A). 
and

$$
\begin{aligned}
& c=-0.609 \ln \frac{v}{w}, \quad u=-\frac{v^{2.94}}{w^{1.94}}, \\
& v=\ln \frac{(c l+s i)^{-1}-1}{c l^{-1}-1}, \quad w=\ln \frac{(c l+s i+f v f s)^{-1}-1}{c l^{-1}-1}
\end{aligned}
$$

The function is valid for particle sizes in the range $2 \mu \mathrm{m} \leq \mathrm{x} \leq 2000 \mu \mathrm{m}$.

For the Amargosa Valley soils, the approximate clay fraction is $c l=0.09$ (from Table 6.5-4). The fraction of silt as well as fine and very fine sand can be estimated from the plot of the percentage of soil separates, based on data given in Table 6.5-4, which is shown in Figure 6.5-3.

From Figure 6.5-3, it can be estimated that the cumulative percentage of particles with diameters less than $50 \mu \mathrm{m}$ (silt and clay) is about 0.4. The fraction of silt is thus 0.31 (0.40 silt and clay fraction minus 0.09 clay fraction). Also from Figure 6.5-3, the fraction of particles less than $250 \mu \mathrm{m}$ in diameter is about 0.67 , so the mass fraction of fine and very fine sand (particles in the range from $50 \mu \mathrm{m}$ to $250 \mu \mathrm{m}$ ) is about $0.27(0.67$ minus 0.4$)$. The objective of these calculations is to develop the range of parameter values, rather than the exact values, because of other unquantifiable uncertainties that are involved. Therefore, this simplified method of estimating fractions of soil separates is justified.

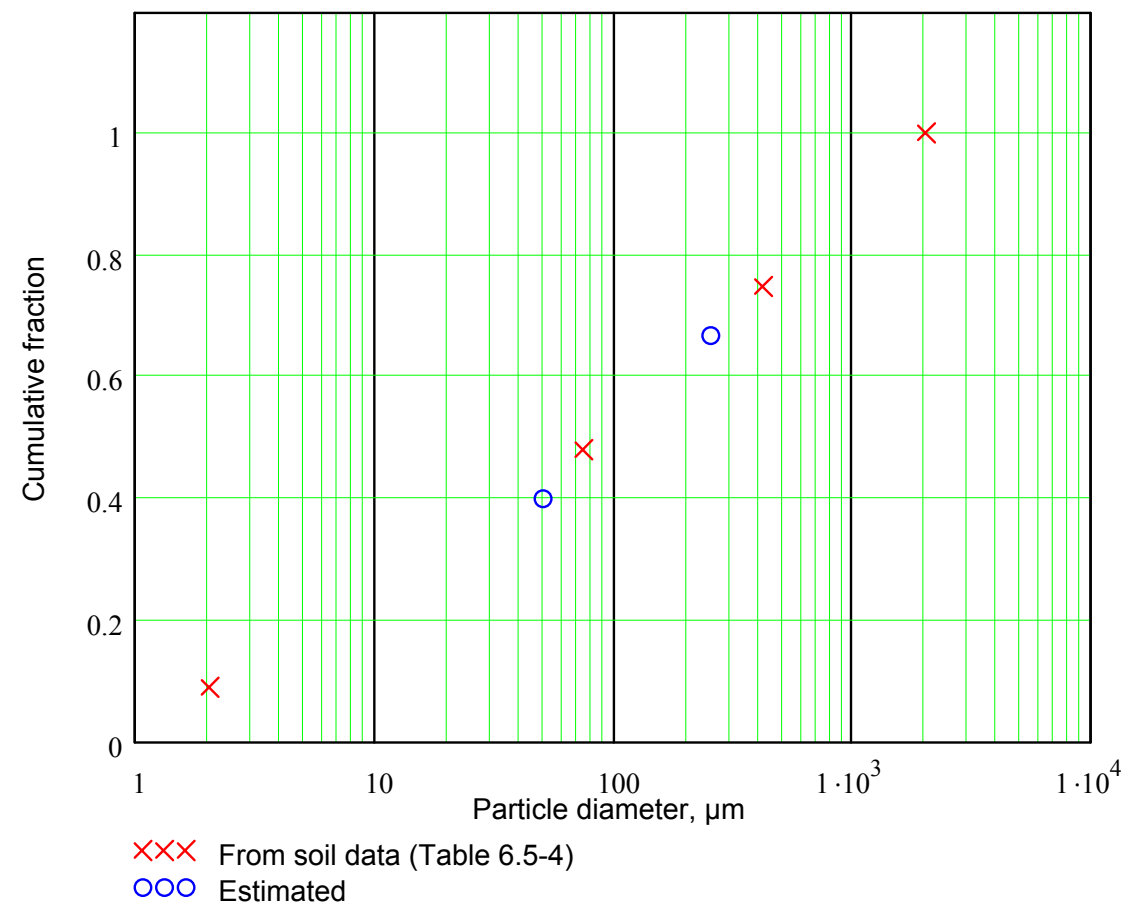

Source: Graph produced in Mathcad file Particle Size Distributions for Soil and TSP.mcd (Appendix A).

NOTE: Crosses represent the fractions of soil separates taken from Table 6.5-4. Circles represent estimated fractions of silt and fine and very fine sand.

Figure 6.5-3. Cumulative Percent of Soil Separates in Amargosa Valley Soils 
Mathcad calculations and a graph of the cumulative distribution function for particle sizes in Amargosa Valley soils are illustrated in Figure 6.5-4. The calculations are included in the Mathcad file Size Distributions for Soil and TSP.mcd (Appendix A). The data that the function is based on, plotted in Figure 6.5-3, are also shown in Figure 6.5-4 to verify the fit.

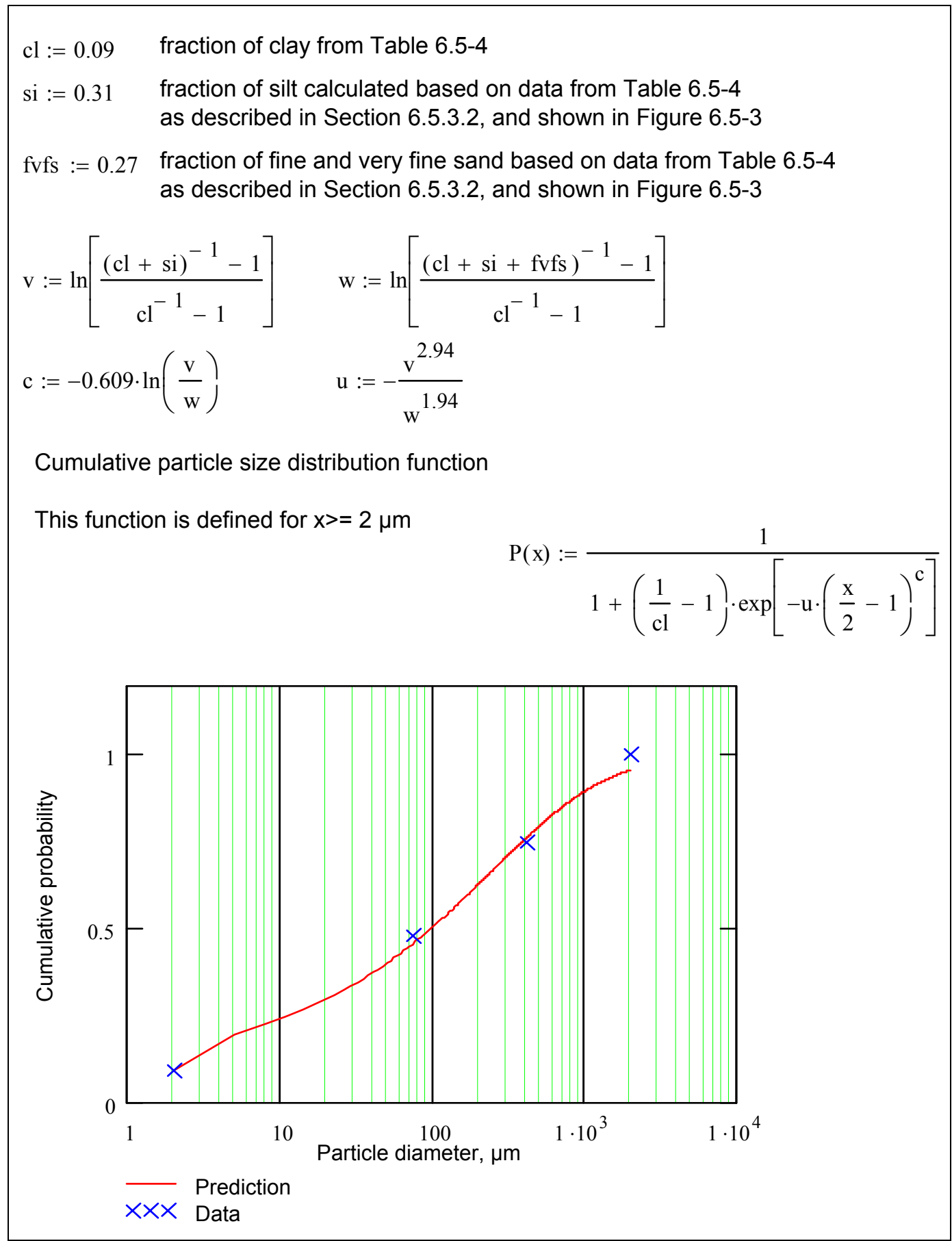

Source: Mathcad file Particle Size Distributions for Soil and TSP.mcd (Appendix A).

Figure 6.5-4. Cumulative Particle Size Distribution Function for Amargosa Valley Soils 
The shape of the distribution shown in Figure 6.5-4 agrees well with the particle size distribution for sandy loam illustrated in the article by Skaggs et al. (2001 [DIRS 177368], p. 1041). The probability density function $\mathrm{p}(\mathrm{x})$ for the particle size distribution represented by the cumulative distribution function $\mathrm{P}(\mathrm{x})$ was calculated in Mathcad by taking a derivative of the function $\mathrm{P}(\mathrm{x})$, $\mathrm{p}(\mathrm{x})=\frac{\mathrm{d}}{\mathrm{dx}} \mathrm{P}(\mathrm{x})$.

\subsubsection{Particle Size Distribution of Suspended Particulate Matter}

Many reports identified in Section 6.5.2 included evaluations of the particle size distribution of TSP. When mass loading is relatively low, the measurements indicate that the particle size distribution of airborne particulates can be represented by a lognormal probability density function. Such a function represents the probability density of particle mass versus particle size. The parameters that were used to characterize such a distribution are MMAD and mass geometric standard deviation (MGSD). MMAD is the calculated aerodynamic diameter that divides the particles of an aerosol in half, based on the mass of the particles. This quantity is equivalent to the geometric mean aerodynamic diameter for the lognormal particle size distribution.

Because most of the measurements described in Section 6.5.2 are of the particle size distribution of airborne activity, the corresponding parameters used to describe such distributions are activity median aerodynamic diameter (AMAD) and the associated geometric standard deviation. In several instances (Shinn et al. 1989 [DIRS 177231]; Shinn et al. 1997 [DIRS 177223]; Shinn 2003 [DIRS 177226]; Shinn 2002 [DIRS 177225]), the distributions of suspended mass and suspended activity were very similar. In such cases it is possible to characterize the corresponding distributions by one value of MAD.

As noted in Section 6.5.1.2, in the absence of active soil disturbance, TSP that originates from soil was found to be approximately lognormally distributed with the MMAD in the range from 2 to $6 \mu \mathrm{m}$. The results of experiments summarized in Table 6.5-1 confirm this range because most measured MMAD are in the range from 2 to $6 \mu \mathrm{m}$ except for one that is higher and one that is lower (Shinn et al. 1989 [DIRS 177231], p. 776; Shinn et al. 1997 [DIRS 177222], Table 1 and Results; Shinn 2003 [DIRS 177226], Table 1; Shinn 2002 [DIRS 177225], Tables 1 and 2; Shinn et al. 1982 [DIRS 177224], p. 1136; Shinn et al. 1997 [DIRS 177223], Table 3; Shinn et al. 1994 [DIRS 177228], Results and Table 1). The average MMAD for these field experiments was $3.7 \mu \mathrm{m}$ with a standard deviation of about 2 (Excel file MMADs of Suspended Particles.xls in Appendix A). The GSD of TSP distributions varied from 2.2 to 10 (Table 6.5-1); however, the highest value of 10 does not reflect the true shape of a lognormal distribution because it implies that the distribution includes unrealistic particle sizes (Shinn et al. 1994 [DIRS 177228], Results). If this value is excluded, the average GSD of those summarized in Table 6.5-1 is 3.9. This value compares well with the GSD of 5 recommended in the absence of measurements (NCRP 1999 [DIRS 155894], p. 68). Typical particle size distributions of suspended particulate matter are illustrated in Figure 6.5-5 (equations and plots). 


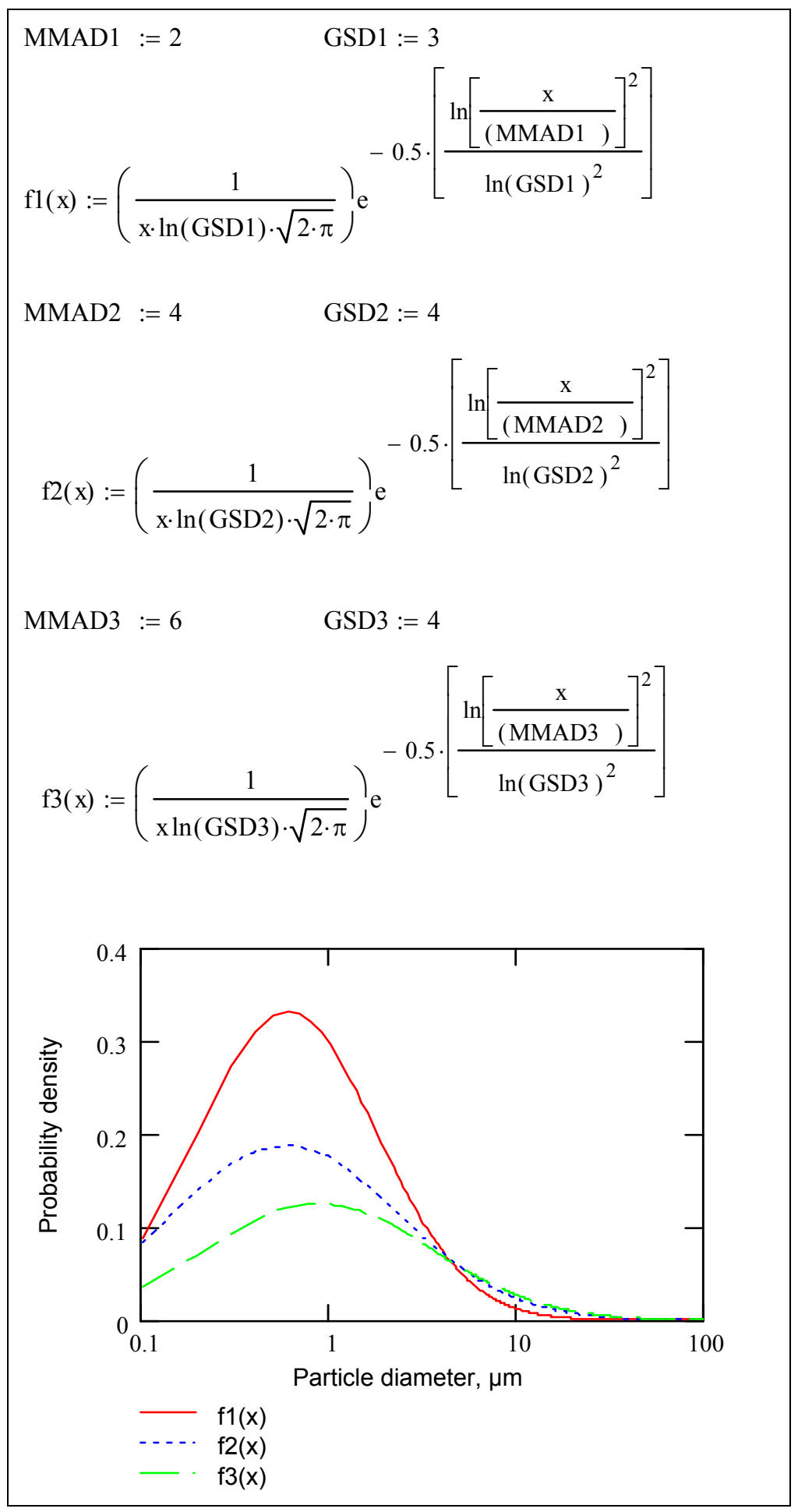

Source: Mathcad file Particle Size Distributions for Soil and TSP.mcd (Appendix A).

NOTE: In the graph, $x$ is the aerodynamic diameter of suspended particles; $f 1(x), f 2(x)$, and $f 3(x)$ are three different probability density functions for distribution of suspended particle mass as a function of $\mathrm{x}$.

Figure 6.5-5. Illustration of Probability Density Function for Particle Size Distribution of Suspended Aerosols for Environments without Active Soil Disturbance 
The plots illustrated in Figure 6.5-5 are the functions of particle diameter $x$ and depend on the values of two parameters: MMAD (the geometric mean of the distribution) and the GSD. Three MMAD values were selected to represent the range of typical values: 2,4 , and $6 \mu \mathrm{m}$. From Table 6.5-1, distributions with an MMAD around $2 \mu \mathrm{m}$ had the GSD of about 3 (based on measured GSD for particles with the lowest MMAD). For the 4 and $6 \mu \mathrm{m} \mathrm{MMAD,} \mathrm{the} \mathrm{GSD} \mathrm{of} 4$ was used, which is an average measured value, as described in the previous paragraph. The probability density functions for the distributions with MMAD of 2, 4, and $6 \mu \mathrm{m}$ are represented in Figure $6.5-5$ by the functions $f 1(x), f 2(x)$, and $f 3(x)$, respectively. The equation for lognormal probability density function shown in Figure 6.5-5 was obtained from GoldSim User's Manual (GoldSim Technology Group 2003 [DIRS 166227], Appendix B).

As noted above, the shape of the particle size distribution of atmospheric aerosols in the coarse particles mode is represented by a lognormal probability density function (Lundgren and Burton 1995 [DIRS 177699], p. 131). Such a function is a mathematical approximation of the true distribution of particle sizes that was fitted to the measured MMAD and GSD of the aerosols. This is especially evident in the small-size and large-size tails of the distribution. Very small particles, although present among atmospheric aerosols, originate from other sources and through other mechanisms than mechanical suspension of underlying soil (EPA 1996 [DIRS 160121], Section 3.1.3.2). Very large particles would be difficult to suspend and, even if suspended, would very quickly settle out, and would not be likely to be inhaled or sampled, especially if an inhalable sampler is used. Therefore, in this analysis upper and lower particle size cut-off diameters are used, consistent with size distributions of atmospheric aerosols under consideration.

For the environments where soil is actively disturbed by mechanical means, the distribution of TSP changes and MMAD increases significantly. As noted in Section 6.5.1.2, measurements in California (Nieuwenhuijsen et al. 1998 [DIRS 150855], p. 36) found an average MMAD of $49 \mu \mathrm{m}$ (range from 22 to $150 \mu \mathrm{m}$ ) for agricultural operations involving significant dust generation; however, the authors of that publication noted that other researchers found MMAD in the range from 12 to $20 \mu \mathrm{m}$. Also, a second mode may appear in the distribution in the particle size range from about $15 \mu \mathrm{m}$ (NCRP 1999 [DIRS 155894], p. 67) and greater.

Experiments involving driving heavy military equipment on unpaved dusty roads in New Mexico identified bimodal distributions of suspended particulate matter with one mode, on average, at about $10 \mu \mathrm{m}$ and GSD of 2.1 and the other mode, on average, at $88 \mu \mathrm{m}$ and GSD of 1.6 (Pinnick et al. 1985 [DIRS 159577], Table 3). The distributions representing, in this analysis, the conditions with active soil disturbance are based on the data described above and are as follows: function $f 4(x)$ has a MMAD of $49 \mu \mathrm{m}$ and a GSD of 4 ; functions $f 5(x)$ and $f 6(x)$ are components of a bimodal distribution with MMAD of $10 \mu \mathrm{m}$ and GSD of 2.1 and MMAD of $88 \mu \mathrm{m}$ and GSD of 1.6, respectively; and function $f 7(x)$ has a MMAD of $15 \mu \mathrm{m}$ and GSD of 4 (see Mathcad file Size Distributions for Soil and TSP.mcd in Appendix A).

\subsubsection{Development of Surface-to-Mass Ratio for Soils and Suspended Particulate Matter}

As described in Section 6.5.3.1, the enhancement factor for radionuclides adsorbed to surfaces of soil grains can be expressed as a ratio of the available surface area per unit mass of suspended 
particulates to the available surface area per unit mass of underlying soil. Based on the particle size distribution functions for soil and for suspended particulates, it is possible to calculate the surface-to-mass ratios for particles characterized by such distributions.

If $f(x)$ represents the probability density function for the distribution of mass over a particle size range, then $f(x) d x$ represents the probability of contribution to the total mass from particles size $x$, or, in other words, the fraction of the total mass that is attributable to particles of size $x$. For the total mass $M$, the mass of particles with size $x$ can be expressed as:

$$
d m=M f(x) d x
$$

One can assume that soil particles have the same density, $\rho$, and a spherical shape (it is shown later that this assumption is not critical), so the volume of a particle, $v$, can be expressed in terms of its diameter $x$ as:

$$
v=\frac{4}{3} \pi\left(\frac{x}{2}\right)^{3}
$$

its mass as:

$$
m=\rho \frac{4}{3} \pi\left(\frac{x}{2}\right)^{3}
$$

and the particle's surface area, $s$, as:

$$
s=4 \pi\left(\frac{x}{2}\right)^{2}=\frac{6 v}{x}
$$

In the mass element $d m$, there are $\frac{M f(x) d x}{\rho \frac{4}{3} \pi\left(\frac{x}{2}\right)^{3}}$ particles, their mass is $M f(x) d x$, and their total surface area is $\frac{M f(x) d x}{\rho \frac{4}{3} \pi\left(\frac{x}{2}\right)^{3}} 4 \pi\left(\frac{x}{2}\right)^{2}=\frac{6 M}{\rho} \frac{f(x)}{x} d x$.

The total surface area in the distribution of particles with sizes in the range from $x_{1}$ to $x_{2}$ is $\int_{x_{1}}^{x_{2}} \frac{6 M}{\rho} \frac{f(x)}{x} d x$, and their mass is $\int_{x_{1}}^{x_{2}} M f(x) d x$. 
The surface-to-mass ratio for these particles can be expressed as:

$$
\frac{\int_{x_{1}}^{x_{2}} \frac{6 M}{\rho} \frac{f(x)}{x} d x}{\int_{x_{1}}^{x_{2}} M f(x) d x}=\frac{6}{\rho} \frac{\int_{x_{1}}^{x_{2}} \frac{f(x)}{x} d x}{\int_{x_{1}}^{x_{2}} f(x) d x}
$$

Likewise, the surface-to-mass ratio for particles of the underlying soil, assuming the same shape and density as those for the suspended particulates, the particle size range from $x_{3}$ to $x_{4}$, and the particle size distribution of their mass represented by a function $g(x)$, is:

$$
\frac{6}{\rho} \frac{\int_{x_{3}}^{x_{4}} \frac{g(x)}{x} d x}{\int_{x_{3}}^{x_{4}} g(x) d x}
$$

If the amount of radioactive contamination in soil is proportional to the available surface area, as postulated in the beginning of this argument, then the enhancement factor, $f_{\text {enhance, }}$ can be expressed as:

$$
f_{\text {enhance }}=\frac{\int_{x_{1}}^{x_{2}} \frac{f(x)}{x} d x}{\int_{x_{1}}^{x_{2}} f(x) d x} \div \frac{\int_{x_{3}}^{x_{4}} \frac{g(x)}{x} d x}{\int_{x_{3}}^{x_{4}} g(x) d x}
$$

All quantities related to particle shape and density cancel out, as long as they are the same for the resuspended particles as for the surface soil from which the particles originate.

\subsubsection{Enhancement Factor for Example Particle Size Distributions}

The soil particle size distribution function for the soil shown in Figure 6.5-4, based on the Amargosa Valley soil texture, is applicable in the particle size range from $2 \mu \mathrm{m}$ to $2000 \mu \mathrm{m}$. The contribution of clay particles (smaller than $2 \mu \mathrm{m}$ ) needs to be included in the surface-tomass ratio because they have the largest surface-to-mass ratio. The surface area of these particles can be estimated by assuming that the representative particle size is an average (1.25 $\mu \mathrm{m}$ ) for the range from 0.5 to $2 \mu \mathrm{m}$, where $0.5 \mu \mathrm{m}$ was chosen as a cut-off point for the coarse (mineral) fraction of suspended particulate matter (EPA 2004 [DIRS 175978], Figure 2-8), and that clay constitutes about $9 \%$ of the mass of Amargosa Valley soil (Table 6.5-2). (A discussion of the sensitivity of the results to the selection of the lower cut-off point is presented later in this section.) 
Mathcad calculations of the surface-to-mass ratio for the Amargosa Valley soils, SMRS, are shown in Figure 6.5-6. $S 1$ and $S 2$ represent surface area contributions from particles with diameters $x$ in the range $2 \mu \mathrm{m} \leq x \leq 2000 \mu \mathrm{m}$ and $0.5 \mu \mathrm{m} \leq x \leq 2 \mu \mathrm{m}$, respectively. $M 1$ and $M 2$ represent mass contributions for the same particle size ranges. The units of the surface-to-mass ratio calculated in such a manner are $\mu \mathrm{m}^{-1}$. The surface-to-mass ratio for the soil, SMRS, is calculated as a weighted mean of the surface-to-mass ratios of the clay particles and particles in the $0.5 \mu \mathrm{m} \leq x \leq 2000 \mu \mathrm{m}$ range, with the weights being the fractions of the clay and the larger-than-clay particles in surface soil.

Probability density function

$$
\mathrm{p}(\mathrm{x}):=\frac{\mathrm{d}}{\mathrm{dx}} \mathrm{P}(\mathrm{x})
$$

For soil particles $\geq 2 \mu \mathrm{m}$, i.e., larger than clay

$$
\begin{aligned}
& \mathrm{S} 1:=\int_{2}^{2000} \frac{\mathrm{p}(\mathrm{x})}{\mathrm{x}} \mathrm{dx} \quad \mathrm{S} 1=0.06 \\
& \mathrm{M} 1:=0.91
\end{aligned}
$$

For soil particles $0.5 \mu \mathrm{m} \leq \mathrm{x}<2 \mu \mathrm{m}$, i.e., clay

Average particle size is $1.25 \mu \mathrm{m}$

Amargosa Valley soils contain on average $9 \%$ of clay and $100 \%-9 \%=91 \%$ of larger particles

$$
\begin{aligned}
& \mathrm{S} 2:=\frac{0.09}{1.25} \quad \mathrm{~S} 2=0.07 \\
& \text { M2 := } 0.09
\end{aligned}
$$

Surface to mass ratio for soil, SMRS, is:

$$
\text { SMRS }:=0.91 \cdot \frac{\mathrm{S} 1}{\mathrm{M} 1}+0.09 \cdot \frac{\mathrm{S} 2}{\mathrm{M} 2} \quad \mathrm{SMRS}=0.13
$$

Source: Mathcad file Particle Size Distributions for Soil and TSP.mcd (Appendix A).

Figure 6.5-6. Mathcad Calculations of Surface-to-Mass Ratio for Amargosa Valley Soils

Mathcad calculations of surface-to-mass ratios, SMR1, SMR2, and SMR3, for the three example distributions of TSP shown in Figure 6.5-5, $f 1(x), f 2(x)$, and $f 3(x)$, representing the conditions when the soil is not being actively disturbed, are shown in Figure 6.5-7 (Mathcad file Particle Size Distributions for Soil and TSP.mcd in Appendix A).

The lower cut-off point of $0.5 \mu \mathrm{m}$ was selected to account for the coarse particle mode. As noted before (Section 6.5.1.2), atmospheric aerosols include particles in the sub-micrometer range (fine particle modes), but these particles originate from mechanisms other than dispersion of local soils. 


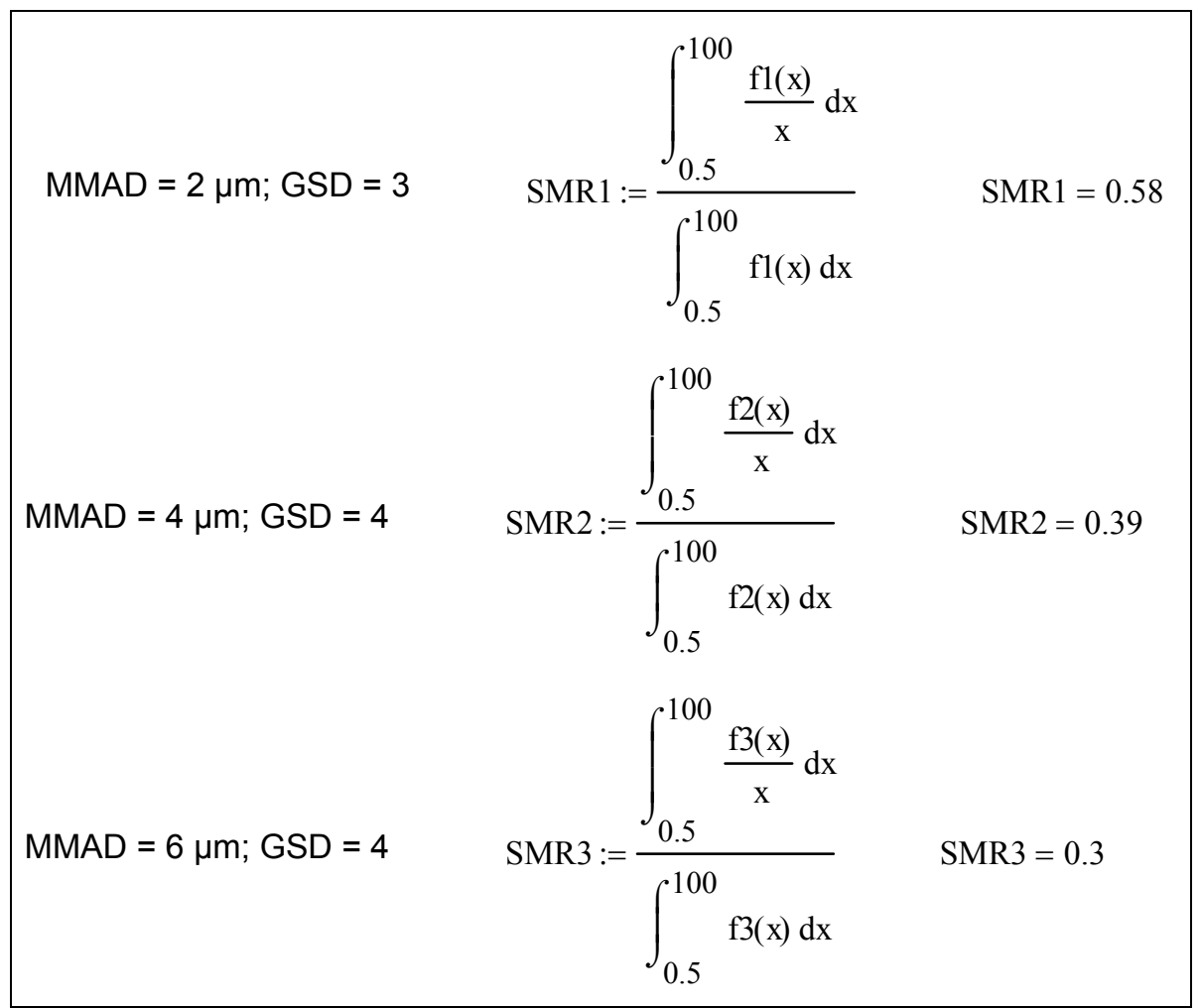

Source: Mathcad file Particle Size Distributions for Soil and TSP.mcd (Appendix A).

Figure 6.5-7. Mathcad Calculations of Surface-to-Mass Ratio for Particle Size Distributions for Undisturbed Soil

Some measurements indicate that atmospheric concentrations of particles in the 10 to $100 \mu \mathrm{g} \mathrm{m}^{-3}$ range are lognormally distributed with the MMAD of 10 to $30 \mu \mathrm{m}$ and a GSD of 2 (Lundgren and Burton 1995 [DIRS 177699], p. 131). Such distributions would produce a lower surface-tomass ratio than those shown in Figure 6.5-7.

Surface-to-mass ratios for the distributions $f 4(x)$ and $f 7(x)$, representing active soil disturbance conditions, are calculated in an analogous way to that shown in Figure 6.5-7 (Mathcad file Particle Size Distributions for Soil and TSP.mcd in Appendix A). The resulting surface to mass ratios are 0.07 and 0.16 for $f 4(x)$ and $f 7(x)$, respectively. For a bimodal distribution (functions $f 5(x)$ and $f 6(x)$ in Mathcad file Particle Size Distributions for Soil and TSP.mcd in Appendix A), contributions of both modes must be taken into account. In this case, surface-to-mass ratio for the individual modes is calculated analogous to the method shown in Figure 6.5-7. The total surface-to-mass ratio is then calculated as a weighted average of the surface-to-mass ratios for the modes, with the weights being fractions of the TSP mass in those modes calculated from the data in Table 1 of the report by Pinnick et al. (1985 [DIRS 159577]). The small mode contributes $42.5 \%$ of the TSP mass; the large mode contributes $57.5 \%$ of the mass. The upper integration limits for the small and large modes were selected at $100 \mu \mathrm{m}$ and $300 \mu \mathrm{m}$, respectively, which is consistent with the distributions of suspended mass shown in that reference (Pinnick et al. (1985 [DIRS 159577], Figure 4). The calculations of surface-to-mass 
ratio are illustrated in Figure 6.5-8 (Mathcad file Particle Size Distributions for Soil and TSP.mcd in Appendix A).

$$
\text { SMR56: }=0.425 \frac{\int_{0.5}^{100} \frac{f 5(x)}{x} d x}{\int_{0.5}^{100} f 5(x) d x}+0.575 \frac{\int_{10}^{300} \frac{f 6(x)}{x} d x}{\int_{10}^{300} f 6(x) d x} \quad \text { SMR56 }=0.06
$$

Source: Mathcad file Particle Size Distributions for Soil and TSP.mcd (Appendix A).

Figure 6.5-8. Mathcad Calculations of Surface-to-Mass Ratio for Bimodal Particle Size Distributions for Actively Disturbed Soil

Finally, the enhancement factors were calculated for all functions, as shown in Figure 6.5-9, as a ratio of the surface-to-mass ratio of suspended particulates to that of underlying soil. It can be seen that the enhancement factor for TSP with MMAD of $2 \mu \mathrm{m}$ is about 4.6, decreasing, as particle size increases, to about 2.4 for the 6- $\mu$ m MMAD particles. As the MMAD of suspended particulates increases even further, such as under dusty conditions in the active outdoors environment, the enhancement factor is around one or less than one, i.e., the radionuclide concentration in the bulk soil is generally higher than that in resuspended particulates.

\begin{tabular}{|c|c|c|c|}
\hline Undisturbed soil & & & \\
\hline $\begin{array}{l}\text { Enhancement factor for distribution } \mathrm{f} 1 \\
\mathrm{MMAD}=2 \mu \mathrm{m} ; \mathrm{GSD}=3\end{array}$ & $\mathrm{EF} 1:=$ & $\frac{\text { SMR1 }}{\text { SMRS }}$ & $\mathrm{EF} 1=4.48$ \\
\hline $\begin{array}{l}\text { Enhancement factor for distribution } \mathrm{f} 2 \\
\mathrm{MMAD}=4 \mu \mathrm{m} ; \mathrm{GSD}=4\end{array}$ & $\mathrm{EF} 2:=$ & $\frac{\text { SMR2 }}{\text { SMRS }}$ & $\mathrm{EF} 2=3$ \\
\hline $\begin{array}{l}\text { Enhancement factor for distribution } \mathrm{f} 3 \\
\mathrm{MMAD}=6 \mu \mathrm{m} ; \mathrm{GSD}=4\end{array}$ & $\mathrm{EF} 3:=$ & $\frac{\text { SMR3 }}{\text { SMRS }}$ & $\mathrm{EF} 3=2.36$ \\
\hline Actively disturbed soil & & & \\
\hline $\begin{array}{l}\text { Enhancement factor for distributions } \mathrm{f} 4 \\
\mathrm{MMAD}=49 \mu \mathrm{m} ; \mathrm{GSD}=4\end{array}$ & $\mathrm{EF} 4:=$ & $\frac{\text { SMR4 }}{\text { SMRS }}$ & $\mathrm{EF} 4=0.56$ \\
\hline $\begin{array}{l}\text { Enhancement factor for distributions } \mathrm{f} 5 \text { and } \mathrm{f} 6 \\
\text { bimodal: } \mathrm{MMAD}=10 \mu \mathrm{m} ; \mathrm{GSD}=2.1 \text { and } \\
\mathrm{MMAD}=88 \mu \mathrm{m} ; \mathrm{GSD}=1.6\end{array}$ & EF56:= & $=\frac{\text { SMR56 }}{\text { SMRS }}$ & $\mathrm{EF} 56=0.49$ \\
\hline $\begin{array}{l}\text { Enhancement factor for distribution } \mathrm{f} 7 \\
\mathrm{MMAD}=15 \mu \mathrm{m} ; \mathrm{GSD}=4\end{array}$ & $\mathrm{EF} 7:=$ & $\frac{\text { SMR7 }}{\text { SMRS }}$ & $\mathrm{EF} 7=1.28$ \\
\hline
\end{tabular}

Source: Mathcad file Particle Size Distributions for Soil and TSP.mcd (Appendix A).

Figure 6.5-9. Mathcad Calculations of Enhancement Factor for Various Distributions of Suspended Particulates for Average Amargosa Valley Soils 
The value of the surface-to-mass ratio for suspended particles, and thus the enhancement factor, depends on the characteristics of the particle size distribution of suspended particles. From the preceding discussion, it can be seen that the MMAD of the suspended particles is an important parameter; the GSD of the distribution, as well as the shape of the distribution in the small (silt and clay) particle size range, are also important. To investigate this effect, test cases were constructed by selecting different, yet reasonable, GSDs for suspended particles for the single-mode functions. In Test 1, the GSDs were decreased by one; in Test 2, GSDs were increased by one. The results are summarized in Table 6.5-5.

Table 6.5-5. Effect of GSD Change on the Value of Enhancement Factor

\begin{tabular}{|c|c|c|c|c|}
\hline Function & $\begin{array}{c}\text { MMAD } \\
\mu \mathrm{m}\end{array}$ & GSD & EF & Reference (Mathcad File Name) \\
\hline \multicolumn{5}{|c|}{ Undisturbed Soil } \\
\hline \multirow[t]{3}{*}{$f 1(x)$} & 2 & 3 & 4.5 & Particle Size Distributions for Soil and TSP.mcd \\
\hline & 2 & 2 & 4.6 & Particle Size Distributions for Soil and TSP_Test 1.mcd \\
\hline & 2 & 4 & 4.2 & Particle Size Distributions for Soil and TSP_Test 2.mcd \\
\hline \multirow[t]{3}{*}{$f 2(x)$} & 4 & 4 & 3.0 & Particle Size Distributions for Soil and TSP.mcd \\
\hline & 4 & 3 & 2.9 & Particle Size Distributions for Soil and TSP_Test 1.mcd \\
\hline & 4 & 5 & 3.0 & Particle Size Distributions for Soil and TSP_Test 2.mcd \\
\hline \multirow[t]{3}{*}{$f 3(x)$} & 6 & 4 & 2.4 & Particle Size Distributions for Soil and TSP.mcd \\
\hline & 6 & 3 & 2.1 & Particle Size Distributions for Soil and TSP_Test 1.mcd \\
\hline & 6 & 5 & 2.5 & Particle Size Distributions for Soil and TSP_Test 2.mcd \\
\hline \multicolumn{5}{|c|}{ Actively Disturbed Soil } \\
\hline \multirow[t]{3}{*}{$f 4(x)$} & 49 & 4 & 0.6 & Particle Size Distributions for Soil and TSP.mcd \\
\hline & 49 & 3 & 0.4 & Particle Size Distributions for Soil and TSP_Test 1.mcd \\
\hline & 49 & 5 & 0.8 & Particle Size Distributions for Soil and TSP_Test 2.mcd \\
\hline \multirow[t]{3}{*}{$f 7(x)$} & 15 & 4 & 1.3 & Particle Size Distributions for Soil and TSP.mcd \\
\hline & 15 & 3 & 1.0 & Particle Size Distributions for Soil and TSP_Test 1.mcd \\
\hline & 15 & 5 & 1.5 & Particle Size Distributions for Soil and TSP_Test 2.mcd \\
\hline
\end{tabular}

NOTE: $\quad$ Mathcad files are included in Appendix A.

Another parameter that has an effect on the enhancement factor is the lower cut-off diameter for the particle size distribution function, because small particles have the largest surface-to-mass ratio. Typically, particles that originate from soil have a lower bound diameter on the order of a few tenths of a $\mu \mathrm{m}$. A mathematical representation of particle size distribution function for suspended particles includes particle sizes that are outside the true distribution of suspended particles. In other words, particles that are very large or very small do not belong to such a distribution. To investigate the effect of the lower cut-off diameter selection on the enhancement factor, the calculations described in this section were repeated for the $0.1 \mu \mathrm{m}$ cut-off diameter. The results of these calculations, presented in Table 6.5-6, indicate that selection of the lower cut-off diameter has virtually no effect on the enhancement factor for the actively disturbed soil. However, it increases the enhancement factor for the undisturbed soil up to almost 7 for the distribution with a $2 \mu \mathrm{m}$ MMAD.

The enhancement factor is also strongly dependent on the soil texture, as explained in the following section. 
Table 6.5-6. Effect of GSD Change on the Value of Enhancement Factor

\begin{tabular}{|c|c|c|c|c|c|}
\hline Function & $\begin{array}{c}\text { MMAD } \\
\mu \mathrm{m}\end{array}$ & GSD & $\begin{array}{c}\text { Lower } \\
\text { Cut-off } \\
\mu \mathrm{m}\end{array}$ & $E F$ & Reference \\
\hline \multicolumn{6}{|c|}{ Undisturbed Soil } \\
\hline \multirow[t]{2}{*}{$f 1(x)$} & \multirow[t]{2}{*}{2} & \multirow[t]{2}{*}{3} & 0.5 & 4.5 & Particle Size Distributions for Soil and TSP.mcd \\
\hline & & & 0.1 & 6.8 & Particle Size Distributions for Soil and TSP_Test 3.mcd \\
\hline \multirow[t]{2}{*}{$f 2(x)$} & \multirow[t]{2}{*}{4} & \multirow[t]{2}{*}{4} & 0.5 & 3.0 & Particle Size Distributions for Soil and TSP.mcd \\
\hline & & & 0.1 & 4.6 & Particle Size Distributions for Soil and TSP_Test 3.mcd \\
\hline \multirow[t]{2}{*}{$f 3(x)$} & \multirow[t]{2}{*}{6} & \multirow[t]{2}{*}{4} & 0.5 & 2.4 & Particle Size Distributions for Soil and TSP.mcd \\
\hline & & & 0.1 & 3.3 & Particle Size Distributions for Soil and TSP_Test 3.mcd \\
\hline \multicolumn{6}{|c|}{ Actively Disturbed Soil } \\
\hline \multirow[t]{2}{*}{$f 4(x)$} & \multirow[t]{2}{*}{49} & \multirow[t]{2}{*}{4} & 0.5 & 0.6 & Particle Size Distributions for Soil and TSP.mcd \\
\hline & & & 0.1 & 0.6 & Particle Size Distributions for Soil and TSP_Test 3.mcd \\
\hline \multirow[t]{2}{*}{$f 5(x)$} & \multirow{2}{*}{$\begin{array}{l}10 \text { and } \\
88\end{array}$} & \multirow{2}{*}{$\begin{array}{l}2.1 \text { and } \\
1.6\end{array}$} & 0.5 & 0.5 & Particle Size Distributions for Soil and TSP.mcd \\
\hline & & & 0.1 & 0.5 & Particle Size Distributions for Soil and TSP_Test 3.mcd \\
\hline \multirow[t]{2}{*}{$f 7(x)$} & \multirow[t]{2}{*}{15} & \multirow[t]{2}{*}{4} & 0.5 & 1.3 & Particle Size Distributions for Soil and TSP.mcd \\
\hline & & & 0.1 & 1.5 & Particle Size Distributions for Soil and TSP_Test 3.mcd \\
\hline
\end{tabular}

NOTE: $\quad$ Mathcad files are included in Appendix A.

\subsubsection{Development of Parameter Distribution}

The enhancement factor that results from preferential sorption of contaminant to fine soil particles is not unique to radioactive contaminants. It has been recognized in the context of assessment of exposure to other pollutants that exhibit a similar behavior, i.e., undergo adsorption onto the surface of soil particles (DEFRA 2002 [DIRS 177376], p. 55). Artificial dust-raising experiments conducted at nuclear test sites in Australia showed that fine particle sizes usually had a greater activity per unit mass than did the bulk soil at a site (Johnston et al. 1992 [DIRS 177227], p. 634); the same results were obtained when soil particles less than $45 \mu \mathrm{m}$ in diameter were compared to the bulk soil (Johnston et al. 1992 [DIRS 177227], p. 634).

The enhancement factor was used in the Contaminated Land Exposure Assessment Model (CLEA) developed under the auspices of the British Department for Environment, Food and Rural Affairs and the Environmental Agency. In the technical basis report for this model it is noted that while the enhancement effect is increasingly recognized in the literature, there has been little documented about how to quantify such effects (DEFRA 2002 [DIRS 177376], p. 55). The CLEA model uses default values based on the experimental study of soil adhesion to skin by Sheppard and Evenden (1994 [DIRS 177467]). The enhancement factors used in that model (referred to as enrichment factors) are higher for coarse-grained sandy soils and decrease for the fine-textured soils. This is because sandy soils begin with a smaller proportion of silt and clay particles, leading to the concentrating effect being more pronounced (DEFRA 2002 [DIRS 177376], p. 56).

The values of enhancement factor used in the CLEA model are 6 for sandy soils, 3 for loam, 1.5 for clay, and 1 for organic soils (DEFRA 2002 [DIRS 177376], Table 5.2). These values agree with the enhancement factors under the conditions of no active soil disturbance calculated in Section 6.5.3.4 for the representative TSP distributions. From these calculations, for the particles 
with MMAD in the range from 2 to $6 \mu \mathrm{m}$, the typical range for undisturbed conditions, the enhancement factor was in the range from about 2.1 to 6.8 (Tables 6.5-5 and 6.5-6). For the average MMAD of $4 \mu \mathrm{m}$, the enhancement factor is in the range from 2.9 to 4.6. Therefore, an enhancement factor of 4 (an average rounded up to the nearest integer) is recommended as a mode of a triangular distribution of the enhancement factor for the conditions of no active soil disturbance for the groundwater exposure scenario. The upper limit of 7 (highest value in Table 6.5-6), and the lower limit of 2 (Table 6.5-5) are recommended. This range also accounts for uncertainties due to the distribution of soil particle sizes and is corroborated by the enhancement factor values used in the CLEA model.

The calculations in Section 6.5.3.4 indicate that when soil is actively disturbed and the MMAD of suspended particulates increases, a reduction of contaminant concentration in airborne particulates relative to that of bulk soil occurs. The enhancement factor varies from 0.4 to 1.5 (Table 6.5-5). Based on these values it is recommended that a triangular distribution be used to represent the enhancement factor for the undisturbed soil with a minimum of 0.4 , mode of 1 (no enhancement), and a maximum value of 1.5. This distribution accounts for uncertainties in the particle size distribution of suspended particulates.

\subsubsection{Summary of the Recommendations}

The summary of the enhancement factor recommendations is presented in Table 6.5-7. In cases where deterministic values are required for estimating purposes, the mode of distributions for the groundwater exposure scenario and geometric mean of distributions for the volcanic ash exposure scenario, defined in Table 6.5-7, should be used.

Table 6.5-7. Distribution Parameters for the Enhancement Factor

\begin{tabular}{|c|c|c|c|c|c|}
\hline Environment & Distribution & \multicolumn{4}{|c|}{ Enhancement Factor (dimensionless) } \\
\hline \multicolumn{6}{|c|}{ Groundwater Exposure Scenario } \\
\hline & & Mode & Low Bound & High Bound & \\
\hline Active outdoors & Triangular & 1 & 0.4 & 1.5 & \\
\hline $\begin{array}{l}\text { Inactive outdoors } \\
\text { Active indoors } \\
\text { Asleep indoors }\end{array}$ & Triangular & 4 & 2 & 7 & \\
\hline \multicolumn{6}{|c|}{ Volcanic Ash Exposure Scenario } \\
\hline & & $\begin{array}{c}\text { Geometric } \\
\text { Mean }\end{array}$ & $\begin{array}{l}\text { Geometric } \\
\text { Standard } \\
\text { Deviation }\end{array}$ & Low bound & High bound \\
\hline Active outdoors & Lognormal & 1.2 & 2.0 & 0.3 & 4.6 \\
\hline $\begin{array}{l}\text { Inactive outdoors } \\
\text { Active indoors } \\
\text { Asleep indoors }\end{array}$ & Lognormal & 2.9 & 1.8 & 0.9 & 9.4 \\
\hline
\end{tabular}




\subsection{VOLUMETRIC WATER CONTENT OF SOIL}

The process of leaching contaminants from surface soil is described in the biosphere model using the expression developed by Baes and Sharp (1983 [DIRS 109606]) and reproduced in this report in Equation 6.1-2. One of the parameters used in this equation is the volumetric water content of soil. From the theoretical standpoint, volumetric water content of soil can assume any value between zero (complete desiccation) and the total available porosity (saturation of all pore space) (Baes and Sharp 1983 [DIRS 109606], p. 19). The maximum quantity of water the soil can hold is expressed as the volumetric water content at field capacity. The actual quantity of water in soil at any time is a function of physical properties of soil as well as the environmental variables (Baes and Sharp 1983 [DIRS 109606], p. 20). Another term used to describe the amount of water in the soil is the wilting point, which quantifies the water content of soil at the point when capillary water becomes unavailable to plants. Baes and Sharp note that, for their model, any volumetric water content between field capacity and wilting point is probable for agricultural soils (Baes and Sharp 1983 [DIRS 109606], p. 20).

The most common soil type farmed in Amargosa Valley is sandy loam (Section 6.2). The volumetric water content for sandy loam soil at wilting point and at field capacity were provided by Baes and Sharp (1983 [DIRS 109606], p. 20). These data are reproduced in Table 6.6-1.

Table 6.6-1. Volumetric Water Content at Field Capacity and Wilting Point for Sandy Loam Soil

\begin{tabular}{|l|c|c|c|}
\hline & Midpoint & Lower Limit & Upper Limit \\
\hline Field capacity & 0.22 & 0.124 & 0.329 \\
\hline Wilting point & 0.08 & 0.029 & 0.158 \\
\hline
\end{tabular}

Source: Baes and Sharp 1983 [DIRS109606], p. 20.

NOTE: $\quad$ Midpoint values were hand-calculated from the mean of the logarithms of the observed values provided in the source reference.

The soil water content is used in the biosphere model to calculate the leaching rate constant, which was discussed earlier in Section 6.1 (Equation 6.1-2), which is then used to calculate radionuclide concentration in surface soil (Equation 6.1-1). From Equations 6.1-1 and 6.1-2, it can be shown that the contaminant concentration in soil is proportional to the term $\left[\theta\left(1+\rho K d_{i} / \theta\right)\right]$. From Section 6.2, the bulk density of surface soil, $\rho$, has a mean value of $1.5 \mathrm{~g} \mathrm{~cm}^{-3}\left(1.5 \times 10^{3} \mathrm{~kg} \mathrm{~m}^{-3}\right)$; from Table $6.6-1$, the midpoint of water content at field capacity, $\theta$, is 0.22 . If an element has a partition coefficient, $K d_{i}$, of $10 \mathrm{~L} \mathrm{~kg}^{-1}\left(10^{-2} \mathrm{~m}^{3} \mathrm{~kg}^{-1}\right)$ or more, as is the case for all elements considered in this analysis except chlorine, iodine, and technetium (Table 6.3-6), then the term $\rho K d_{i} / \theta(\approx 65)$ in Equation 6.1-2 is much greater than unity and the parenthetical term $\left(1+\rho K d_{i} / \theta\right)$ can be replaced, without significant error, by $\rho K d_{i} / \theta$. In this case, the $\theta$ term cancels and the leaching rate is independent of the soil water content (see Table 6.6-2, where the $\left[\theta\left(1+\rho K d_{i} / \theta\right)\right]$ term is calculated for different values of the partition coefficient, and the Excel file Calcs for Water Content.xls in Appendix A). Any small resulting error can be considered to be accommodated by the uncertainty in the partition coefficient. 
Table 6.6-2. Calculations of the Term $\left[\theta\left(1+\rho K d_{i} / \theta\right)\right]$ in Support of the Volumetric Water Content Analysis

\begin{tabular}{|c|c|c|c|c|c|}
\hline \multirow[b]{2}{*}{ Element } & \multirow{2}{*}{$\begin{array}{c}\text { Partition } \\
\text { Coefficient }\left(K d_{i}\right)\end{array}$} & $\begin{array}{c}\text { Wilting Point } \\
\text { Midpoint }\end{array}$ & $\begin{array}{l}\text { Field Capacity } \\
\text { Midpoint }\end{array}$ & $\begin{array}{l}\text { Lower Limit for } \\
\text { Wilting Point }\end{array}$ & $\begin{array}{l}\text { Upper Limit for } \\
\text { Field Capacity }\end{array}$ \\
\hline & & \multicolumn{4}{|c|}{ Volumetric Water Content, $\boldsymbol{\theta}^{\text {a }}$} \\
\hline & & 0.08 & 0.22 & 0.029 & 0.329 \\
\hline & & \multicolumn{4}{|c|}{ Value of the Term $\left[\theta\left(1+\rho K d_{i} / \theta\right)\right]^{\mathrm{b}}$} \\
\hline Technetium & $0.14^{c}$ & 0.29 & 0.43 & 0.24 & 0.54 \\
\hline Iodine & $4.5^{c}$ & 6.83 & 6.97 & 6.78 & 7.08 \\
\hline Hypothetical case \#1 & 10 & 15.08 & 15.22 & 15.03 & 15.33 \\
\hline Hypothetical case \#2 & 100 & 150.08 & 150.22 & 150.03 & 150.33 \\
\hline
\end{tabular}

a From Table 6.6-1.

b Soil density, $\rho=1.5 \mathrm{~g} \mathrm{~cm}^{-3}\left(1.5 \times 10^{3} \mathrm{~kg} \mathrm{~m}^{-3}\right)$ from Section 6.2 .

${ }^{c}$ Partition coefficients for technetium and iodine were taken from Table 6.3-6.

NOTE: Calculations are in the Excel file Calcs for Water Content.xls (Appendix A).

In cases where the partition coefficient is small, as is the case for technetium, and possibly iodine and chlorine, the approximation above does not apply (for technetium, $\rho K d_{i} / \theta \approx 0.9$ ). In this case, the value used for the water content of the soil has an effect on the value of the leaching rate and, consequently, on the concentration of these elements in surface soil. For these elements, leaching is the dominant mechanism of contaminant removal from surface soil. Calculations of the $\left[\theta\left(1+\rho K d_{i} / \theta\right)\right]$ term for technetium and iodine are shown in Table 6.6-2 (also see Excel file Calcs for Water Content.xls in Appendix A). With the other variables being equal, the surface soil concentration is higher for the greater values of the volumetric water content of soil.

Because agricultural fields and gardens in Amargosa Valley must be irrigated frequently to maintain healthy crops, soil water content is usually at or near field capacity. Therefore, it is recommended that the volumetric water content at field capacity be used in the biosphere model as the soil water content. Field capacity water content is defined as the water content remaining in soils after complete saturation (such as would occur after flood irrigation or prolonged heavy precipitation) and at the time that all free drainage has ceased (Brady and Weil 1999 [DIRS 160019], Section 5.8). After free drainage has ceased, the soil micropores or capillary pores remain filled with water, but water has moved out of the macropores due to gravitational forces.

Direct measurement of volumetric water content at field capacity is not a routine analysis in standard USDA soil survey procedures, and this information was not available for the major soil series considered in this analysis. However, the site-specific data on available water capacity of soils are provided in Soil Survey of Nye County, Nevada, Southwest Part (USDA 2004 [DIRS 173916], Part II, Table 12). These data are reproduced in Table 6.2-2. The available water capacity, defined as the quantity of water that the soil can store for use by plants, is different from the water content at field capacity that quantifies the overall amount of water the soil can hold, regardless of its availability to plants. Because of physical forces that bind water to soil, not all the water present in soil is available for use by plants. Allen et al. (1998 [DIRS 157311], Equation 82) give the relationship between the available water capacity and 
field capacity. The available water content is the water content at field capacity less the water content at the plant wilting point. This latter parameter is a measure of the soil water content that the plant is unable to avail itself of.

The range of values of available water content for the soils occurring in Amargosa Valley is from 0.04 to 0.13 (USDA 2004 [DIRS 173916], Part II, Table 12; see Table 6.2-2). Allen et al. (1998 [DIRS 157311], Table 19) provide the expected generic range of soil water capacity at wilting point (crop dependent) of 0.06 to 0.16 for sandy loams. Using a midpoint of 0.11 from the range of wilting points for sandy loams from the reference by Allen et al. (1998 [DIRS 157311], Table 19), the water content at field capacity is in the range from 0.15 to 0.24 . The mean value for this range is 0.20 .

Generic data for soil water content at field capacity are provided by Allen et al. (1998 [DIRS 157311], Table 19). These values are reproduced in Table 6.6-3 and provide ranges for water content at field capacity for a range of soils, some of which are found in Amargosa Valley. The data show that as the soil under consideration changes from sand to loam (i.e., towards smaller particles with fewer macropores), the lower and upper limits of water content at field capacity increase. The soil water content at field capacity for sandy loam soils ranges from 0.18 to 0.28 . These values agree well with the values based on site-specific information.

Table 6.6-3. Soil Water Content at Field Capacity

\begin{tabular}{|l|c|c|}
\hline \multirow{2}{*}{ Soil Type } & \multicolumn{2}{|c|}{ Soil Water Content at Field Capacity $\left(\mathrm{m}^{\mathbf{3}} \mathrm{m}^{-3}\right)$} \\
\cline { 2 - 3 } & Lower Limit & Upper Limit \\
\hline Sand & 0.07 & 0.17 \\
\hline Loamy Sand & 0.11 & 0.19 \\
\hline Sandy Loam & 0.18 & 0.28 \\
\hline Loam & 0.20 & 0.30 \\
\hline
\end{tabular}

Source: Allen et al. 1998 [DIRS 157311], Table 19.

The soil water content at field capacity developed based on the site-specific data and generic data encompasses a wider range of values and sufficiently accounts for the uncertainties in the value of this parameter and is, therefore, adequate for the intended purpose. The recommended range of values for the soil water content is 0.15 to 0.28 with a uniform distribution over the defined range. If a deterministic value for the soil water content is required then a value of 0.20 should be used.

\subsection{IRRIGATION DURATION}

The surface soil submodel of the biosphere model (BSC 2004 [DIRS 169460], Section 6.4.1) represented irrigation as a process occurring continuously until the equilibrium radionuclide concentration in surface soil was established. Such a representation did not account for the actual agricultural land use characteristics of Amargosa Valley. This resulted in a model that was reasonable for those elements with high mobility in the environment, irrespective of the time frames involved, but very conservative for highly-sorbing immobile elements and long time frames. The updated surface soil model adopts a representation of land use appropriate for the Amargosa Valley area (BSC 2006 [DIRS 176938], Sections 1 and 2). 
The purpose of this analysis is to evaluate irrigation practices with respect to land management and sustainability of agriculture as well as social factors characteristic of the local population and, if appropriate, to develop parameters that quantify long-term irrigation duration.

\subsubsection{Regulatory Basis}

The two regulatory concepts applicable to this analysis are those that define the required characteristics of the reference biosphere and the RMEI. Reference biosphere means the description of the environment inhabited by the RMEI (10 CFR 63.2 [DIRS 173164]). In this context, the reference biosphere is the modeling domain representing, in the performance assessment model, the accessible environment (biosphere) where the RMEI can receive radiation doses from radionuclide releases from the repository.

Required characteristics of the reference biosphere are the following (10 CFR 63.305 [DIRS 173164]):

- Features, events, and processes that describe the reference biosphere must be consistent with present knowledge of the conditions in the region surrounding the Yucca Mountain site.

- DOE should not project changes in society, the biosphere (other than climate), human biology, or increases or decreases of human knowledge or technology. In all analyses done to demonstrate compliance with this part, DOE must assume that all of those factors remain constant as they are at the time of submission of the license application.

- DOE must vary factors related to the geology, hydrology, and climate based upon cautious, but reasonable assumptions consistent with present knowledge of factors that could affect the Yucca Mountain disposal system during the period of geologic stability and consistent with the requirements for performance assessments specified at $\S 63.34$.

- Biosphere pathways must be consistent with arid or semi-arid conditions.

The RMEI is a hypothetical receptor that meets the following criteria (10 CFR 63.312 [DIRS 173164]):

- Lives in the accessible environment above the highest concentration of radionuclides in the plume of contamination.

- Has a diet and living style representative of people who now reside in the Town of Amargosa Valley, Nevada. DOE must use projections based on surveys of the people residing in the Town of Amargosa Valley, Nevada, to determine their current diets and living styles and use the mean values of these factors in the assessments conducted for 10 CFR 63.311 and 10 CFR 63.321.

- Uses well water with average concentrations of radionuclides based on an annual water demand of 3,000 acre-feet. 
- Drinks 2 liters of water per day from wells drilled into the groundwater from a point above the highest concentration of radionuclides in the plume of contamination.

- Is an adult with metabolic and physiological considerations consistent with present knowledge of adults.

The current biosphere model is designed to produce the results expressed in terms of the annual dose to the RMEI, consistent with the format of the individual exposure standard (10 CFR 63.311 [DIRS 173164]). Therefore, many biosphere model input parameters that quantify lifestyle and diet of the RMEI are expressed as annual average values. The current lifestyle of the Amargosa Valley population includes some characteristics that could be categorized as descriptions of population dynamics. These include the current rates of change in building occupancy, as well as the current population mobility and the pattern of land use. These characteristics, representing the current conditions, rather than projections of future societal changes, are discussed in Section 6.7.3 and subsequently used to develop the long-term irrigation durations for the biosphere model.

\subsubsection{Evaluation of Physical Limitations on Agricultural Practices}

The evaluation of some physical limitations on agricultural practices was investigated as a part of this analysis and is described in the report by Bland (2006 [DIRS 177219], pp. 1 to 6). This section summarizes the findings of that evaluation.

It is believed that the primary physical limitations on duration of irrigation and usefulness of the fields in the Amargosa Valley are sufficient water, fertility of the soil, and salinity of the soil. The evaluation concentrated on buildup of salts in soil as a result of current practices because availability of water and soil fertility were shown not to be limiting factors.

The questions asked were (1) whether under current practices, or best management practices, irrigation is deliberately limited, such as allowing fields to lie fallow for a year or two and (2) whether under current practices the soil can be expected to become unproductive due to increased salinity. These questions were asked for commercial fields and for home gardens.

To answer these questions, a literature search was conducted to determine whether historical increases in salinity have occurred and whether historical antecedents or current farming experience in similar climates could be applied to the Amargosa Valley area. Then, telephone calls were made to local experts who are knowledgeable about Amargosa Valley farming practices.

\subsubsection{Results of Literature Search}

Desertification, or degradation of arable land in arid or semi-arid areas, can be caused by several factors, including erosion, depletion of groundwater, off-road vehicle damage, overgrazing, and salinization of the soil (Dregne 1983 DIRS 177445], pp. 29-35). Of these, salinization is potentially of concern in the Amargosa Valley.

There is evidence of salinization occurring for thousands of years in arid and semi-arid regions around the world. In many instances, accumulation of salts in soil led to drastic changes in 
agricultural practices, including replacing less salt-tolerant crops with the more salt-tolerant types and, in the extreme cases, abandonment of the degraded fields. Salinization of the soil is usually brought on by either poor drainage or insufficient overwatering that allows salts to accumulate in the root zone or on the surface. Arid and semi-arid areas are particularly affected because of high evapotranspiration and insufficient rainfall to remove salts from the soil. However, salinization can be mitigated and actions can be taken to maintain productivity. These mitigation methods include irrigation techniques appropriate for a given site and type of soil to prevent accumulation by promoting removal of salts from the plat root zone or by controlling water application. These include better ways to accurately water and fertilize fields in a manner consistent across the targeted field, use of drip irrigation (as opposed to spray irrigation) to minimize water usage, use of drainage, and other methods (Dregne 1983 [DIRS 177445], Section 5). Formulas have been developed that incorporate evapotranspiration (ET), amount of rainfall, and conductivity of the soil (BSC 2004 [DIRS 169673], Section 6.9 and Appendix E) to calculate the amount of irrigation necessary to avoid accumulation of salts in arable soils.

Within Nevada, the Nevada Division of Environmental Protection has developed a Best Management Practices Handbook (NDEP 1994 [DIRS 176309]) that includes agricultural land management recommendations. The recommendations pertain to having a site-specific, professionally designed irrigation system for proper irrigation water management. Further, the farmer should "schedule irrigations to meet crop requirements plus a minimum leaching fraction" (NDEP 1994 [DIRS 176309], p. 7-3).

\subsubsection{Interviews with Local Experts}

As a part of the evaluation of potential limitations on agricultural practices, interviews were conducted with two organizations expected to have knowledge of farming conditions and agricultural practices in Southern Nevada, most specifically the Amargosa Valley area. These organizations were USDA NRCS, Las Vegas, and University of Nevada Cooperative Extension (UNCE), Las Vegas . The list of questions asked and the contacts within organizations are given in the report by Bland (2006 [DIRS 177219]). The findings presented in this section are also largely taken from that report.

Local experts believed that there was little or no reason for physical limitations on the growth of field crops or home garden crops with regard to salinity caused by irrigation. The NRCS representative pointed out that alfalfa is the primary crop. Alfalfa is a perennial and is irrigated year round, although crops are periodically rotated. A typical rotation starts with the planting of alfalfa. The crop is allowed to grow and is cut for animal feed, each field providing approximately seven cuttings per year. Irrigation is by sprinkler, principally center pivot. Every three to four years a different set of crops is planted. Generally, in the fall the field is disked and winter forage crops are planted. These are small grain annual crops, such as wheat, rye, or oats. These are cut green for animal feed. In the spring, forage sorghum is planted and there are three to four cuttings of this during the summer. In the fall, alfalfa is re-planted and the cycle begins anew. During this process, fields are not typically taken out of circulation (i.e., lie fallow).

With regard to the duration that the fields could remain productive in light of possibilities of salinization, both the NRCS and UNCE interviewees responded that they did not see salinization as an issue in the Amargosa Valley. It was noted that the water quality was good and that 
overwatering the crops would allow leaching of the salt. This would be consistent with Nevada's Best Management Practices Handbook (NDEP 1994 [DIRS 176309], p. 7-3), as discussed above. A study by the U.S. Geological Survey (Stonestrom et al. 2003 [DIRS 165862], p. 1) has shown that deep percolation and groundwater recharge occurred beneath areas of irrigation, so there was no impermeable layer that could cause the area to become waterlogged. Both interviewees confirmed that water quality was good, and that build-up of salinity was not an issue under good land management.

Good land management practices notwithstanding, the problem of salinization is still occurring in the United States and is common in nearly all of irrigated regions (Dregne 1983 [DIRS 177445], p. 199). It is estimated that two-thirds of the arid regions in North America are moderately desertified and less than one-third is severely desertified. Desertification is the degradation of land in arid, semi-arid and dry sub-humid areas resulting from various factors including climate and human activities. On this type of land, agriculture is possible when the land is irrigated, but human activities may stress the ecosystem beyond its tolerance limits. The Yucca Mountin region is an example of such an arid to semi-arid ecosystem. The introduction of sprinkler irrigation systems, especially the center pivot systems common in Amargosa Valley, enabled the previously unsuitable soils to be successfully farmed. However, if and when those soils are abandoned, because of water shortage or economic or social factors, there is a potential for an accelerated erosion of such lands because abandoned fields lack natural ground cover that limits erosion (Dregne 1983 [DIRS 177445], p. 204 to 206).

Desertification is occurring to various degrees in many regions in the Southwestern United States, for example, in San Joaquin Valley and Imperial Valley in California (Dregne 1983 [DIRS 177445], p. 204). These areas have rich soils and belong to one of the most productive regions in the world, so one would expect that good land management should be essential for maintainig this productivity. Considering the overall magnitude of desertification (it is estimated that nearly $90 \%$ of arid lands in North America are moderatly and severly desertified; see Dregne 1983 [DIRS 177445], p. 206), it is reasonable to expect that degradation of arable land will also occur to some extent in Amargosa Valley. The reasons for failing to prevent desertification from occurring is the emphasis on short-term versus long-term benefits, inability to finance improvments, and lack of direct evidence that desertification control is profitable in the immediate future (Dregne 1983 [DIRS 177445], p. 209).

\subsubsection{Evaluation of Local Agricultural Practices and Related Social Limitations}

This section examines whether social issues could be expected to affect farming or home garden practices.

History of Amargosa Valley Settlement-The history of agriculture in Amargosa Valley is relatively recent (less than 100 years). The first pioneers arrived in the second half of the 19th century and settled in Ash Meadows, the area where there are natural discharges of groundwater from springs and seeps. This grassland supported the first free range cattle operation in the 1870s (McCracken 1992 [DIRS 177198], p. 15). The wells were relatively shallow and until the availability of pumping technology, water had to be hauled to the surface and transported manually to the point of need (Lee et al. 2005 [DIRS 177197], p. 27). Irrigation-based agriculture arrived into the area with the establishment of the 10-acre T\&T Ranch in 1915 
to 1917 (Lee et al. 2005 [DIRS 177197], p. 36). However, the modern development of agriculture did not occur until electric power was turned on in the Valley in 1963 (McCracken 1992 [DIRS 177198], p. 63), which reduced the cost of pumping water and made the area more attractive for people to settle in.

Tenure and Mobility Status of the Local Population-Much of the Amargosa Valley population is generally new to the area and transient. The 1997 food consumption survey included a question on how long a respondent lived in the area (DOE 1997 [DIRS 100332], p. B-3). The answers to this question are shown graphically in Figure 6.7-1 (see Excel file AV Data_Life Style.xls in Appendix A). Figure 6.7-1 shows that most of the population had moved into the area 10 years, or less, before the survey. Among the survey respondents, nobody moved into the area more than 40 years before the time of the survey.

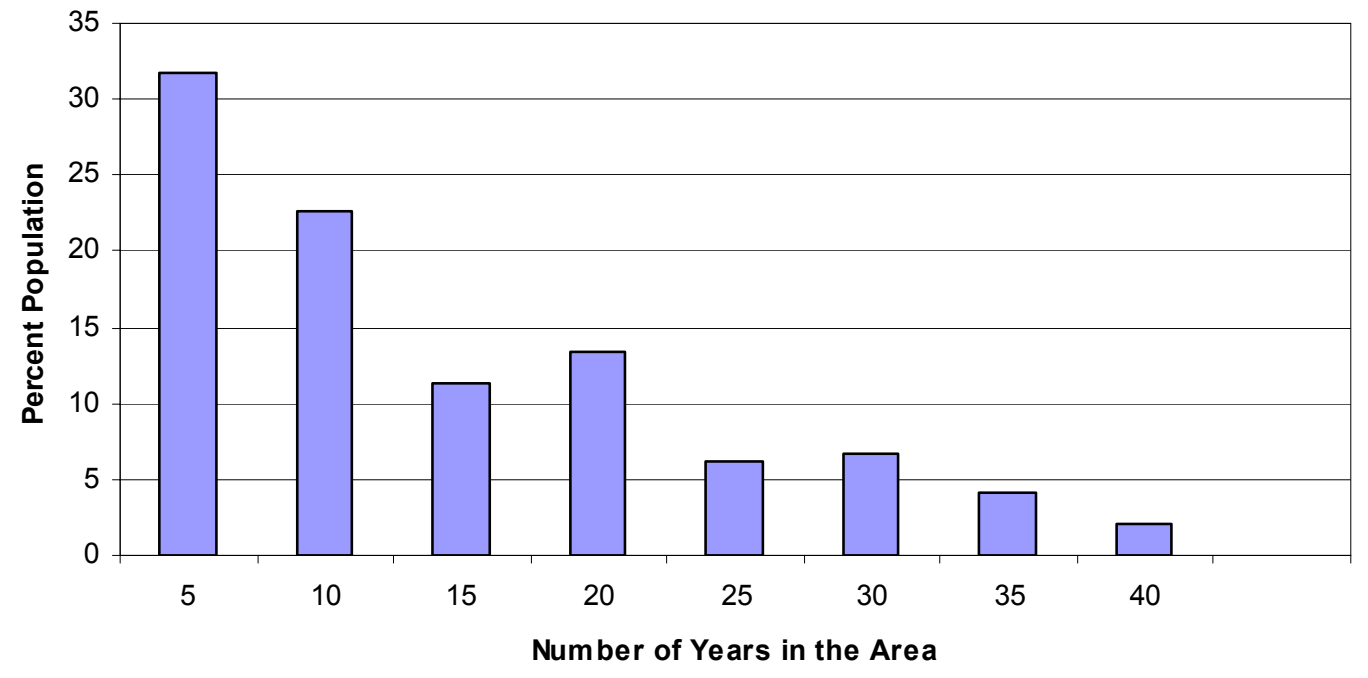

Source: DTN: MO0010SPANYE00.001 [DIRS 154976].

NOTE: Histogram was produced in Excel file AV Data_Life Style.xls (Appendix A).

Figure 6.7-1. Population Tenure in Amargosa Valley in 1997

At the time of the 2000 Census, there were 422 occupied housing units in Amargosa Valley; 280 houses $(66 \%)$ were occupied by owners, while 142 houses (34\%) were renter occupied (Bureau of the Census 2002 [DIRS 177451], Table H7). For the 280 owner-occupied housing units, 55\% of residents had moved into that structure the decade leading up to the census. Of the 142 renter-occupied houses in 2000, all tenants had moved into those structures during the previous decade, $30 \%$ had moved in within 15 months of the 2000 Census, and $75 \%$ of those had begun their tenancy within five years of the census (Bureau of the Census 2002 [DIRS 177451], Table H38).

Overall, $55 \%$ of all residents moved to a different house in the previous five years (Bureau of the Census 2002 [DIRS 177451], Table P115). The median year that a householder moved into a housing unit was 1991 for owner-occupied homes and 1997 for renter-occupied homes (Bureau of the Census 2002 [DIRS 177451], Table H39). The above data indicate a relatively high 
mobility of the Amargosa Valley population. Further evidence of this population mobility is reflected in the growth of the Amargosa Valley population from 724 in 1990 (Bureau of Census 2000 [DIRS 173531], Table P001) to 1,142 in 2000 (Bureau of the Census 2002 [DIRS 177451], Table H15), an annualized rate of nearly $5 \%$.

Housing in Amargosa Valley - Of the 195 Amargosa Valley houses included in the survey (DOE 1997 [DIRS 100332]), 37 houses (19\%) were conventional homes and 155 (79\%) were mobile/trailer homes (DTN: MO0010SPANYE00.001 [DIRS 154976]; see Excel file $A V$ Data_Life Style.xls included in Appendix A, where the data are reproduced).

Among owner-occupied homes, there were no units built before the 1950s; among renter-occupied homes there were no units built before the 1960s (the data bins in the source reference encompass a decade) (Bureau of the Census 2002 [DIRS 177451], Table H36). Over $20 \%$ of homes were vacant (114 of 536 housing units) (Bureau of the Census 2002 [DIRS 177451], Table H6).

Employment Status and Occupation-According to the 2000 Census, of an estimated total of 862 residents 16 years of age or older, $338(39.2 \%)$ were not in the work force in 1999 (Bureau of the Census 2002 [DIRS 159728], Table P47). This group consists of adults who were unemployed or not in the labor force, including retired persons. Of the 524 working residents, only 26 people were working in agriculture (Bureau of the Census 2002 [DIRS 159728], Table P49), which indicates that only a small fraction of Amargosa Valley residents are professionally involved in farming. The remainder of the employed population works in another occupation and is involved in farming only on a part-time basis, if at all.

Land and Groundwater Use in Amargosa Valley - The depth to the water table in Amargosa Valley varies from less than $20 \mathrm{ft}$. in the Ash Meadows area to more than $300 \mathrm{ft}$. farther north, near the location of the RMEI (Kilroy 1991 [DIRS 103010], Figure 4). Agricultural development is currently confined to the southern portion of the Amargosa Valley where groundwater depths range from 33 to $130 \mathrm{ft}$. below the ground surface (Lee et al. 2005 [DIRS177197], p. 54). Ash Meadows, located south-east of Amargosa Valley, is unavailable for development due to establishment of the Ash Meadows Wildlife Refuge in 1984; the greater depth to water table in the northern portion of Amargosa Valley combined with the more complex terrain make it less desirable for agriculture.

Most of Amargosa Valley residents live in widely spaced farms, ranches, and single-family homes and derive almost all of their water from wells (Lee et al. 2005 [DIRS 177197], p. 54). There is a small agricultural industry in Amargosa Valley, confined to the southern portion of the Valley. Approximately 2,000 acres are commercially farmed, of which more than $90 \%$ is planted in alfalfa or other hay (YMP 1999 [DIRS 158212], Tables 10 and 11; CRWMS M\&O 1998 [DIRS 103210], Tables 3-10 and 3-11; CRWMS M\&O 1997 [DIRS 101090], Tables 3-12 and 3-13). Small grains, pistachios, grapes, orchard crops, garlic, and onions are also grown commercially (YMP 1999 [DIRS 158212], Tables 10 and 11; CRWMS M\&O 1998 [DIRS 103210], Tables 3-10 and 3-11; CRWMS M\&O 1997 [DIRS 101090], Tables 3-12 and 3-13). In addition, evergreen trees are grown on about 1,000 acres for commercial sale as landscape products or Christmas trees. There is a dairy with more than 5,000 cows, and there was a catfish farm that was operational in the 1990s. Many residences have gardens with 
vegetable plots and some have a few cattle, sheep, chickens, and other farm animals (CRWMS M\&O 1997 [DIRS 101090], Section 3.4; Horak and Carns 1997 [DIRS 124149], pp. 4 to 18; YMP 1999 [DIRS 158212], Section 3.4; BSC 2004 [DIRS 169673], Appendix A).

Acres of plant agriculture constitute a small fraction of available land in Amargosa Valley as shown in the satellite image of the area in Figure 6.7-2 (reproduced from Lee et al. 2005 [DIRS 177197], Figure 8). Commercial crops are irrigated with groundwater, primarily using center pivot and other overhead sprinkler systems. The amount of water withdrawal in Amargosa Desert was about 5,000 Mgal (15,000 acre-ft.) in 1998 but decreased to about 4,100 Mgal (13,000 acre-ft.) in 2000. Not all that water was used in agriculture; some of it was used in mining. From 1988 to 1998, annual irrigation use increased from 1,000 Mgal (3,000 acre-ft.) to 3,900 Mgal (12,000 acre-ft.) (Fenelon and Moreo 2002 [DIRS 164662], p. 30).

Fenelon and Moreo (2002 [DIRS 164662], p. 1) report that depth to water table in the Amargosa Farms area, where most agriculture of the region occurs, declined from about 10 to $30 \mathrm{ft}$ from 1964 to 2000. (It needs to be recognized that 1964 coincides with the advent of electric power in Amargosa Valley, which allowed more economical withdrawal of groundwater.) All groundwater in Nevada belongs to the public and is regulated through permitting or appropriation by the Office of the State Engineer in the Division of Water Resources (Lee et al. [DIRS 177197], Section 3.5). The maximum amount of water that can be appropriated from a hydrogeologic basin is limited to its perennial yield. However, overdrafting has occurred in Southern Nevada, including the Amargosa Valley basin, because of over-appropriation of aquifers. To protect the aquifer, the State Engineer issued a designation order for that area that restricts issuance of new water permits (Lee et al. [DIRS 177197], Section 3.5). Records indicate that some permit holders do not use their water rights (Buqo 1996 [DIRS 101542], p. 30).

As indicated in Section 6.7.1, there are no physical limitations for continuous use of arable land under proper land management. However, there is evidence that large plots of agricultural land are not in continuous use, or that the fields are relocated. Satellite images for the same area of Amargosa Valley that were acquired at different times show different patterns of central-pivotirrigated fields (Stonestrom et al. 2003 [DIRS 165862], Figure 2; Lee et al. 2005 [DIRS 177197], Figure 8 ) indicating that field locations vary in time.

Ground Water Pumpage Inventory reports available at the State of Nevada Department of Conservation and Natural Resources, Division of Water Resources (State of Nevada 1997 [DIRS 110951]), indicate that the acreage irrigated is usually less than acreage owned by the users. Some commercial users may own more land than can be irrigated using their appropriated water. This situation could lead to practices that favor short-term gains over long-term agricultural land stewardship. To maximize short-term yield of forage crops, such as alfalfa, all water allotment may be used meet plant irrigation requirements and minimize the leaching fraction. Such a practice in the long term would lead to salt build-up at the original location. However, if this happens, agricultural fields could be moved to another location that was not previously irrigated. 


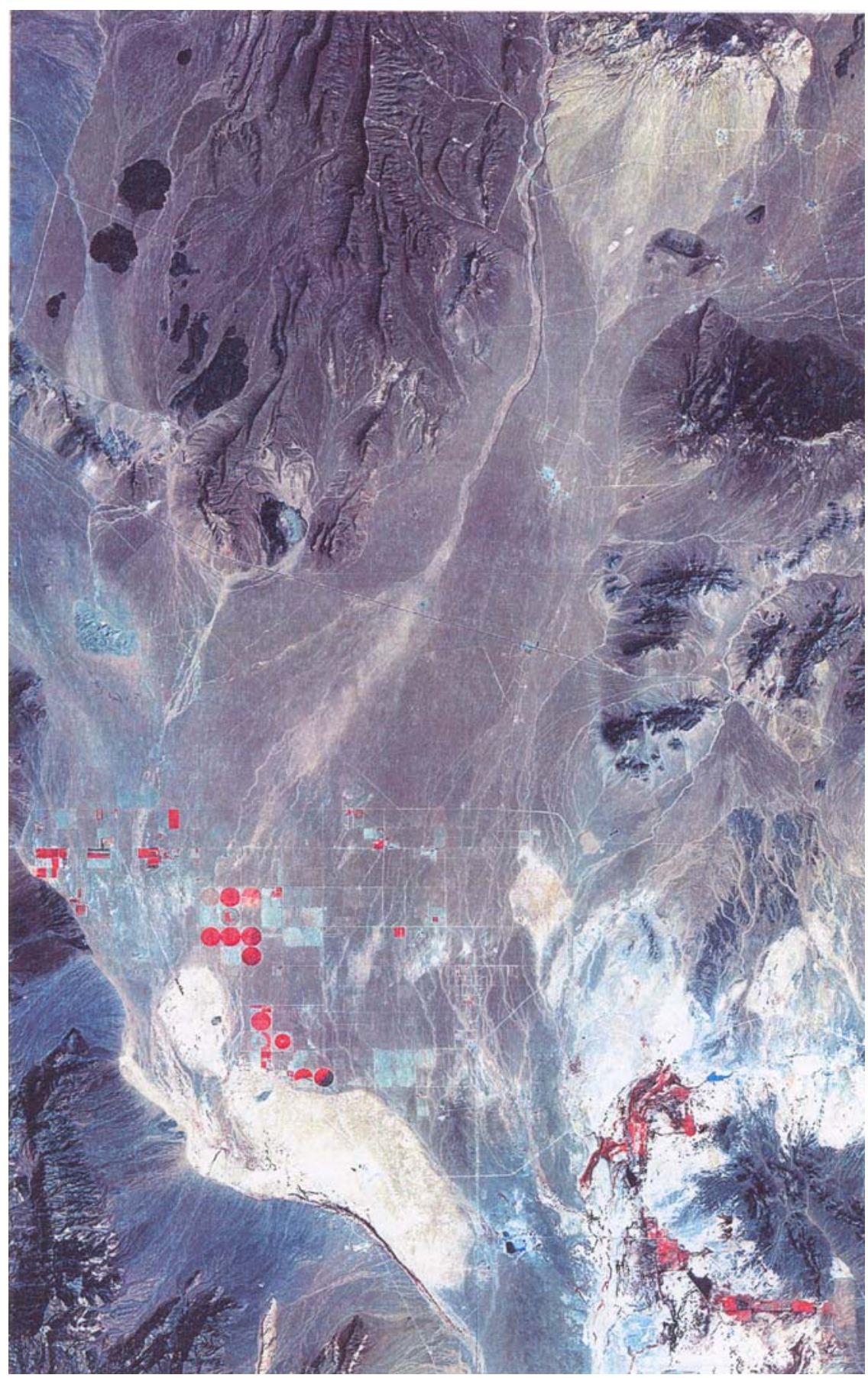

Source: Lee et al. 2005 [DIRS 177197], Figure 8.

NOTE: The areas where irrigation occurs are limited to the lower left side of the image and are shown in red. Also shown in red in the lower right side of the image is Ash Meadows Wildlife Refuge, where water naturally discharges to the surface.

Figure 6.7-2. Satellite Image of the Amargosa Desert Area 
Soil Quality-All soil series occurring in Amargosa Valley have one or more characteristics that make them unfavorable for farming. These include high rock fragment content, high $\mathrm{pH}$, low organic fraction, insufficient capacity for retaining moisture, and low fertility (CRWMS M\&O 1999 [DIRS 107736], p. v; Lee at al. 2005 [DIRS 177197], Section 3.6.2). However, through careful selection of crops and appropriate management practices, farming can exist in the area.

Business Longevity - The history of Amargosa Valley settlement and development is described in the publication The Modern Pioneers of the Amargosa Valley (McCracken 1992 [DIRS 177198]). Lee et al. (2005 [DIRS 177197]) also present a description of historical development of the Amargosa Valley in the report History of Water Development on the Amargosa Desert Area: A Literature Review. These two publications present numerous examples from the past, as well as more recent ones, of businesses and operations in the area lasting a few years to a few tens of years and disappearing or operating on a limited basis, and new businesses opening in their place. This reflects dynamic nature of the local population, including its growth and transience (also see section on tenure and mobility status of the local population earlier in this section).

Home Gardens - In 1997, at the time of the dietary and lifestyle survey, 46\% of Amargosa residents had home gardens (DTN: MO0010SPANYE00.001 [DIRS 154976]). The interviews with the NRCS and UNCE employees, described in Section 6.7.1.2, indicated that relatively fewer homes have kitchen gardens than just a few years ago. When prompted with the fact that a DOE-sponsored survey a few years ago showed that the percentage of homes with a home garden was a bit higher than $40 \%$, the UNCE interviewee estimated that the percentage of homes today would be less, maybe around 30\% of homes with a home food garden (Bland 2006 [DIRS 177219]). In a separate interview, a person from the Pahrump Office of UNCE also expressed a thought that there were relatively fewer home gardens than there used to be and agreed that newer residents were less likely to have such a garden (Bland 2006 [DIRS 177219]). This is consistent with a belief that home gardens are most likely to be paired with longer tenured residents. Specifically, much of the Amargosa Valley population is generally new to the Valley and transient.

\subsubsection{Inclusion of Irrigation Duration in the Surface Soil Submodel}

The description of irrigation duration used in the biosphere model is provided in Section 6.1.1 (Equation 6.1-7). As noted in Section 6.1.1, the time necessary to establish equilibrium concentration in soil varies, depending on a radionuclide, and can range from a few years to about 2,000 years (BSC 2004 [DIRS 169460], Section 7.4.2.1). To approach equilibrium radionuclide concentration in surface soil for radionuclides that build up in the soil slowly, such as some isotopes of thorium, plutonium, and americium, it would take over 2,000 years of irrigation on a given field. Relatively short-lived or mobile radionuclides would approach equilibrium concentrations much quicker, some after only a few years.

Irrigation that continues in the same field for thousands of years is inconsistent with the current agricultural land use by Amargosa Valley residents. The living style representative of the people who now reside in Amargosa Valley is required to be used to define characteristics of the RMEI in 10 CFR 63.312(b) [DIRS 173273]. Therefore, incorporation into the surface soil model of 
irrigation duration that is consistent with the current practices in Amargosa Valley area improves the overall degree of realism in the biosphere model.

\subsubsection{Development of Parameter Distribution}

The annual dose to the RMEI is calculated in the TSPA model by multiplying radionuclide concentration in groundwater by the appropriate BDCF and summing up these products over all radionuclides of interest. The annual dose for a point in time, $t$, is calculated using the activity concentration in water at time $t, C w(t)$. The product of the radionuclide concentration in groundwater and the BDCF represents the dose that would prevail if the radionuclide concentration in water, $C w(t)$, persisted prior to time $t$, for as long as the agricultural land is irrigated, i.e., for the irrigation duration developed in this analysis.

The biosphere model considers five types of locally grown crops: leafy vegetables, other vegetables, fruit, grain, and forage crops (BSC 2004 [DIRS 169460], Section 6.3.1.6). Grain and forage are field crops, while vegetables and fruit that people consume are likely grown in home gardens. More than $90 \%$ of arable land in Amargosa Valley is planted in alfalfa, other hay, and grains (YMP 1999 [DIRS 158212], Tables 10 and 11; CRWMS M\&O 1998 [DIRS 103210], Tables 3-10 and 3-11; CRWMS M\&O 1997 [DIRS 101090], Tables 3-12 and 3-13). Therefore, these crops are produced in relatively large fields, while most vegetables and fruit are grown in home gardens. Consequently, irrigation duration was developed separately for field and for garden crops.

The analysis of physical and social limitations on agricultural practices, presented in Sections 6.7.2 and 6.7.3, did not identify definite temporal or spatial patterns of agricultural land use. However, the literature search and interviews with experts led to a conclusion that limitations on farming in the Yucca Mountain region could, nevertheless, be identified. These included physical limitations to agricultural land and the evidence of degradation of agricultural land quality in arid regions as well as socioeconomic limitations to continuous land use. These considerations were used in Section 5.2 to develop assumptions about the duration of irrigation for garden and field crops that, while considered conservative, reflect in a more realistic manner the land management practices and population lifestyle in the Yucca Mountain region.

The analysis presented in Sections 5.2, 6.7.2, and 6.7.3 led to a conclusion that it was reasonable to assume that under the present conditions it was unlikely for the same plot of land to be irrigated for millennia or even centuries. On the basis of available information about the history of the settlement and agriculture in the region, a triangular distribution was assumed for the irrigation duration of field crops (Section 5.2) with a lower bound and a mode of 100 years, based on the history of agriculture in Amargosa Valley. The higher bound of irrigation duration for field crops was assumed to be an order of magnitude higher, i.e., 1,000 years. The data presented in Section 6.7.3 suggest that the likelihood of a field being used decreases over time. A triangular distribution reflects such a trend, and is therefore appropriate for intended use. A triangular distributions ranging from 100 years to 1,000 years also sufficiently represents uncertainty in the parameter value. The mean value of such a distribution is 400 years (equal to one-third of the sum of the lower bound, the upper bound, and the mode; GoldSim Technology Group 2003 [DIRS 166227], Appendix B). 
The consideration of social and lifestyle factors limiting persistence and thus irrigation of a home garden at the same location led to a conclusion that it was reasonable to assume that there existed limitations on the use of home gardens. A triangular distributions was assumed (Section 5.2) for irrigation duration for garden crops with a lower bound and a mode of 25 years, i.e., approximately one generation. Duration of 250 years, or 10 generations, was assumed as a higher bound. The data presented in Section 6.7.3 suggest that the likelihood of a garden being used decreases over time. A triangular distribution reflects such a trend, and is therefore appropriate for intended use. A triangular distribution ranging from 25 to 250 years also sufficiently represents uncertainty in the parameter value. The mean value of such a distribution is 100 years (equal to one-third of the sum of the lower bound, the upper bound, and the mode; GoldSim Technology Group 2003 [DIRS 166227], Appendix B).

\subsubsection{Evaluation of Occupancy of Land Contaminated by Irrigation}

Evaluation of irrigation practices did not identify physical limitations on agricultural land use. With proper land management, fields could continue to remain productive. There are, however, social reasons, based on documented lifestyle patterns, why continuous land use in the region is unlikely. They were discussed in Section 6.7.3 and used to develop distributions of irrigation duration for field and garden crops. This section evaluates occupancy of land subject to these two different levels of irrigation.

The biosphere model (BSC 2004 [DIRS 169460]) used a method based on equilibrium between radionuclide gains and losses in surface soil to calculate radionuclide concentration in soil from long-term irrigation. The receptor was exposed to radionuclides in surface soil at all times while in potentially contaminated areas. The exposure to contaminated soil occurred through direct exposure and inhalation of resuspended soil particles. Exposure conditions were different in different receptor environments (BSC 2005 [DIRS 172827], Section 6.3), but the radionuclide concentration in surface soil was the same for all receptor environments within the contaminated area.

When different values of irrigation duration are used in the surface soil submodel for field and garden crops, radionuclide concentration in surface soil is no longer the same for all irrigated land. Garden crop irrigation was developed in the context of home gardens, so the resulting radionuclide concentration in soil is appropriate for representing the exposure conditions while indoors and around the house. Field crop irrigation is representative of work conditions. It is therefore recommended that for estimating inhalation and external exposure of the receptor while in the indoor environments and in the inactive outdoor environment, the irrigation duration for garden crops be used. For estimating inhalation and external exposure while the receptor is active outdoors, the irrigation duration for field crops should be used. 


\section{CONCLUSIONS}

\subsection{PARAMETER DISTRIBUTIONS}

This analysis report documents the development of distributions for six soil-related parameters for the biosphere model that are representative of environmental conditions in the region surrounding the Yucca Mountain site identified in 10 CFR 63.305 [DIRS 173164]. These distributions quantify the uncertainties in the parameter values appropriate for the region and for the condition for which they were developed. The values and distributions developed for these six soil-related parameters support the biosphere model that is consistent with arid or semi-arid climates (10 CFR 63.305(d) [DIRS 173164]) and are the same for the range of climate conditions supported by the biosphere model, i.e., for the present-day, monsoon, and glacial transition climates. This constitutes a restriction for subsequent use of the recommended parameter distributions. The developed distributions of input parameters are intended for use in the biosphere model and are appropriate for the conditions and equations for which they were developed (Section 6.1).

This analysis does not provide any direct input to the TSPA model.

The product output data presented in this section are in the Technical Data Management System with a data tracking number of MO0609SPASRPBM.004, under the title "Soil Related Parameters for the Biosphere Model.”

\subsubsection{Soil Bulk Density}

The soil bulk density presented below applies to the groundwater exposure scenario and the volcanic ash exposure scenario. The recommended distribution of soil bulk density is triangular with a minimum of $1.3 \mathrm{~g} \mathrm{~cm}^{-3}\left(1,300 \mathrm{~kg} \mathrm{~m}^{-3}\right)$, a mode of $1.5 \mathrm{~g} \mathrm{~cm}^{-3}\left(1,500 \mathrm{~kg} \mathrm{~m}^{-3}\right)$, and a maximum of $1.7 \mathrm{~g} \mathrm{~cm}^{-3}\left(1,700 \mathrm{~kg} \mathrm{~m}^{-3}\right)$. If a deterministic value of soil bulk density is required, then a value of $1.5 \mathrm{~g} \mathrm{~cm}^{-3}\left(1,500 \mathrm{~kg} \mathrm{~m}^{-3}\right)$ should be used.

\subsubsection{Partition Coefficient}

The partition coefficients presented below apply to the groundwater exposure scenario. It is recommended that the partition coefficient values used in the biosphere model be lognormally distributed with parameters as defined in Table 7.1-1. In the event that a single deterministic value for the partition coefficient is required, the GM given in Table 7.1-1 should be used. 
Table 7.1-1. Lognormal Distribution Parameters for Partition Coefficients

\begin{tabular}{|l|c|c|c|c|}
\hline \multirow{2}{*}{\multicolumn{1}{|c|}{ Element }} & \multicolumn{3}{|c|}{ Parameter Values for a Lognormal Distribution } \\
\cline { 2 - 5 } & Geometric Mean, L/kg & $\begin{array}{c}\text { Geometric Standard } \\
\text { Deviation }\end{array}$ & Low Bound, L/kg & High Bound, L/kg \\
\hline Actinium (Ac) & $1.5 \times 10^{3}$ & 6.0 & $4.3 \times 10^{1}$ & $5.0 \times 10^{4}$ \\
\hline Americium (Am) & $2.0 \times 10^{3}$ & $1.4 \times 10^{1}$ & $1.2 \times 10^{1}$ & $3.3 \times 10^{5}$ \\
\hline Carbon (C) & $1.8 \times 10^{1}$ & 6.0 & $5.3 \times 10^{-1}$ & $6.2 \times 10^{2}$ \\
\hline Cesium (Cs) & $4.4 \times 10^{3}$ & 3.7 & $1.6 \times 10^{2}$ & $1.3 \times 10^{5}$ \\
\hline Chlorine (Cl) & $1.4 \times 10^{-1}$ & 6.0 & $1.3 \times 10^{-3}$ & $1.4 \times 10^{1}$ \\
\hline lodine (I) & 4.5 & 7.4 & $8.9 \times 10^{-2}$ & $2.3 \times 10^{2}$ \\
\hline Lead (Pb) & $1.6 \times 10^{4}$ & 4.1 & $1.0 \times 10^{3}$ & $2.5 \times 10^{5}$ \\
\hline Neptunium (Np) & $2.5 \times 10^{1}$ & 3.3 & 2.3 & $2.6 \times 10^{2}$ \\
\hline Protactinium (Pa) & $1.8 \times 10^{3}$ & 6.0 & $5.3 \times 10^{1}$ & $6.2 \times 10^{4}$ \\
\hline Plutonium (Pu) & $1.2 \times 10^{3}$ & 3.3 & $1.2 \times 10^{2}$ & $1.3 \times 10^{4}$ \\
\hline Radium (Ra) & $3.6 \times 10^{4}$ & $2.2 \times 10^{1}$ & $8.3 \times 10^{1}$ & $1.6 \times 10^{7}$ \\
\hline Selenium (Se) & $1.5 \times 10^{2}$ & 6.0 & 4.4 & $5.1 \times 10^{3}$ \\
\hline Strontium (Sr) & $2.0 \times 10^{1}$ & 5.5 & $7.2 \times 10^{-1}$ & $5.6 \times 10^{2}$ \\
\hline Technetium (Tc) & $1.4 \times 10^{-1}$ & 6.0 & $1.3 \times 10^{-3}$ & $1.4 \times 10^{1}$ \\
\hline Thorium (Th) & $3.0 \times 10^{3}$ & 8.2 & $4.9 \times 10^{1}$ & $1.8 \times 10^{5}$ \\
\hline Tin (Sn) & $4.5 \times 10^{2}$ & 6.0 & $1.3 \times 10^{1}$ & $1.5 \times 10^{4}$ \\
\hline Uranium (U) & $3.3 \times 10^{1}$ & $2.5 \times 10^{1}$ & $6.3 \times 10^{-1}$ & $1.8 \times 10^{4}$ \\
\hline
\end{tabular}

\subsubsection{Soil Erosion Rate}

The erosion rates presented below apply to the groundwater exposure scenario. It is recommended that the distribution for the annual erosion rate be triangular with a lower limit and mode at $0.2 \mathrm{~kg} \mathrm{~m}^{-2} \mathrm{yr}^{-1}$, and an upper limit at $1.1 \mathrm{~kg} \mathrm{~m}^{-2} \mathrm{yr}^{-1}$. If a single deterministic value is required to estimate the erosion rate, it is recommended that the mode of the distribution be used, which is $0.2 \mathrm{~kg} \mathrm{~m}^{-2} \mathrm{yr}^{-1}$.

\subsubsection{Enhancement Factor for Resuspension}

The enhancement factor values apply to the groundwater exposure scenario and the volcanic ash exposure scenario and are receptor environment specific. The recommended enhancement factor distributions are identified in Table 7.1-2. In the event that a single value is required for the parameters, the mode for the groundwater exposure scenario and the geometric mean for the volcanic ash exposure scenario should be used. 
Table 7.1-2. Distribution Parameters for the Enhancement Factor

\begin{tabular}{|c|c|c|c|c|c|}
\hline Environment & Distribution & \multicolumn{4}{|c|}{ Enhancement Factor (dimensionless) } \\
\hline \multicolumn{6}{|c|}{ Groundwater Exposure Scenario } \\
\hline & & Mode & Low Bound & High Bound & \\
\hline Active outdoors & Triangular & 1 & 0.4 & 1.5 & \\
\hline $\begin{array}{l}\text { Inactive outdoors } \\
\text { Active indoors } \\
\text { Asleep indoors }\end{array}$ & Triangular & 4 & 2 & 7 & \\
\hline \multicolumn{6}{|c|}{ Volcanic Ash Exposure Scenario } \\
\hline & & $\begin{array}{c}\text { Geometric } \\
\text { Mean }\end{array}$ & $\begin{array}{l}\text { Geometric } \\
\text { Standard } \\
\text { Deviation }\end{array}$ & Low bound & High bound \\
\hline Active outdoors & Lognormal & 1.2 & 2.0 & 0.3 & 4.6 \\
\hline $\begin{array}{l}\text { Inactive outdoors } \\
\text { Active indoors } \\
\text { Asleep indoors }\end{array}$ & Lognormal & 2.9 & 1.8 & 0.9 & 9.4 \\
\hline
\end{tabular}

\subsubsection{Volumetric Water Content of Soil}

The volumetric water content applies to the groundwater exposure scenario and is represented by a uniform distribution over the range of 0.15 to 0.28 . If a deterministic value for the soil water content is required, then a value of 0.20 should be used.

\subsubsection{Irrigation Duration}

The irrigation duration applies to the groundwater exposure scenario. For the irrigation duration of field crops it is recommended that a triangular distribution be used with a minimum of 100 years, a mode also at 100 years, and a maximum of 1,000 years. If a deterministic value is required, 100 years should be used.

For the irrigation duration of garden crops it is recommended that a triangular distribution be used with a minimum of 25 years, a mode of 25 years, and a maximum of 250 years. If a deterministic value is required, 25 years should be used.

It is recommended that for estimating inhalation and external exposure of the receptor while in the indoor environments and in the inactive outdoor environment, the irrigation duration for garden crops be used. For estimating inhalation and external exposure while the receptor is active outdoors, the irrigation duration for field crops should be used.

\subsection{HOW THE ACCEPTANCE CRITERIA WERE ADDRESSED}

The following information describes how this analysis contributes to satisfying the acceptance criteria in Yucca Mountain Review Plan, Final Report (NRC 2003 [DIRS 163274], Sections 2.2.1.3.13 and 2.2.1.3.14). Only those acceptance criteria that are applicable to this report, as identified in Section 4.2, are discussed. 
This analysis report is one of seven reports (Figure 1-1) supporting biosphere modeling and describes how the biosphere model has addressed the applicable acceptance criteria. Consideration of the seven reports is required to understand how the biosphere model satisfies the biosphere acceptance criteria.

The manner in which the acceptance criteria applicable to this analysis were addressed is described below.

\section{Acceptance Criteria from Section 2.2.1.3.13: Redistribution of Radionuclides in Soil}

\section{Acceptance Criterion 2: Data Are Sufficient for Model Justification}

(1) This analysis generates the distributions for soil-related parameters as required by the biosphere model to predict the transport of radionuclides through soil and by resuspension of soil (BSC 2004 [DIRS 169460], Sections 6.4.1.3, 6.4.1.4, and 6.4.2.1). The justifications for the parameter distributions developed in this report, and the consistency of those distributions with the conditions in the Yucca Mountain region, are described in Section 6, with additional justification for the assumption regarding uncertainty for some partition coefficients given in Section 5. The data identified in Section 4.1 were used, interpreted, and appropriately synthesized into the parameter distributions as described in Section 6.

(2) The sufficiency of data used to develop parameter distributions used in the modeling of radionuclide redistribution in soil is described in Sections 4.1 and 6. Demonstration that the parameter distributions are consistent with present knowledge of the conditions in the Yucca Mountain region is provided in Section 6. Sensitivity and uncertainty analyses are addressed in other biosphere modeling reports listed in Figure 1-1.

\section{Acceptance Criterion 3: Data Uncertainty Is Characterized and Propagated Through the Model Abstraction}

(1) The soil-related parameters and their distributions to support the biosphere model are developed in Section 6 of this analysis from the data identified in Section 4.1. These data account for the expected uncertainty and variability in the site-specific parameters required to provide a reasonable assessment of the dose consequences to the specified receptor. An assumption about uncertainty for some partition coefficients is given in Section 5. Sensitivity and uncertainty analyses are addressed in other biosphere modeling reports listed in Figure 1-1.

(2) The data used in this analysis for soil type, texture, density, water content, and enhancement factor discussed in Section 4.1 are based upon local conditions. The data identified in Section 4.1.4 were based in part on data measured at the nearby Nevada Test Site.

(3) The data identified in Section 4.1 permitted the analysis in Section 6 to develop distributions representing parametric uncertainty and variability for use in the biosphere process model and alternative conceptual submodels. Sensitivity and uncertainty analyses are addressed in other biosphere modeling reports listed in Figure 1-1. 


\section{Acceptance Criteria from Section 2.2.1.3.14: Biosphere Characteristics}

\section{Acceptance Criterion 1: System Description and Model Integration Are Adequate}

(3) This analysis considers information about climate change, soil characteristics, partition coefficients, erosion, and radionuclide resuspension that is used to developed parameters to support the biosphere model in a manner that is consistent with other reports identified in Figure 1-1.

\section{Acceptance Criterion 2: Data Are Sufficient for Model Justification}

(1) The justification for the parameter distributions developed in this report, and the consistency of those distributions with the conditions in the Yucca Mountain region, are described in Section 6. The data identified in Section 4.1 were used, interpreted, and appropriately synthesized into the parameter distributions as described in Section 6.

(2) The sufficiency of data used to develop parameter distributions used in the modeling of features, events, and processes related to biosphere characteristics modeling is described in Sections 4.1 and 6. Demonstration that the parameter distributions are consistent with present knowledge of the conditions in the Yucca Mountain region is provided in Section 6. Sensitivity and uncertainty analyses and consideration of alternative conceptual models are addressed in other biosphere modeling reports listed in Figure 1-1.

\section{Acceptance Criterion 3: Data Uncertainty Is Characterized and Propagated Through the Model Abstraction}

(1) The technical defensibility of the assumption used in this analysis is included in Section 5. The technical defensibility of the probability distribution developed for each parameter is described in Section 6. These distributions of parameter uncertainty and variability are shown in Section 6 to reasonably represent local conditions while not under-representing any risk estimate made from their subsequent use in the biosphere model. The consideration given to local conditions and climate states in developing parametric data is consistent with the definition of the RMEI.

(2) The defensibility of the technical bases for the parameter distributions is described in Section 6. The data (Section 4.1) and developed distributions (Section 7.1) for parameters are based on or are consistent with site characterization data and the arid to semi-arid climate in the Yucca Mountain region.

(4) The bounding values of the parameter distributions developed in this analysis were selected to adequately represent uncertainty, as described in Section 6. 


\section{INTENTIONALLY LEFT BLANK}




\section{INPUTS AND REFERENCES}

\subsection{DOCUMENTS CITED}

Allen, R.G.; Pereira, L.S.; Raes, D.; and Smith, M. 1998. Crop

157311

Evapotranspiration, Guidelines for Computing Crop Water Requirements. FAO Irrigation and Drainage Paper 56. Rome, Italy: Food and Agriculture Organization of the United Nations. TIC: 245062.

Andrews, R.W. 1999. "A Request to Have Data from the Journal Article Entitled 'Default Soil Solid/Liquid Partition Coefficients $\mathrm{K}_{\mathrm{d}} \mathrm{s}$ for Four Major Soil Types: A Compendium' (Sheppard and Thibault 1990) Approved for Use in Quality-Affecting Work as 'Accepted' Data.” Letter from R.W. Andrews (CRWMS M\&O) to S.P. Mellington (DOE/YMSCO), December 21, 1999, LV.PA.RWA.12/99-128. ACC: MOL.20000117.0164.

Anspaugh, L.R.; Shinn, J.H.; Phelps, P.L.; and Kennedy, N.C. 1975.

"Resuspension and Redistribution of Plutonium in Soils." Health Physics, 29, (4), 571-582. New York, New York: Pergamon Press. TIC: 248619.

Baes, C.F., III and Sharp, R.D. 1983. "A Proposal for Estimation of Soil Leaching 109606 and Leaching Constants for Use in Assessment Models." Journal of Environmental Quality, 12, (1), 17-28. Madison, Wisconsin: American Society of Agronomy. TIC: 245676.

Baes, C.F., III; Sharp, R.D.; Sjoreen, A.L.; and Shor, R.W. 1984. A Review and 103766 Analysis of Parameters for Assessing Transport of Environmentally Released Radionuclides through Agriculture. ORNL-5786. Oak Ridge, Tennessee: Oak Ridge National Laboratory. ACC: NNA.19870731.0041.

BIOMASS (Biosphere Modelling and Assessment) 2003. "Reference Biospheres" 168563 for Solid Radioactive Waste Disposal, Report of BIOMASS Theme 1 of the BIOsphere Modelling and ASSessment (BIOMASS) Programme, Part of the IAEA Co-ordinated Research Project on Biosphere Modelling and Assessment (BIOMASS). IAEA-BIOMASS-6. Vienna, Austria: International Atomic Energy Agency, Waste Safety Section. TIC: 255411.

BIOPROTA 2005. Modelling the Inhalation Exposure Pathway, Key Issues in 177377 Biosphere Aspects of Assessment of the Long-Term Impact of Contaminant Releases Associated with Radioactive Waste Management. Risley, United Kingdom: BNFL (Nexia Solutions Ltd). ACC: MOL.20060906.0082.

Bland, J. 2006. "Irrigation and Salinity in the Amargosa Valley and Similar 177219 Locations." Memorandum from J. Bland to M. Wasiolek, June 28, 2006. ACC: MOL.20060724.0160. 
Brady, N.C. and Weil, R.R. 1999. The Nature and Properties of Soils.

BSC (Bechtel SAIC Company) 2004. Agricultural and Environmental Input

Parameters for the Biosphere Model. ANL-MGR-MD-000006 REV 02.

Las Vegas, Nevada: Bechtel SAIC Company. ACC: DOC.20040915.0007.

BSC 2004. Biosphere Model Report. MDL-MGR-MD-000001 REV 01.

Las Vegas, Nevada: Bechtel SAIC Company. ACC: DOC.20041108.0005.

BSC 2004. Environmental Transport Input Parameters for the Biosphere Model.

ANL-MGR-MD-000007 REV 02. Las Vegas, Nevada: Bechtel SAIC Company.

ACC: DOC.20040913.0003.

BSC 2004. Future Climate Analysis. ANL-NBS-GS-000008 REV 01. Las Vegas,

Nevada: Bechtel SAIC Company. ACC: DOC.20040908.0005.

BSC 2004. Soil-Related Input Parameters for the Biosphere Model.

169459

ANL-NBS-MD-000009 REV 02. Las Vegas, Nevada: Bechtel SAIC Company.

ACC: DOC.20040913.0002.

BSC 2005. Atmospheric Dispersal and Deposition of Tephra from a Potential

Volcanic Eruption at Yucca Mountain, Nevada. MDL-MGR-GS-000002 REV 02.

Las Vegas, Nevada: Bechtel SAIC Company. ACC: DOC.20050825.0001;

DOC.20050908.0001; DOC.20060306.0008.

BSC 2005. Characteristics of the Receptor for the Biosphere Model.

172827

ANL-MGR-MD-000005 REV 04. Las Vegas, Nevada: Bechtel SAIC Company.

ACC: DOC.20050405.0005.

BSC 2005. Q-List. 000-30R-MGR0-00500-000-003. Las Vegas, Nevada: Bechtel SAIC Company. ACC: ENG.20050929.0008.

BSC 2006. Inhalation Exposure Input Parameters for the Biosphere Model.

ANL-MGR-MD-000001 REV 04. Las Vegas, Nevada: Bechtel SAIC Company.

ACC: DOC.20060605.0011.

BSC 2006. Technical Work Plan for Biosphere Modeling. TWP-NBS-MD-000004

REV 06. Las Vegas, Nevada: Bechtel SAIC Company.

ACC: DOC.20060515.0001.

Buqo, T.S. 1996. Baseline Water Supply and Demand Evaluation of Southern Nye

101542

County, Nevada. Pahrump, Nevada: Nye County Nuclear Waste Repository Project

Office. TIC: 235774. 
Bureau of Census 2000. "1990 Summary Tape File 3 (STF 3) - Sample Data."

Detailed Tables - American FactFinder. Washington, D.C.: Bureau of Census. Accessed April 7, 2005. ACC: MOL.20050505.0096.

URL: http://factfinder.census.gov/servlet/DTTable?

Bureau of the Census. 2002. "2000 Summary File 3 (SF 3) Sample Data, Amargosa Valley CCD, Nye County, Nevada." Washington, D.C.: U.S.

Department of Commerce, Bureau of the Census. Accessed August 28, 2002.

TIC: 253098. URL: http://factfinder.census.gov/servlet/

DTTable? ts $=48597952130$

Burley, G. 1990. "Environmental Transport \& Exposure Pathways.” In Elements of Radiation Protection, Volume 1, Section 5.1 of Transuranium Elements. EPA 520/1-90-015. Washington, D.C.: U.S Environmental Protection Agency, Office of Radiation Programs. ACC: MOL.20060809.0068.

Church, B.W.; Shinn, J.H.; Williams, G.A.; Martin, L.J.; O’Brien, R.S.; and Adams, S.R. 2000. Comparative Plutonium-239 Dose Assessment for Three Desert Sites: Maralinga, Australia; Palomares, Spain; and the Nevada Test Site, USA-Before and After Remedial Action. UCRL-JC-139690. Livermore, California: Lawrence Livermore National Laboratory.

ACC: MOL.20060809.0053.

CRWMS (Civilian Radioactive Waste Management System) M\&O (Management and Operating Contractor) 1997. Yucca Mountain Site Characterization Project Summary of Socioeconomic Data Analyses Conducted in Support of the Radiological Monitoring Program First Quarter 1996 to First Quarter 1997. Las Vegas, Nevada: CRWMS M\&O. ACC: MOL.19971117.0460.

CRWMS M\&O 1998. Yucca Mountain Site Characterization Project: Summary 103210 of Socioeconomic Data Analyses Conducted in Support of the Radiological Monitoring Program, April 1997 to April 1998. Las Vegas, Nevada: CRWMS M\&O. ACC: MOL.19980803.0064.

CRWMS M\&O 1999. Evaluation of Soils in the Northern Amargosa Valley. 107736 B00000000-01717-5705-00084 REV 00. Las Vegas, Nevada: CRWMS M\&O. ACC: MOL.19990224.0268.

Davis, P.A; Zach, R.; Stephens, M.E.; Amiro, B.D.; Bird, G.A.; Reid, J.A.K.; 103767 Sheppard, M.I.; Sheppard, S.C.; and Stephenson, M. 1993. The Disposal of Canada's Nuclear Fuel Waste: The Biosphere Model, BIOTRAC, for Postclosure Assessment. AECL-10720. Pinawa, Manitoba, Canada: Atomic Energy of Canada Limited. TIC: 244741. 
DEFRA (Department for Environment, Food \& Rural Affairs) 2002. The 177376 Contaminated Land Exposure Assessment (CLEA) Model: Technical Basis and Algorithms. R\&D Publication CLR 10. Bristol, United Kingdom: Department for Environment, Food \& Rural Affairs, and Environment Agency. TIC: 258511.

DOE (U.S. Department of Energy) 1997. The 1997 “Biosphere” Food 100332 Consumption Survey Summary Findings and Technical Documentation.

Las Vegas, Nevada: U.S. Department of Energy, Office of Civilian Radioactive Waste Management. ACC: MOL.19981021.0301.

Dregne, H.E. 1983. Desertification of Arid Lands. Advances in Desert and Arid Land Technology and Development. Volume 3. Bishay, A. and McGinnies, W.G., eds. New York, New York: Harwood Academic Publishers. TIC: 258447.

EPA (U.S. Environmental Protection Agency) 1996. Air Quality Criteria for Particulate Matter. EPA/600/P-95/001. Three volumes. Washington, D.C.: U.S. Environmental Protection Agency. TIC: 250648.

EPA 2004. Air Quality Criteria for Particulate Matter. EPA/600/P-99/002aF and 175978 EPA/600/P-99/002bF. Two volumes. Research Triangle Park, North Carolina: U.S. Environmental Protection Agency. ACC: MOL.20060105.0151; MOL.20060105.0152.

Fenelon, J.M. and Moreo, M.T. 2002. Trend Analysis of Ground-Water Levels 164662 and Spring Discharge in the Yucca Mountain Region, Nevada and California, 1960-2000. Water-Resources Investigations Report 02-4178. Carson City, Nevada: U.S. Geological Survey. ACC: MOL.20030812.0306.

Freeze, R.A. and Cherry, J.A. 1979. Groundwater. Englewood Cliffs, New Jersey: Prentice-Hall. TIC: 217571.

GoldSim Technology Group. 2003. User's Guide, GoldSim Distributed Processing Module. Version 8.01. Redmond, Washington: Golder Associates. TIC: 255233.

Jasinska, M.; Niewiadomski, T.; and Schwabenthan, J. 1980. "On a New 177445 Possibility of Estimating Population Exposure to Terrestial [Terrestrial] Sources." Health Physics, 38, 416-419. New York, New York: Pergamon Press.

TIC: 258500.

Johnston, P.N.; Lokan, K.H.; and Williams, G.A. 1992. "Inhalation Doses for 177227 Aboriginal People Reoccupying Former Nuclear Weapons Testing Ranges in South Australia." Health Physics, 63, (6), 631-640. Baltimore, Maryland: Lippincott Williams \& Wilkins. TIC: 258564. 
Kashparov, V.A.; Protsak, V.P.; Yoschenko, V.I.; and Watterson, J.D. 1994.

"Inhalation of Radionuclides During Agricultural Work in Areas Contaminated as a Result of the Chernobyl Reactor Accident." Journal of Aerosol Science, 25, (5), 761-766. New York, New York: Pergamon. TIC: 258495.

Kilroy, K.C. 1991. Ground-Water Conditions in Amargosa Desert,

Nevada-California, 1952-87. Water-Resources Investigations Report 89-4101.

Carson City, Nevada: U.S. Geological Survey. TIC: 209975.

LaPlante, P.A. and Poor, K. 1997. Information and Analyses to Support Selection

101079

of Critical Groups and Reference Biospheres for Yucca Mountain Exposure

Scenarios. CNWRA 97-009. San Antonio, Texas: Center for Nuclear Waste

Regulatory Analyses. ACC: MOL.20010721.0035.

Lee, M.P.; Coleman, N.M.; and Nicholson, T.J. 2005. History of Water

Development in the Amargosa Desert Area: A Literature Review. NUREG-1710.

Volume 1. Washington, D.C.: U.S. Nuclear Regulatory Commission, Advisory

Committee on Nuclear Waste. ACC: MOL.20060905.0194.

Lundgren, D.A. and Burton, R.M. 1995. "Effect of Particle Size Distribution on the

Cut Point Between Fine and Coarse Ambient Mass Fractions." Inhalation

Toxicology, 7, 131-148. London, England: Taylor \& Francis. TIC: 252361.

Mathews, T.J. and Hamilton, B.E. 2002. "Mean Age of Mother, 1970-2000."

177463

National Vital Statistics Reports, 51, (1), 1-13 and 16. Hyattsville, Maryland: U.S.

Department of Health and Human Services, Centers for Disease Control and

Prevention. ACC: MOL.20060830.0033.

McCracken, R.D. 1992. The Modern Pioneers of the Amargosa Valley. Tonopah, Nevada: Nye County Press. TIC: 240675.

Merriam-Webster. 1993. Merriam-Webster's Collegiate Dictionary, 10th Edition. Springfield, Massachusetts: Merriam-Webster. TIC: 8883.

Microsoft Encarta Online Encyclopedia 2006. “Ancient Greece.” Ancient

Civilizations. Redmond, Washington: Microsoft Corporation. Accessed

August 24, 2006. TIC: 258580. URL: http://encarta.msn.com

Microsoft Encarta Online Encyclopedia 2006. “Ancient Rome.” Ancient

177695

Civilizations. Redmond, Washington: Microsoft Corporation. Accessed

August 24, 2006. TIC: 258581. URL: http://encarta.msn.com

Microsoft Encarta Online Encyclopedia 2006. "Aztec Empire.” Ancient

177198

Civilizations. Redmond, Washington: Microsoft Corporation. Accessed

August 24, 2006. TIC: 258585. URL: http://encarta.msn.com 
Microsoft Encarta Online Encyclopedia 2006. "Inca Empire." Ancient 177698 Civilizations. Redmond, Washington: Microsoft Corporation. Accessed August 24, 2006. TIC: 258584. URL: http://encarta.msn.com

Microsoft Encarta Online Encyclopedia 2006. "Mesopotamia." Ancient 177696 Civilizations. Redmond, Washington: Microsoft Corporation. Accessed August 24, 2006. TIC: 258582. URL: http://encarta.msn.com

Microsoft Encarta Online Encyclopedia 2006. "Middle East.” Ancient Civilizations. Redmond, Washington: Microsoft Corporation. Accessed August 24, 2006. TIC: 258583. URL: http://encarta.msn.com

NCRP (National Council on Radiation Protection and Measurements) 1997. 160260 Deposition, Retention and Dosimetry of Inhaled Radioactive Substances. NCRP Report No. 125. Bethesda, Maryland: National Council on Radiation Protection and Measurements. TIC: 232976.

NCRP 1999. Recommended Screening Limits for Contaminated Surface Soil and 155894 Review of Factors Relevant to Site-Specific Studies. NCRP Report No. 129. Bethesda, Maryland: National Council on Radiation Protection and Measurements. TIC: 250396.

NDEP (Nevada Division of Environmental Protection) 1994. Best Management Practices Handbook. Carson City, Nevada: State of Nevada, Nevada Division of Environmental Protection. ACC: MOL.20060206.0352.

Nieuwenhuijsen, M.J.; Kruize, H.; and Schenker, M.B. 1998. "Exposure to Dust and Its Particle Size Distribution in California Agriculture." American Industrial Hygiene Association Journal, 59, 34-38. Fairfax, Virginia: American Industrial Hygiene Association. TIC: 248134.

NRC (U.S. Nuclear Regulatory Commission) 2003. Yucca Mountain Review Plan, 163274 Final Report. NUREG-1804, Rev. 2. Washington, D.C.: U.S. Nuclear Regulatory Commission, Office of Nuclear Material Safety and Safeguards. TIC: 254568.

Pinnick, R.G.; Fernandez, G.; Hinds, B.D.; Bruce, C.W.; Schaefer, R.W.; and Pendleton, J.D. 1985. "Dust Generated by Vehicular Traffic on Unpaved Roadways: Sizes and Infrared Extinction Characteristics." Aerosol Science and Technology, 4, (1), 99-121. New York, New York: Elsevier. TIC: 252364.

Sheppard, M.I. and Thibault, D.H. 1990. "Default Soil Solid/Liquid Partition 109991 Coefficients, Kds, for Four Major Soil Types: A Compendium." Health Physics, 59, (4), 471-482. New York, New York: Pergamon Press. TIC: 249329.

Sheppard, S.C. and Evenden, W.G. 1994. "Contaminant Enrichment and Properties 177467 of Soil Adhering to Skin.” Journal of Environmental Quality, 23, 604-613. Madison, Wisconsin: American Society of Agronomy. TIC: 258565. 
Shinn, J.H. 1998. Assessing Inhalation Exposure from Airborne Soil

177230

Contaminants, An Overview of Particle Transport and Resuspension Studies.

UCRL-ID-130570. Livermore, California: Lawrence Livermore National

Laboratory. ACC: MOL.20060809.0054.

Shinn, J.H. 2002. Complementary Pu Resuspension Study at Palomares, Spain.

177225

UCRL-ID-150980. Livermore, California: Lawrence Livermore National

Laboratory. ACC: MOL.20060809.0055.

Shinn, J.H. 2003. Studies of Plutonium Aerosol Resuspension at the Time of the

177226

Maralinga Cleanup. UCRL-ID-155063. Livermore, California: Lawrence

Livermore National Laboratory. ACC: MOL.20060809.0066.

Shinn, J.H. 1992. "Enhancement Factors for Resuspended Aerosol Radioactivity:

160115

Effects of Topsoil Disturbance." Proceedings of the Fifth International Conference

on Precipitation Scavenging and Atmosphere-Surface Exchange Processes,

Richland, Washington, 15-19 July 1991. 1183-1193. Washington, D.C.:

Hemisphere. TIC: 252292.

Shinn, J.H.; Essington, E.H.; Miller, F.L., Jr.; O’Farrell, T.P.; Orcutt, J.A.;

Romney, E.M.; Shugart, J.W.; and Sorom, E.R. 1989. "Results of a Cleanup and

Treatment Test at the Nevada Test Site: Evaluation of Vacuum Removal of

Pu-Contaminated Soil." Health Physics, 57, (5), 771-779. New York, New York:

Pergamon. TIC: 258501.

Shinn, J.H.; Fry, C.F.; and Johnson, J.S. 1994. Suspended Plutonium Aerosols

177228

Near a Soil Cleanup Site on Johnston Atoll in 1992. UCRL-ID-116495.

Livermore, California: Lawrence Livermore National Laboratory.

ACC: MOL.20060809.0065.

Shinn, J.H.; Homan, D.N.; and Gay, D.D. 1983. "Plutonium Aerosol Fluxes and Pulmonary Exposure Rates During Resuspension from Bare Soils Near a Chemical Separation Facility." Precipitation Scavenging, Dry Deposition, and Resuspension, Proceedings of the Fourth International Conference, Santa Monica, California, 29 November-3 December, 1982. Pruppacher, H.R.; Semonin, R.G.; and Slinn, W.G.N., eds. 2, 1131-1143. New York, New York: Elsevier. TIC: 258535.

Shinn, J.H.; Homan, D.N.; and Robison, W.L. 1997. "Resuspension Studies in the

Marshall Islands." Health Physics, 73, (1), 248-257. Baltimore, Maryland:

Lippincott Williams \& Wilkins. TIC: 258502.

Shinn, J.H.; Patton, S.E.; and Gouveia, F.J. 1997. Seasonal Variations and

177222 Frequency Distributions of Plutonium Resuspension at Tonopah, Nevada. UCRL-JC-126286. Livermore, California: Lawrence Livermore National Laboratory. ACC: MOL.20060809.0067. 
Skaggs, T.H.; Arya, L.M.; Shouse, P.J.; and Mohanty, B.P. 2001. "Estimating 177368

Particle-Size Distribution from Limited Soil Texture Data." Soil Science Society of America Journal, 65, 1038-1044. Madison, Wisconsin: Soil Science Society of America. TIC: 258494.

Stonestrom, D.A.; Prudic, D.E.; Laczniak, R.J.; Akstin, K.C.; Boyd, R.A.; and 165862 Henkelman, K.K. 2003. Estimates of Deep Percolation Beneath Native Vegetation, Irrigated Fields, and the Amargosa-River Channel, Amargosa Desert, Nye County, Nevada. Open-File Report 03-104. Denver, Colorado: U.S. Geological Survey. TIC: 255088.

Troeh, F.R.; Hobbs, J.A.; and Donahue, R.L. 1980. Soil and Water Conservation for Productivity and Environmental Protection. Englewood Cliffs, New Jersey: Prentice-Hall. TIC: 246612.

U.S. Census Bureau 2002. "Census 2000 Summary File 3 (SF 3) - Sample Data, Amargosa Valley CCD, Nye County, Nevada." Washington, D.C.: U.S. Census Bureau. Accessed August 24, 2006. ACC: MOL.20060830.0034. URL: http://factfinder.census.gov/servlet/DTTables?_bm=y\&context=dt\&ds_name=DEC_2000_SF3_U\&-

USDA (U.S. Department of Agriculture) 1993. Soil Survey Manual. Handbook No. 18. Washington, D.C.: U.S. Department of Agriculture. TIC: 240569.

USDA 2000. Summary Report, 1997 National Resources Inventory 160548 (Revised December 2000). Washington, D.C.: U.S. Department of Agriculture. TIC: 253006.

USDA 2004. Soil Survey of Nye County, Nevada, Southwest Part. Two parts. Washington, D.C.: U.S. Department of Agriculture.

ACC: MOL.20050614.0146.

YMP (Yucca Mountain Site Characterization Project) 1999. Yucca Mountain Site Characterization Project: Summary of Socioeconomic Data Analyses Conducted in Support of the Radiological Monitoring Program, April 1998 to April 1999. North Las Vegas, Nevada: Yucca Mountain Site Characterization Office.

ACC: MOL.19991021.0188.

\subsection{CODES, STANDARDS, REGULATIONS, AND PROCEDURES}

10 CFR 63. 2005. Energy: Disposal of High-Level Radioactive Wastes in a 173273 Geologic Repository at Yucca Mountain, Nevada. ACC: MOL.20050405.0118.

IT-PRO-0011, Rev. 0, ICN 0. Software Management. Las Vegas, Nevada: Bechtel SAIC Company. ACC: DOC.20060301.0007. 
LP-2.29Q-BSC, Rev. 1, ICN 0. Planning for Science Activities. Washington, D.C.: U.S. Department of Energy, Office of Civilian Radioactive Waste Management.

ACC: DOC.20060518.0005.

LP-SIII.9Q-BSC, Rev. 1, ICN 0. Scientific Analyses. Washington, D.C.: U.S. Department of Energy, Office of Civilian Radioactive Waste Management.

ACC: DOC.20060518.0006.

LS-PRO-0203, Rev 1, ICN 0. Q-List and Classification of Structures, Systems, Components and Barriers. Las Vegas, Nevada: Bechtel SAIC Company.

ACC: ENG.20060808.0011.

\subsection{SOURCE DATA, LISTED BY DATA TRACKING NUMBER}

MO0010SPANYE00.001. Cleaned Nye County Food Consumption Frequency

Survey. Submittal date: 10/10/2000.

MO0508SEPFEPLA.002. LA FEP List and Screening. Submittal date:

08/22/2005.

MO0603UCCF01JS.001. Total Suspended Particulate Matter (TSP)

Concentrations in Milligrams per Cubic Meter (mg/m3) Measured During Soil Disturbing Activities from 12/15/05 to 12/16/05 in Amargosa Valley.

Submittal date: 03/13/2006.

\subsection{OUTPUT DATA, LISTED BY DATA TRACKING NUMBER}

MO0609SPASRPBM.004. Soil Related Parameters for the Biosphere Model.

Submittal date: 09/26/2006. 


\section{INTENTIONALLY LEFT BLANK}


APPENDIX A

\section{LIST AND DESCRIPTION OF FILES USED IN THIS ANALYSIS}




\section{INTENTIONALLY LEFT BLANK}




\section{APPENDIX A}

\section{LIST AND DESCRIPTION OF FILES USED IN THIS ANALYSIS}

This appendix contains descriptions of the files with data and calculations that were used in this analysis. The files are listed in alphabetical order and can be found on the CD-ROM included as an electronic attachment to this document (Figure A-1).

\begin{tabular}{|c|c|c|c|c|}
\hline \multirow{4}{*}{ 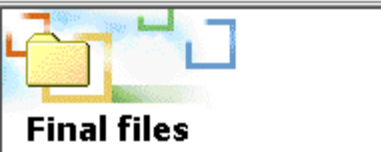 } & Name $A$ & Size & Type & Modified \\
\hline & Av Data_Life Style.xls & $2,106 \mathrm{~KB}$ & Microsoft Excel Worksheet & $8 / 27 / 20067: 50 \mathrm{PM}$ \\
\hline & Calcs for Water Content.xls & $17 \mathrm{~KB}$ & Microsoft Excel Worksheet & $9 / 8 / 20067: 37 \mathrm{AM}$ \\
\hline & Distributions of Enhancement Factors.xls & $34 \mathrm{~KB}$ & Microsoft Excel Worksheet & $9 / 8 / 20062: 45 \mathrm{PM}$ \\
\hline \multirow{3}{*}{$\mp$ This folder is Online. } & QEFs for Undisturbed and Disturbed Soil. med & $11 \mathrm{~KB}$ & Mathcad Document & $9 / 26 / 200611: 03 \mathrm{AM}$ \\
\hline & Td Bounds.xls & $20 \mathrm{~KB}$ & Microsoft Excel Worksheet & $9 / 19 / 20066: 15 \mathrm{PM}$ \\
\hline & MMADs od Suspended Particles.xls & $16 \mathrm{~KB}$ & Microsoft Excel Worksheet & $9 / 18 / 20065: 25 \mathrm{PM}$ \\
\hline Select an item to view its description. & ब्. Size Distributions for Soil and TSP. med & $35 \mathrm{~KB}$ & Mathcad Document & $9 / 27 / 20063: 06 \mathrm{PM}$ \\
\hline \multirow{4}{*}{$\begin{array}{l}\text { See also: } \\
\text { My Documents } \\
\text { My Network Places }\end{array}$} & 9]Size Distributions for Soil and TSP_Test 1 .mcd & $35 \mathrm{~KB}$ & Mathcad Document & $9 / 27 / 20063: 07 \mathrm{PM}$ \\
\hline & 9] Size Distributions for Soil and TSP_Test 2.mcd & $35 \mathrm{~KB}$ & Mathcad Document & $9 / 27 / 20063: 07 \mathrm{PM}$ \\
\hline & (9) Size Distributions for Soil and TSP_Test 3.med & $35 \mathrm{~KB}$ & Mathcad Document & $9 / 27 / 20063: 07 \mathrm{PM}$ \\
\hline & Soil Separates.xls & $19 \mathrm{~KB}$ & Microsoft Excel Worksheet & $9 / 8 / 20067: 11 \mathrm{AM}$ \\
\hline My Computer & Time to Equilibrium.xls & $21 \mathrm{~KB}$ & Microsoft Excel Worksheet & $8 / 28 / 20067: 30 \mathrm{AM}$ \\
\hline
\end{tabular}

Figure A-1. List of Files Used in the Analysis

AV Data_Lifestyle.xls - This Excel file was used to develop summaries of selected lifestyle characteristics of the Amargosa Valley population. The source data were obtained from DTN: MO0010SPANYE00.001 [DIRS 154976] (Excel file SAIC1Qual-2.xls, worksheet "Clean 1079"). The worksheet "Clean 1079" was copied into a separate worksheet with the same name in AV Data_lifestye.xls. The data were the sorted by AREANAME (column D), then the data from columns labeled ID, Q2, Q5, and Q6 for Amargosa Valley were copied into the "AV Data" worksheet. ID is an identification number of a record; Q2 pertains to the number of years an individual spent in the area; Q5 contains housing type data; and Q6 contains the data on home gardens.

The data on the number of years in the area were used to plot a histogram, which is shown in Figure 6.7-1. The housing type data were used to produce counts for each housing category. Counts were also calculated for houses with and without gardens. All of these calculations are included in the worksheet "AV Data." The results of these calculations were used in Section 6.7.3 to support the development of the irrigation duration.

Calcs for Water Content.xls - This Excel file contains calculations of the term $[\theta(1+\rho \mathrm{Kdi} / \theta)]$ that appears in Equation 6.1-2. The results of calculations are reproduced in Table 6.6-2. The data for these calculations were obtained from the following sources: soil density, $\rho$, was taken from Section 6.2 of this analysis; water content, $\theta$, was based on the study by Baes and Sharp (1983 [DIRS 109606], p. 20); and the partition coefficients for technetium and iodine were obtained from Table 6.3-6.

Distributions of Enhancement Factors.xls - This Excel file shows calculations related to the enhancement factor. The file consists of two worksheets. The worksheet "EF Distributions, all" lists all the measured values of the enhancement factor from the references provided in the worksheet. A histogram is produced for all these values in the same worksheet. 
Also in the worksheet "EF Distributions, all," enhancement factors taken from the references were categorized as pertinent to disturbed or undisturbed soil based on the descriptions of experimental conditions. The values and the references are listed in Tables 6.5-2 and 6.5-3 for undisturbed and disturbed soil, respectively. The Rank and Percentile data analysis function of Excel was then used to compute percentiles for the enhancement factors in each category. The enhancement factors and the corresponding percentiles were then used in the Mathcad file EFs for Undisturbed and Disturbed Soil.mcd, described below, to construct cumulative plots of the enhancement factors. In addition, the following statistics for the two categories of enhancement factors were calculated: GM, GSD, minimum, maximum, as well as the lower and upper bounds of the lognormal distribution calculated for the $95 \%$ confidence interval, as the $\mathrm{GM} \times \mathrm{GSD}^{ \pm 1.96}$.

The worksheet "EFs from Kashparov" contains calculation of average enhancement factor from Kashparov et al. (1994 [DIRS 177229], Table 2) based on the results of measurements of radionuclide concentration in air and soil. The enhancement factor is calculated as a ratio of these quantities. An average is then calculated for all measurements, which is used in worksheet "EF Distributions, all."

EFs for Undisturbed and Disturbed Soil.mcd-This Mathcad file was used to plot the cumulative distributions of enhancement factors for the undisturbed and disturbed soil conditions. The data for these plots were prepared in the Excel file Distributions of Enhancement Factors.xls and copied into two matrices in the Mathcad file. The columns from these matrices were used to construct the plots.

Kd Bounds.xls - This Excel file was used to calculate the lower and higher bound for lognormal distributions of partition coefficients at the $99 \%$ and $95 \%$ confidence interval. The GM and GSD were taken from Table 6.3-5. The missing GSDs are calculated in Section 6.3.2 as equal to 1.8. The data for chlorine were assumed to be the same as for technetium. The lower and upper bounds of the partition coefficients at the $95 \%$ and $99 \%$ confidence interval were calculated as $\mathrm{GM} \times \mathrm{GSD}^{ \pm 1.96}$ for the $95 \%$ confidence interval and $\mathrm{GM} \times \mathrm{GSD}^{ \pm 2.576}$ for the $99 \%$ confidence interval. The $95 \%$ values were recommended for all elements except for chlorine and technetium.

MMADs of Suspended Particles.xls - This Excel file calculates average MMAD and average GSD for suspended soil particles from data presented in Table 6.5-1.

Size Distributions for Soil and TSP.mcd-This Mathcad file contains calculations of surface-to-mass ratio for several particle size distributions of suspended particulates and for soil, as well as calculations of enhancement factors based on these surface-to-mass ratios. Extensive documentation of these calculations, including equations, explanation of symbols, and images, can be found in Sections 6.5.3.2 to 6.5.3.4.

Size Distributions for Soil and TSP_Test 1.mcd; Size Distributions for Soil and TSP_Test 2.mcd; Size Distributions for Soil and TSP_Test 3.mcd - These Mathcad files are "clones" of the file Size Distributions for Soil and TSP.mcd, except that MMADs, GSDs, and lower cut-off particle diameter were modified for the sensitivity study, as described in Section 6.5.3.4 (Tables 6.5-5 and 6.5-6). 
Soil Separates.xls - This Excel file contains two worksheets. In the worksheet "AV Soil Texture," data from Table 6.5-4 on percentage of soil separates were reproduced to calculate average proportions of soil separates for Amargosa Valley soils. The percentages in the source reference were provided relative to soil less than $7.62 \mathrm{~mm}$ in diameter, except for percentage of clay, which is given relative to soil less than $2 \mathrm{~mm}$ in diameter. The percentage of particles other than clay that were less than $2 \mathrm{~mm}$ in diameter were normalized to the percentage of soil less than $2 \mathrm{~mm}$ in diameter.

Time to Equilibrium.xls - This Excel file calculates time to equilibrium if leaching is the only removal mechanism for radionuclides in surface soil. The leaching removal constant is calculated using Equation 6.1-2 and inputs as specified in the worksheet. Time to equilibrium is calculated as explained in Section 6.4.1. The calculated values are reproduced in Table 6.4-1. 


\section{INTENTIONALLY LEFT BLANK}

